\title{
HIGH-LEVEL RADIOACTIVE WASTE MANAGEMENT ALTERNATIVES
}

MAY 1974 


\begin{abstract}
NOTICE
This report was prepared as an account of work sponsored by the United States Government. Neither the United States nor the United States Atomic Energy Commission, nor any of their employees, nor any of their contractors, subcontractors, or their employees, makes any warranty, express or implied, or assumes any legal liability or responsibility for the accuracy, completeness or usefulness of any information, apparatus, product or process disclosed, or represents that its use would not infringe privately owned rights.
\end{abstract}

Available from the National Technical Information Service, U. S. Department of Commerce, Springfield, Virginia 22151.

Price: Paper Copy $\$ 5.45$

Microfiche $\$ 1.45$ 


\section{DISCLAIMER}

This report was prepared as an account of work sponsored by an agency of the United States Government. Neither the United States Government nor any agency Thereof, nor any of their employees, makes any warranty, express or implied, or assumes any legal liability or responsibility for the accuracy, completeness, or usefulness of any information, apparatus, product, or process disclosed, or represents that its use would not infringe privately owned rights. Reference herein to any specific commercial product, process, or service by trade name, trademark, manufacturer, or otherwise does not necessarily constitute or imply its endorsement, recommendation, or favoring by the United States Government or any agency thereof. The views and opinions of authors expressed herein do not necessarily state or reflect those of the United States Government or any agency thereof. 


\section{DISCLAIMER}

Portions of this document may be illegible in electronic image products. Images are produced from the best available original document. 
WASH-1297

Distribution Category UC-70

\section{HIGH-LEVEL RADIOACTIVE WASTE MANAGEMENT ALTERNATIVES}

MAY 1974
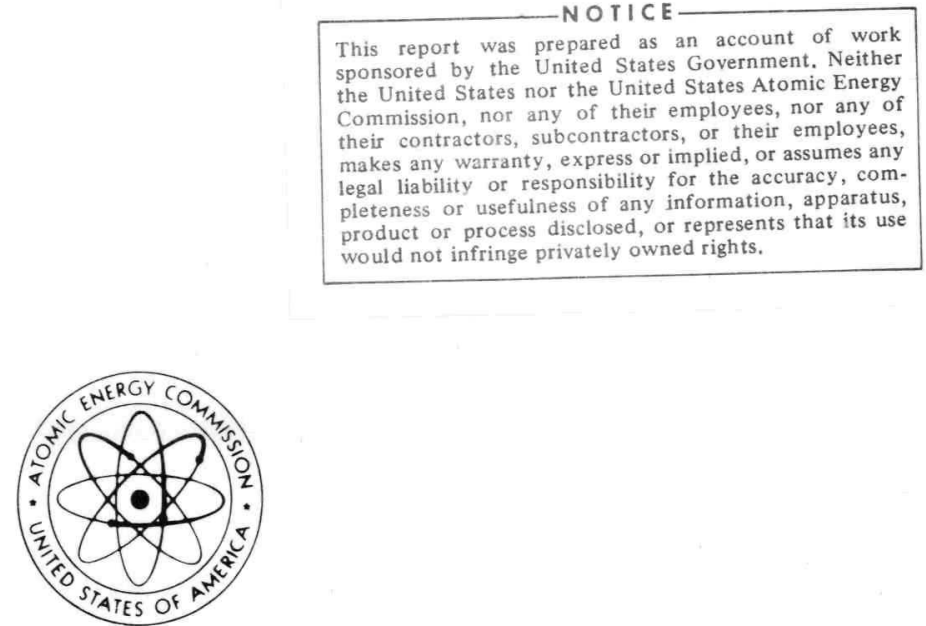

UNITED STATES ATOMIC ENERGY COMMISSION

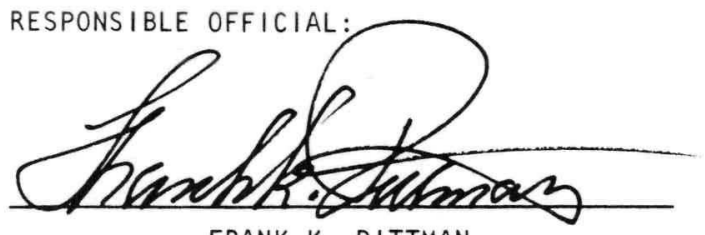

FRANK K. PITTMAN

DIRECTOR, DIVISION OF WASTE

MANAGEMENT and TRANSPORTATION 
0

0 


\section{FOREWORD}

This report is the summary of a comprehensive overview study(a) of potential alternative methods for long-term management of high-level radioactive waste. The study includes a compilation of information relevant to technical feasibility, safety, cost, environmental considerations, policy conflicts, public response and research and development needs for:

1. Disposal in terrestrial locations
a. In geologic settings on land
b. In the seabed
c. In ice sheets

2. Disposal into space

3. Elimination by transmutation (nuclear transformation of certain waste constituents into nuclides having less long-term toxicity).

The study is limited to the management of high-level radioactive waste from nuclear power by variations of these alternatives. Consideration of alternative types of electrical power generation are not within the scope of the study. In addition, evaluation of interim storage of radioactive waste in retrievable surface storage facilities is not part of this study. Disposal of waste in bedded salt deposits was studied extensively in other AEC programs, and the concept is included here as part of the overall matrix of geologic disposal techniques.

To complement these studies, investigations were also conducted on waste partitioning (separation of radionuclides in radioactive waste into different elements or groups of elements according to their long-term toxicity or suitability for different disposal methods), and systems methodology was developed to assess the effects of radionuclides from waste introduced into man's ecological cycle, assuming some failure of the primary waste containment.

Information pertinent to evaluating the various potential waste disposal techniques was developed without promoting any single disposal concept. The study is concerned with management of the waste and does not consider the potential for recovery of resources within the waste, including the heat. Concepts are developed only to the detail necessary to describe them for the overall investigation and in general are studied on a systematic, generic basis. This information can be used in comparing and assessing the various disposal concepts as a basis for decisions regarding their further study.

a. K. J. Schneider and A. M. Platt, Editors, Advanced Waste Management Studies, High-Level Radioactive Waste Disposal Alternatives, U.S. AEC Report BNWL-1900, Battelle, Pacific Northwest Laboratory, Richland, Washington, Sections 1 through 9 in 4 Volumes, May 1974. 
The evaluations of feasibility are not restricted to currently available technology. Rather, the study attempts to take into account technology which can be developed or is expected to be available at least within the next four decades. Indeed, most of the concepts studied are estimated to require 15 to 30 years for full implementation.

The study includes most currently known waste management alternatives, but is not considered to be all-inclusive. As new data become available, and as new or varied concepts become evident (e.g., disposal in rocks in permafrost areas, isotopic dilution of selected materials, etc., ) comparable follow-on studies will be carried out.

This investigation has been performed largely by a multiple-discipline technical staff at the Pacific Northwest Laboratory of Battelle Memorial Institute with significant input from a large number of consultants and outside contributors. This wide involvement of persons was an attempt to assure up-to-date and accurate coverage of the broad scope of subject matter, including areas where there are diversities of opinions. 


\section{CONTENTS}

FOREWCRD

LIST OF FIGURES.

i i i

LIST OF TABLES.

$\checkmark$ i i

1.0 INTRODUCTION

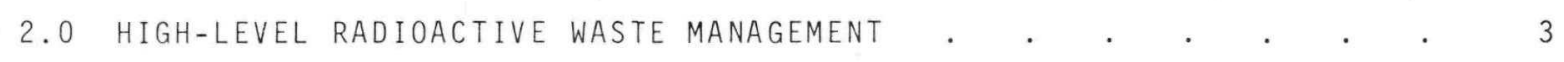

3.0 High-LeVel Radioactive waste . . . . . . . . . . . . . . . . . 6

4.0 STUdY METHODOLOGY. . . . . . . . . . . . . . . . . . . . . . 10

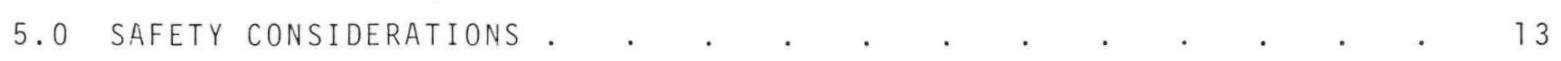

5.1 Failure Mode Analysis and Release Probabilities . . . . . 15

5.1.1 Sample Waste Release Probability Estimate . . . . . . . 16

5.1.2 Application of Fault Trees to Other Disposal Concepts . . . 18

5.2. Transport Mechanisms . . . . . . . . . . . . . . . . . 18

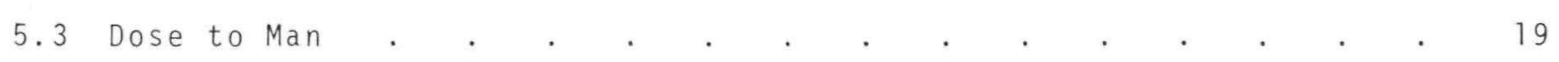

5.4 Risk to $\operatorname{Man} . \quad$. . . . . . . . . . . . . . . . . . . 20

6.0 DisPOSAL CONCEPTS - DESCRIPTION AND SYSTEMS . . . . . . . . . 22

6.1 Geologic Disposal Concepts. . . . . . . . . . . . . 22

6.1 .1 Solid Waste Emplaced in Mined Cavity - No Fluid Cooling. . . . . 24
or Melting.

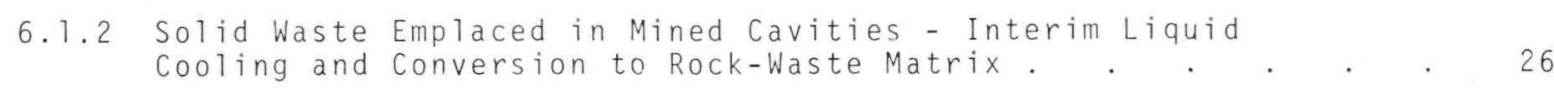

6.1 .3 Solid Waste Emplaced in Manmade Structures in Geologic . . . . . . . 27
Formations - Interim Air Cooling . . . . . .

6.1 .4 Solid Waste Emplaced in Manmade Structures in Geologic . . . . 28
Formations - Interim Water Cooling. . . . . .

6.1.5 Liquid Waste Emplaced in a Mined Cavity - In-Place Drying and
Conversion to Rock-Waste Matrix. . . . 30

6.1 .6 Liquid Waste Emplaced in Exploded Cavities - In-Place Drying and
Conversion to Rock-Waste Matrix. 31

6.1.7 Solid Waste Emplaced in a Matrix of Drilled Holes . . . . 32

6.1 .8 Solid Waste Emplaced in a Deep Hole. . . . . . . . . . 32

6.1.9 Liquid Waste Emplaced in a Deep Hole - In-Place Drying and . . . 33
Conversion to a Rock-Waste Matrix . . . . . . . 33

6.1 .10 Liquid Waste Emplaced by Hydraulic Fracturing - In-Place
Conversion to a Solid . . . . . . . . . . . 34

6.2 Ice Sheet Disposal Concepts . . . . . . . . . . . . . . . . . 34

6.3 Seabed Disposal Concepts . . . . . . . . . . . . . . . . 38 
6.4 Extraterrestrial Disposal Concepts. . . . . . . . . . . 40

6.5 Transmutation Elimination . . . . . . . . . . . . . 42

7.0 TECHNICAL FEASIBILITY . . . . . . . . . . . . . . . . 46

7.1 Geologic Concepts. . . . . . . . . . . . . . . . . . . 46

7.2 Ice Sheet Concepts. . . . . . . . . . . . . . . 52

7.3 Seabed Concepts . . . . . . . . . . . . . . . . 54

7.4 Extraterrestrial Concepts . . . . . . . . . . . . . . . 55

7.5 Transmutation Elimination Concepts. . . . . . . . . . . . . 58

7.6 Waste Partitioning. . . . . . . . . . . . . . 60

8.0 Research, DEVElopment, ANd TIMING . . . . . . . . . . . . 63

8.1 Geologic Concepts. . . . . . . . . . . . . . . . . 63

8.2 Ice Sheet Concepts. . . . . . . . . . . . . . . . . . 65

8.3 Seabed Concepts . . . . . . . . . . . . . . . . . . . 65

8.4 Extraterrestrial Concepts . . . . . . . . . . . . . 66

8.5 Transmutation Elimination Concepts. . . . . . . . . . . . 67

8.6 Waste Partitioning. . . . . . . . . . . . . . . . . 67

9.0 WASTE management costs. . . . . . . . . . . . . . . . . . . 68

10.0 ENVIRONMENTAL CONSIDERATIONS . . . . . . . . . . . . . . . . . 71

11.0 POLICY CONFLICTS . . . . . . . . . . . . . . . . . . . . . . . . 73

12.0 PUBLIC RESPONSE . . . . . . . . . . . . . . . . . . . . . 74

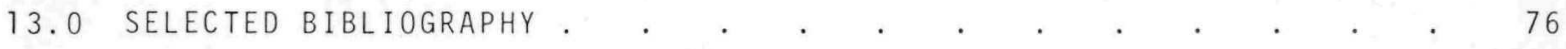

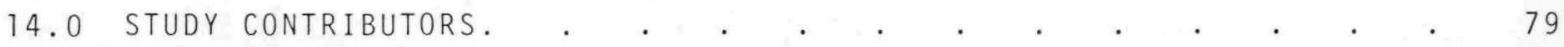

15.0 ACKNOWLEDGMENTS . . . . . . . . . . . . . . . . . 80

APPENDix A - High-LEVEl WASTE PROJeCtiOnS . . . . . . . . . . . A

Appendix B - generalized maps of the united states . . . . . . . . . B- 1 


\section{LIST OF FIGURES}

1 High-Level Radioactive Waste Management Options . . . . . . . . . 4

2 Relationships Among Study Evaluation Factors. . . . . . . . . 10

3 Interrelationships Among Pathway, Probability and Risk . . . . 14

4 System Requirements for High-Level Radioactive Waste Management in Terrestrial Locations. . . . . . . . . . . . . . 25

5 Solid Waste Emplacement in a Mined Cavity - No Fluid

6 Solid Waste Emplacement in a Mined Cavity - Interim Liquid . 27

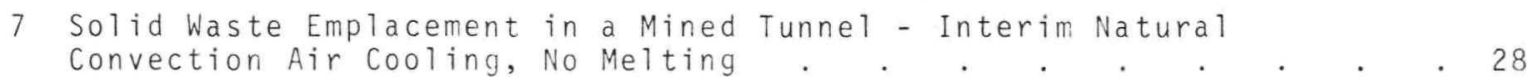

8 Solid Waste Emplacement in Manmade Structure with Interim . . . . . 29
Boiling Water Cooling, No Melting . . . .

9 Liquid Waste Emplacement in a Mined Cavity - In-Place

10 Liquid Waste Emplacement in an Exploded Cavity - In-Place Drying . . 31
and Conversion to Rock-Waste Matrix. . . . . . .

11 Solid Waste Emplacement in a Matrix of Drilled Holes - No . . . . 32

12 Solid Waste Emplacement in a Deep Hole with In-Place Conversion . . 33

13 Liquid Waste Emplacement in a Deep Hole - In-Place Drying and . . . 34
Conversion to Rock-Viaste Matrix. . . . . . . . 34

14 Liquid Waste Emplacement by Hydraulic Fracturing - In-Place
Conversion to a Solid

15 0perations in Ice Sheet Disposal. . . . . . . . . . . . 36

16 Ice Sheet Disposal Concepts . . . . . . . . . . . . 37

17 Operations in Seabed Disposal . . . . . . . . . . . . . . . . . 39

18 Seabed Disposal Concepts . . . . . . . . . . . . . . . . 40

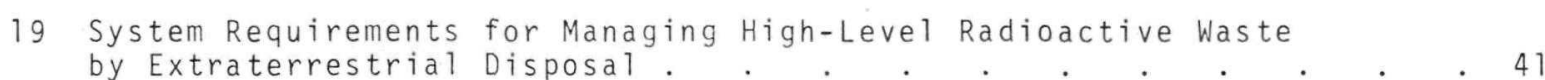

20 Shuttle Launch Deployment Sequence for Extraterrestrial Disposal . . 42

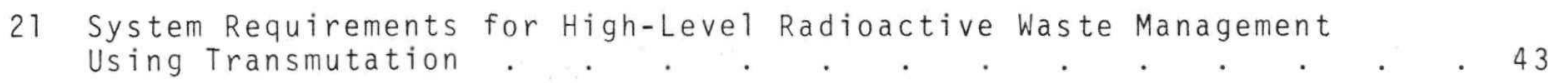

22 Transmutation Waste Management Strategy . . . . . . . . . . 44

23 Potentially Suitable Areas for Geologic Disposal Sites Using . . . 51

24 Potentially Suitable Areas for Geologic Disposal Sites Using the Cavity and Matrix Hole Concepts. . . . . . . . 51 


\section{LIST OF TABLES}

1 Concepts Under Study for High-Level Radioactive Waste Management . . 1

2 Investigation Objectives for Each Waste Management Alternative . . . 2

3 Typical Materials in High-Level Liquid Waste. . . . . . . . . . . 7

4 Characteristics of Solidified High-Level Waste . . . . . . . . . . 8

5 Sample Components of Release Sequence Probabilities for Geologic Disposal. . . . . . . . . . . . . . . . . . . . . 17

6 Calculated Radiation Doses from Hypothetic Release of Waste Inventory of Year 2000 in Geologic Disposal . . . . . . . . . . . 20

7 Summary of system Characteristics for Alternative Waste

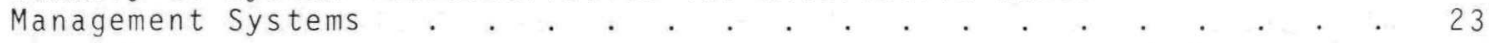

8 Characteristics of Geologic Disposal Concepts . . . . . . . . . . 24

9 Summary of Technical Feasiblity for Alternative Waste Management Systems . . . . . . . . . . . . . . . . . . . . . . 47

10 Summary of Potential Space Destinations $\quad . \quad$. $\quad . \quad . \quad . \quad . \quad . \quad . \quad . \quad . \quad 56$

11 Summary of Transmutation Device Feasibility . . . . . . . . . . . . 58

12 Partitioning Feasibility Study Conclusions $. . \quad . \quad . \quad . \quad . \quad . \quad . \quad .61$

13 Estimated Research and Development Needs and Timing to Routine
Operation
.

14 Summary of Concept Cost Evaluations . . . . . . . . . . . . . . . . 69 


\subsection{INTRODUCTION}

This report is a summary of a comprehensive overview study of potential alternatives for long-term management of high-level radioactive waste sponsored by the United States Atomic Energy Commission Division of Waste Management and Transporta- tion. ( $a, b)$ The report describes the various waste management alternatives that have been studied by the Pacific Northwest Laboratory and outlines the methods being used for evaluation. The following items in Table 1 were subjects of the study.

TABLE 1. Concepts Under Study for High-Level
Radioactive Waste Management

\section{A. PROCESSING}

Partitioning*

B. DISPOSAL ON THE EARTH

\section{Geologic}

Hined Cavity Nuclear Cavity Deep Hole

Drilled Hole Matrix Manmade Structures in Geologic Formations Hydraulic Fracturing

\section{Seabed}

Stable Deep Sea Floor

Subduction Zones and Deep Trenches

Rapid Sedimentation Areas

\section{Ice Sheet}

Ice Burial - Free Flow Ice Burial - Anchored Ice Surface Facility

\begin{tabular}{l} 
C. DISPOSAL OFF THE EARTH \\
$\frac{\text { Extraterrestrial }}{\text { Solar Impact }}$ \\
Earth and Solar Orbit \\
Solar EScape to Deep Space \\
D. ELIMINATION \\
\hline Transmutation \\
Accelerator \\
Fission Reactor \\
Nuclear Explosive \\
Control led Thermonuclear Reactor \\
(Fusion Reactor)
\end{tabular}

* Partitioning is a chemical separation of waste constituents into two fractions: one which contains the long-lived actinide elements and one which contains the fission products. Variations from this basic definition are also included in the study.

a. See K. J. Schneider and A. M. Platt, Editors, Advanced Waste Management Studies: High-Level Radioactive Waste Disposal Alternatives, USAEC Report, BNWL-1900, Battelle, Pacific Northwest Laboratory, Richland, Washington, May 1974 .

b. See Section 3 of this report for a description of high-level radioactive waste. 
For each waste management alternative under investigation the information in Table 2 is presented:

TABLE 2. Investigation Objectives for Each Waste Management Alternative

Compile and Investigate:

- Technical Feasibility Information

- Safety Information and Methodology for Analysis

- Policy, Environmental, and Public Response Considerations

- Advantages and Disadvantages

- Needed Research and Development

Estimate:

- Research and Development Costs

- Schedules and Capital and Operating Costs for Implementation

In this general order the report describes:

- High-level nuclear waste management

- High-level nuclear waste--its origin, characteristics and conditioning processes

- Study methodology

- Safety considerations

- Disposal concepts--descriptions and system requirements

- Technical feasibility, advantages and disadvantages of concepts

- Research and development needs and commercialization schedules

- Capital and operating costs

- Special nonradiological environmental considerations
- Policy considerations

- Public response considerations

Following the description of waste management considerations and methodology for this investigation, all the elements listed from "Technical Feasibility" (Section 7) through "Public Response Considerations" (Section 12) are discussed for each disposal concept. The disposal concepts were studied on a systematic, generic basis and developed only to the extent necessary to perform the overall evaluations. Continued studies will develop a plan for development of advanced concepts which might be selected. 


\subsection{HIGH-LEVEL RADIOACTIVE WASTE MANAGEMENT}

Radioisotopes of concern in highlevel waste originate in a nuclear reactor. The fission products (other chemical elements formed by nuclear fragmentation of actinide elements such as uranium or plutonium, etc.) accumulate in the nuclear fuel, along with plutonium and other transuranic (a) nuclides.

Fuel discharged from the nuclear reactor is reprocessed to recover uranium and plutonium by chemical dissolution and treatment. During this step currently favored treatment processes form high-level waste as an acidic aqueous stream. Other processes are being considered which would produce high-level waste in different forms. This high-leve? waste contains most of the reactorproduced fission products and actinides, with slight residues of the uranium and plutonium. These waste products generate sufficient heat to require substantial cooling and emit large amounts of potentially hazardous ionizing radiation. Because the reprocessing step normally does not dissolve much of the nuclear fuel fuel cladding, high-level waste normally contains only a small amount of the radionuclides formed as activation products within the cladding. This cladding huli waste is currentiy managed as a separate solid waste stream and has not been considered in this study.
The first high-level waste was produced in the mid-1940's as a result of Manhattan Project activities. since then such waste, arising from defense production and nuclear power development, has been stored as either aqueous solutions or solids at AEC installations, and as aqueous solutions at the one only operational commercial fuel reprocessing plant (Nuclear Fuel Services at West Valley, New York).

The exponential growth of nuclear power in the United States will result in increased quantities of highlevel waste. Installed U.S. nuclear electrical generating capacity is projected to increase from about 25,000 megawatts in 1974 to about 1,200,000 megawatts by the year 2000 . The anticipated volume of solidified high-level waste accumulated from now until the year 2000 is about 13,000 cubic meters. If this amount of solid waste were stacked as a solid cube, the cube would be about 25 meters on a side. Approximately 150,000 megacuries of radioactivity and 700 megawatts of heat will be associated with this projected waste inventory in the year 2000. This heat content is equivalent to about one-third of the waste heat rejected from one Light Water Reactor (LWR) which generates 1000 megawatts of electricity. This study uses the LWR as the reference type of nuclear

a. Transuranic elements are those higher than uranium on the periodic table of chemical elements. Transuranic elements are also actinide elements. 
reactor and generally considers the projected amount of waste accumulated in the U.S. through the year 2000. More information on projected waste quantities from Light Water Reactors (LWR), High Temperature Gas Cooled Reactors (HTGR) and Liquid Metal Fast Breeder Reactors (LMFBR) are given in Appendix $A$.

Major options for waste management are shown in Figure 1. This logic diagram indicates most of the potential routings of nuclear waste, starting with its presence in the discharged reactor fuel and continuing to its final disposal or elimination step. Partitioning (removal of actinides), fractionation (removal of certain fission products), fixation or conversion to encapsulated solids, and retrievable storage are identified as processing steps of the waste management scheme used.

Constituents in high-level nuclear waste may be broadly categorized as a mixture of long-lived and short-lived radioisotopes from the standpoint of waste management. The short-lived

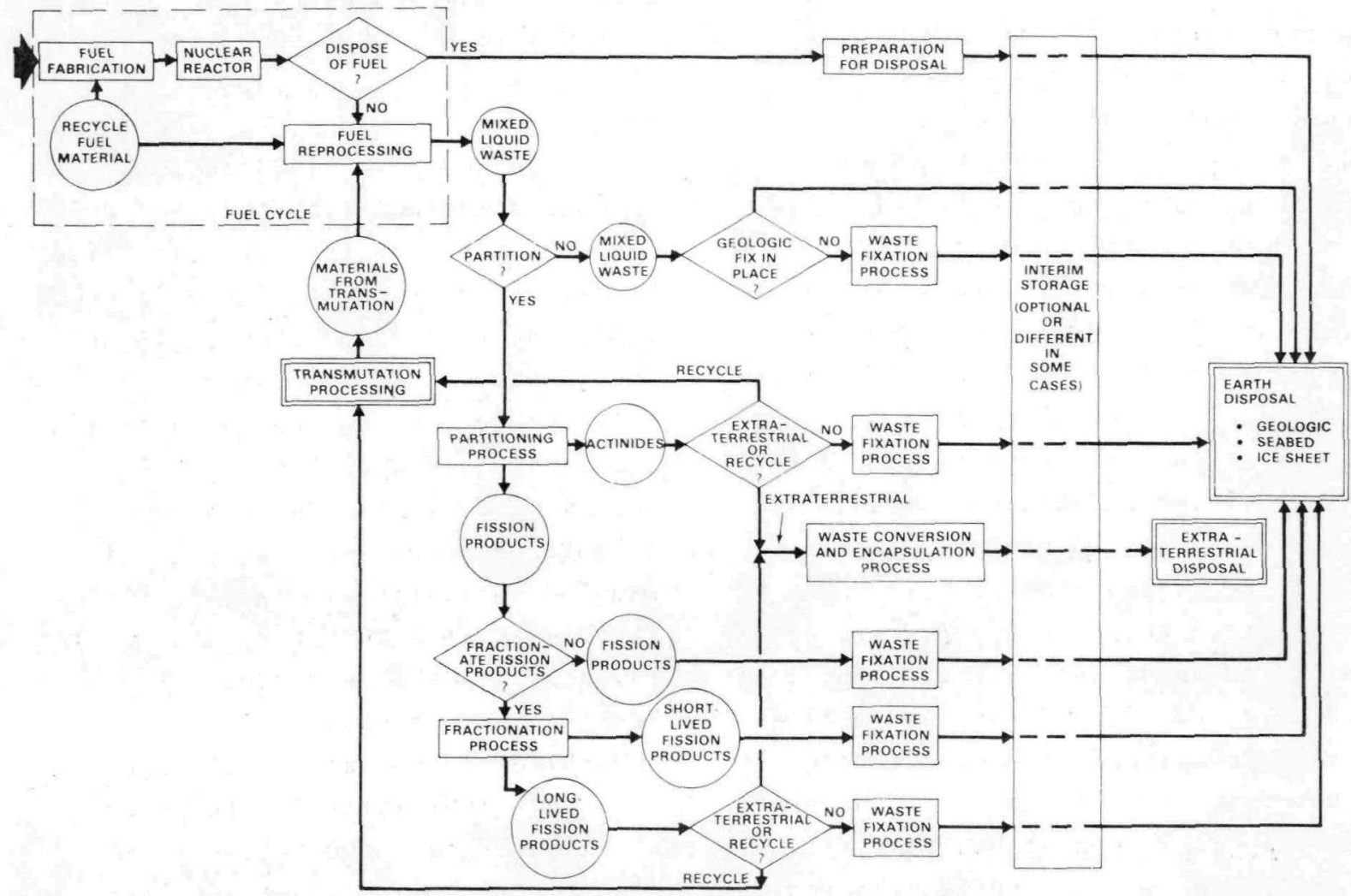

FIGURE 1. High-Level Radioactive Waste Management Options 
waste materials are defined as those with radioactive decay half-lives of no more than tens of years, whereas the long-lived are those with half1 ives of hundreds or more years.

Partitioning treatment of the waste is a key element in certain of the waste management systems. Dividing the high-level waste into longand short-lived fractions allows the two waste fractions to be managed separately. The short-lived fraction will diminish to very low levels in about a thousand years, and the longlived fraction, much smaller in quantity and heat generation rate, can be handled by other waste management options. In the broadest sense only three management options exist for the longer-lived and highly toxic actinide fraction of the waste:

1) elimination of the waste constituents by beneficial transmutation (nuclear conversion to other less undesirable isotopes), or 2) safe extraterrestrial transport off the earth, or 3) isolation from man's environment somewhere on earth for long time periods to allow natural radioactive decay.

In this report "disposal" refers to a plan to permanently place the waste in isolation, sometimes supplemented by manmade barriers to provide adequate protection for the time required to decay to unimportant radioactivity levels. The shortlived waste fractions will decay to become non-radioactive in relatively short times--times short enough to perhaps consider long-term storage such as in manmade structures. Manmade artifacts have existed for per- iods of time well in excess of 1000 years. Art objects from chinese and Egyptian cultures are in good condition after time periods more than 6000 years. Modern man should be able to equal or better this performance and beneficially use containment to supplement isolation for the short-lived fraction of waste.

To produce a short-lived waste fraction which would decay to unimportant radioactivity in about 1000 years would require separation of the actinide elements and perhaps samarium, technetium, tin, iodine, and nickel (radioactive nickel is present due to irradiation and dissolution of some fuel cladding). Very large decontamination factors (ratio of initial concentration in waste to final concentration in waste) in the $10^{6}$ to $10^{8}$ range would be required for some of the elements, particularly the actinides, to render the remainder of the waste materials nonradioactive after 21000 years' decay time. Realistically, it is reasonable to take into account the actual circumstances of a waste release, including dilution of waste within a geologic formation, the low leach rate of many solidified waste forms and the sorption of radionuclides in the soil. With these natural attenuation factors, the long-lived radionuclides may not need to be removed so completely from the mixed wastes. Preliminary use of failure mode and radiological pathway analyses on sample cases indicates that perhaps only the actinide elements need be removed and these only by decontamination factors of 100 to $1000\left(10^{2}\right.$ to $\left.10^{3}\right)$. 


\subsection{HIGH-LEVEL RADIOACTIVE WASTE}

Typical constituents of the liquid high-level waste expected from the solvent extraction reprocessing of irradiated fuels from Light water Reactors (LWR), Liquid Metal Fast Breeder Reactors (LMFBR), and High Temperature Gas-Cooled Reactors (HTGR) are shown in Table 3 . The waste is a nitric acid solution of chemical salts which typically contains a few volume percent of solids. The waste constituents include nonradioactive chemicals added during reprocessing, almost all the fission products

(radioactive and nonradioactive), the transuranium actinides formed in the reactor, and about 0.5 percent of the fuel materials (uranium, plutonium, thorium) which are not recovered during reprocessing. Most of the chemical materials are those added during fuel reprocessing.

Present Atomic Energy Commission (AEC) regulations require that the liquid high-level waste from fuel reprocessing 1) be converted to a solid material within 5 years after separation in the fuel reprocessing step, and 2) be encapsulated and shipped to a federal repository within 10 years of $i$ ts production for long-term management by the AEC. For this study the solidified high-level waste is assumed to be encased in steel canisters averaging 30 centimeters $(12$ inches) in diameter and 300 centimeters (10 feet) long. Thus solidification and encapsulation must occur prior to initiation of most disposal schemes.
Four solidification processes have been developed in the United States to the point of radioactive demonstration on an engineering scale: fluidized bed calcination, spray solidification, pot calcination, and phosphate glass solidification. In all four processes, heat is applied to drive off volatile constiuents, primarily water and nitrates, resulting in either a calcined solid or a melt that will cool to a monolithic solid. The latter generally requires dilution of the waste with nonradioactive materials (20 to 40 percent of the total solid) to incorporate the waste into materials (glass or ceramics) that have low solubility in water and are fusible at reasonably low temperatures (1ess than about $1200^{\circ} \mathrm{C}$ ).

Characteristics of typical final solid waste forms from the four processes are shown in Table 4. The processes are described briefly below.

Fluidized Bed Calcination. Liquid waste is atomized into a heated fluidized bed where it is deposited and calcined on granular bed particles. The resulting granular "spheres". of waste calcine may be the final waste form or they may be incorporated into crystalline or glassy solids in a melting stage.

Spray Solidification. Atomized droplets of waste fall through a heated chamber where flash evaporation results in solid oxide particles. Glassmaking solid frit or phosphoric acid can then be added to provide for 
TABLE 3. Typical Materials in High-Level

Liquid Waste

\begin{tabular}{|c|c|c|c|c|}
\hline & & Grams/M & from Rea & or Tyne ${ }^{(a)}$ \\
\hline & Material (b) & $\operatorname{LWR}^{(C)}$ & ${ }_{H T G R}(\mathrm{~d})$ & $\operatorname{LMFBR}(\mathrm{e})$ \\
\hline $\begin{array}{l}\text { Reprocessing } \\
\text { Chemicals }\end{array}$ & Hydrogen & 400 & 3,800 & 1,300 \\
\hline & Iron & 1,100 & 1,500 & 26,200 \\
\hline & Nickel & 100 & 400 & 3,300 \\
\hline & Chromium & 200 & 300 & 6,900 \\
\hline & Silicon & -- & 200 & -- \\
\hline & Lithium & -- & 200 & -- \\
\hline & Boron & -- & 1,000 & -- \\
\hline & Molybdenum & -- & 40 & -- \\
\hline & Aluminum & -- & 6,400 & -- \\
\hline & Copper & -- & & -- \\
\hline & Borate & -- & -- & 98,000 \\
\hline & Nitrate & 65,800 & 435,000 & 244,000 \\
\hline & Phosphate & 900 & & -- \\
\hline & Sulfate & -- & 1,100 & -- \\
\hline & Fluoride & -- & 1,900 & -- \\
\hline & Sub-total & 63,500 & 452,000 & $\overline{380,000}$ \\
\hline Fuel Product & & & & \\
\hline Losses $(f, g)$ & Uranium & 4,800 & 250 & 4,300 \\
\hline & Plutonium & & 1,000 & 500 \\
\hline & Sub-total & $\overline{4,840}$ & 5,450 & 4,800 \\
\hline Transuranic & & & & \\
\hline Elements $(\mathrm{g})$ & Neptunium & 480 & 1,400 & $\begin{array}{l}260 \\
250\end{array}$ \\
\hline & $\begin{array}{l}\text { Americium } \\
\text { Curium }\end{array}$ & $\begin{array}{r}140 \\
40\end{array}$ & 10 & $\begin{array}{r}1,250 \\
50\end{array}$ \\
\hline & Sub-total & 660 & 1,440 & 7,560 \\
\hline Other Actinid & (g) & $<0.001$ & 20 & $<0.001$ \\
\hline Total Fission & Products $(h)$ & 28,800 & 79,400 & 33,000 \\
\hline & TOTAL & 103,000 & 538,000 & 419,000 \\
\hline
\end{tabular}

a. Water content is not shown; all quantities are rounded.

b. Most constituents are present in soluble, ionic form.

c. U-235 enriched PWR, using 378 liters of aqueous waste per metric ton, 33000 MWd/MT exposure. (Integrated reactor power is expressed in megawatt-days [Mwd] per unit of fuel in metric tons [MT].)

d. Combined waste from separate reprocessing of "fresh" fuel and fertile particles, using 3,785 liters of aqueous waste per metric ton, 94,200 MWd/MT exposure.

e. Mixed core and blanket, with boron as soluble poison, $10 \%$ of cladding dissolved, 1,249 1iters per metric ton, 37,100 MWd/MT average exposure.

f. $0.5 \%$ product loss to waste.

g. At time of reprocessing.

h. Volatile fission products (tritium, noble qases, iodine and bromine) excluded. 
TABLE 4. Characteristics of Solidified High-Level Waste

\begin{tabular}{|c|c|c|c|c|c|}
\hline & Pot Calcine & $\begin{array}{l}\text { Spray Phosphate } \\
\text { Ceramic } \\
\end{array}$ & $\begin{array}{l}\text { Phosphate } \\
\text { Glass }\end{array}$ & $\begin{array}{l}\text { Borosilicate } \\
\text { Glass(a) }\end{array}$ & $\begin{array}{c}\text { Fluidized } \\
\text { Bed Calcine } \\
\end{array}$ \\
\hline Form & Scale & Monolithic & Monolithic & Monolithic & Granular \\
\hline Description & $\begin{array}{l}\text { Calcine } \\
\text { Cake, Friable }\end{array}$ & $\begin{array}{l}\text { Ceramic } \\
\text { Hard, Tough }\end{array}$ & $\begin{array}{l}\text { Glass } \\
\text { Hard, Brittle }\end{array}$ & $\begin{array}{l}\text { Glass } \\
\text { Hard, Brittle }\end{array}$ & $\begin{array}{l}\text { Calcine, Mean } \\
\text { Particle Diameter } \\
100 \text { to } 500 \mu\end{array}$ \\
\hline $\begin{array}{l}\text { Bulk Density } \\
\text { g/cc }\end{array}$ & 1.2 to 1.4 & 2.7 to 3.3 & 2.7 to 3.0 & 3.0 to 3.5 & 1.0 to 1.7 \\
\hline $\begin{array}{l}\text { Wt\% Fission Product } \\
\text { Oxides (Max.) }\end{array}$ & 90 & 30 & 25 & 50 & 50 \\
\hline $\begin{array}{l}\text { Therma } 1 \text { Conductivity, } \\
W /\left(\mathrm{m}^{2}\right)\left({ }^{\circ} \mathrm{C} / \mathrm{m}\right.\end{array}$ & 0.3 to 0.4 & 1.0 to 1.4 & 0.8 to 1.2 & 1.0 to 1.4 & 0.2 to 0.4 \\
\hline $\begin{array}{l}\text { Leachability in Cold } \\
\text { Water, } \mathrm{g} / \mathrm{cm}^{2}-\text { Day }\end{array}$ & 1 to $10^{-1}$ & $10^{-3}$ to $10^{-5}$ & $10^{-4}$ to $10^{-6^{(b)}}$ & $10^{-5}$ to $10^{-7}$ & 1.0 to $10^{-1}$ \\
\hline \multicolumn{6}{|c|}{$\begin{array}{l}\text { a. Produced by either spray or fluidized bed calcining followed by } \\
\text { melting, or by in-canister vitrification processing. }\end{array}$} \\
\hline \multicolumn{6}{|c|}{$\begin{array}{l}\text { b. Devitrified phosphate glass exhibits increased leachability } \\
\text { (leach rates }=10^{-2} \text { to } 10^{-3} \mathrm{~g} / \mathrm{cm}-\text { day). }\end{array}$} \\
\hline
\end{tabular}

melting and glass formation in a continuous melter or directly in the vessel that will serve as the waste canister. The molten glass or ceramic is cooled and solidified.

Pot Calcination. Liquid is continuously added to and boiled away in a processing vessel which also serves as the storage canister. When the canister is full of solids, the addition of aqueous waste is stopped and the solid then heated and held at about $900^{\circ} \mathrm{C}$ to complete denitration and dehydration. Feed additives can be used to result in a glass rather than a calcine cake.

\section{Phosphate Glass Solidification.} Liquid waste and phosphoric acid are mixed and concentrated to a thick sludge in an evaporator. The sludge goes to a melter where dehydration and denitration are completed and the
- material is melted. The molten phosphate glass then drops into a storage canister where it cool's and solidifies.

The $A E C$ has in progress at the Pacific Northwest Laboratory a Waste Fixation Program (WFP). Its chief goal is to provide technology and assistance for reprocessors by developing appropriate calcining and melting technology for high-level waste. Developed systems will be taken all the way through a radioactive pilot plant demonstration. Solid waste forms produced from these demonstrations will be studied to determine the suitability of the waste forms and their resistance to adverse effects of time and environment.

The major emphasis of the WFP is to provide early solidification technology by working with silicate glass. or ceramic systems. Because these 
solids have had prior extensive development effort on a worldwide basis, development of acceptable systems to produce the solids should be nearterm. The silicate solids will offer a significant improvement in waste management safety over 1 iquids or calcined solids because of their resistance to leaching and physical transport in the environment.

In an effort parallel to the silicate solid development, studies are aimed at determining and developing a final waste form capable of longer term containment. An example of this would be a multiple-barrier material. This could involve coating small pieces of chemically stable solid waste with a protective inert material. The coated solids could then be dispersed and further encased in a protective matrix to consolidate the particles in a massive solid. Additional protection could be provided by outer wrappers. 


\subsection{STUDY METHODOLOGY}

The overall method of analysis by which each disposal concept and its waste management system elements were studied is presented briefly in this section. The relationships among the major study elements are shown in Figure 2 .

The waste management concepts were first developed to the detail needed to describe them for overal1 investigations and in general were studied on a systematic, generic basis. Concepts were generally developed on the reference basis of having the capa- bility to handle the waste from a plant which reprocesses 5 metric tons/day (i825 MT/yr) of spent nuclear fuel. (a) This reference capacity was then scaled up as a function of time to accommodate the total need for the U.S. nuclear economy through the year 2000 .

After the various disposal concepts were defined, the technical feasibility of each potential concept was determined in this study by answering the questions:

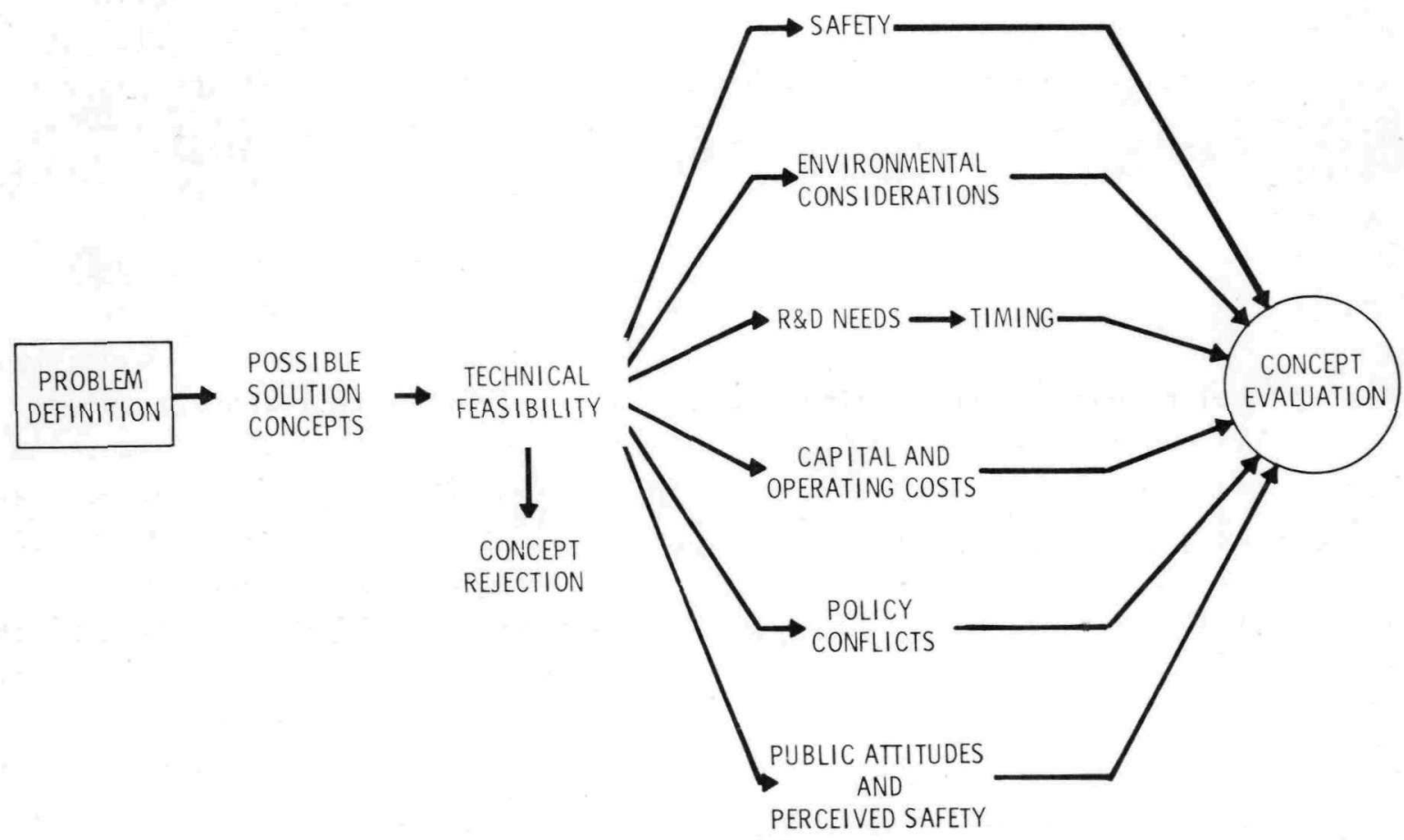

FIGURE 2. Relationships Among Evaluation Factors

a. High-level waste produced is about 19001 iters/day as aqueous waste. This quantity amounts to 45,625 metric tons of fuel reprocessed during the assumed 25-year 1 ife of the plant. Total accumulated solid waste is in 14,700 "typical" canisters 30 centimeters in diameter and 30 meters long. 
1) Can the disposal concept be implemented using today's technology?

2) Or can the disposal concept be implemented with future technology based upon current theory?

-3) Can the disposal concept provide the potential for confining or eliminating the waste over the rerequired time period?

4) Does the concept have a favorable energy balance?

Those few concepts that did not pass this technical feasibility test (i.e., some transmutation and space disposal variations) were rejected from further studies.

Once the technical feasibility of a concept was established, the other elements were studied in parallel. The potential for system safety was scanned for each concept. A sample safety analysis was performed for one generic type of geologic disposal concept to develop and test the safety analysis methodology. The safety analysis (discussed later) estimated the radiation dose(a) from a hypothetical release of waste from a disposal area.

Environmental considerations, aside from the potential release of radioactive materials, were reviewed such as overall effects on land, air, sea or water use.

The technology needs were assessed, and Research and Development needs (scope, time, and dollars) were esti- mated. From the Research and Development time needs, the total time for implementation of each concept was estimated.

Capital and operating costs were estimated, using the basic assumption that the necessary Research and Development had been successfully completed. Costs were estimated and summed for total waste management system activities such as partitioning, interim liquid and solid storage, shipping and disposal.

Major policy conflicts that a concept would have with international and national policies were reviewed such as agreements that prohibit the use of the oceans or the Antarctic continent for waste disposal. The problems involved with changes can then be weighed against the safety and economic potentials of a particular waste management concept.

The potential public response to a chosen waste management scheme was examined in a preliminary pilot test. Obviously this is a complex subject and very difficult to evaluate. An initial study of methodology was designed to identify those aspects of the waste management systems that might be deemed most important by the general public. With future analysis in depth, information on public attitudes could be factored into concept design. The public's acceptance of a technically sound waste management system is a most important goal.

a. Radiation dose is an expression for the energy absorbed by matter as a result of exposure to radiation and has the unit "rad." For these safety studies we have actually used the radiation dose-equivalent, expressed in "rem," which is a measure of the physiological effects of radiation on people. 
The final product of the study is a compilation of information regarding the evaluation factors for the various disposal concepts. The outcome of each of these elements is described in different units. Therefore, the concepts cannot be evaluated by simply adding up the performance level by elements. Instead, the technique being developed for future studies is one of determining if a dis- posal concept passes a performance test for each evaluation factor listed. For instance, a passing of the technical feasibility hurdle or test would be required before detailed analysis of other requirements be undertaken. The order in which the pass-reject tests are applied and the criteria for the various performance hurdles (or concept evaluation factor tests) have not been developed in this study. 


\subsection{SAFETY CONSIDERATIONS}

Safety is a major consideration in decisions on the use of any potential disposal scheme. An acceptable option must provide adequate protection during operational phases and provide the necessary isolation during the long time periods of the disposal phase.

Long-term immobilization or isolation and containment of disposed waste are the two major protective devices requisite to the implementation of a nuclear waste management system. Substantial interaction can and does exist between these two factors. In this context, isolation is used to mean the factors which influence the time required for migration of waste to man's environment; containment is used to mean immobilization and confinement of the waste constituents within known barriers. Typical isolation factors could include distance, the ion-exchange capacity of interposed earth materials, the lack of a transfer medium such as water, etc. If waste is adequately isolated so that the migration times are greater than the time for radioactive decay, isolation alone can provide adequate protection. Conversely, if adequate containment is provided by manmade barriers which immobilize the waste-again for the length of time for decay--the waste could be placed in many selected locations even within man's environment. Here the word "barrier" is used to include the matrix for the waste, e.g., silicate glasses, wrappings such as metallic sheets, and facilities such as a concrete building, which serve to provide effective barriers to the escape of radioactive materials.

The disposal options explored in this report seek to utilize the maximum benefits from both isolation and containment although principal emphasis is on isolation.

For this study "safety" was equated directly to the potential risk to man (in terms of radiation dose) that could result if a disposal option were implemented. The key elements in a method of assessing potential risk are illustrated in Figure 3.

Assessment of the risk of a proposed concept starts with the general description of the disposal concept. This implies a generic site description (e.g., ice sheet disposal defines a general location, surrounding geology, and population density), and it implies the characteristics of the waste (e.g., the waste form, containerization, radionuclide content, and age). The most likely sequences of failure events leading to possible release of radioactive materials to man's environment are then defined and the probability of these sequences taking place is determined. The next step follows the most likely sequences through the physical and chemical mechanisms required to release the waste constituents into man's immediate environment. The generic site defines the media (granite, salt, shale, air, water, etc.)

through which radionuclides must move 


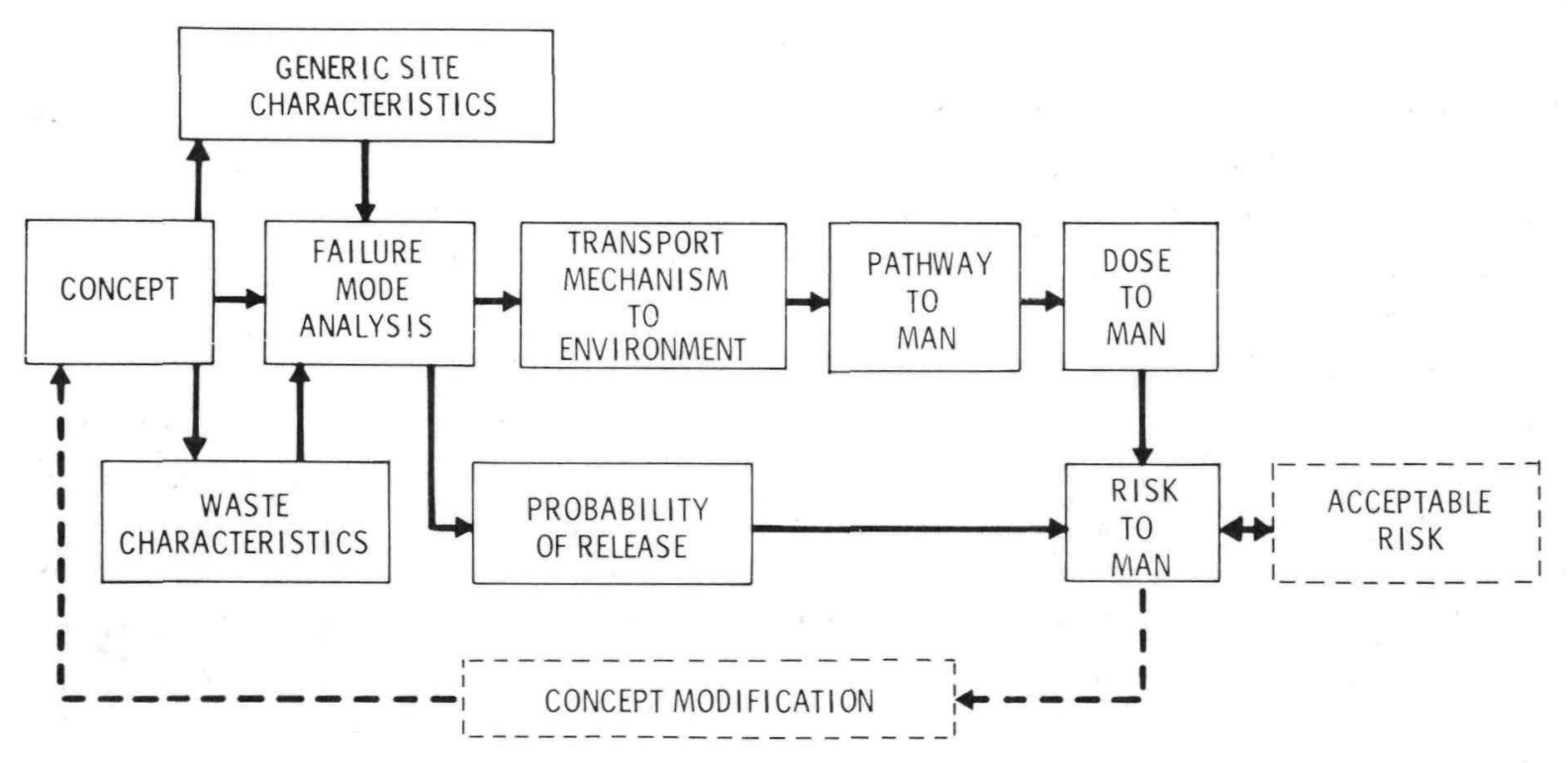

FIGURE 3. Interrelationships Among Pathway, Probability and Risk

into man's environment. Next, based on the population estimated to come in contact with the waste materials, the potential exposure pathways, and the calculated waste release rate, the radiation dose to the population can be estimated.

Finally, the probabilistic risk (dose) to man can be determined by multiplying the probability of the event taking place times the dose if it takes place. By comparing the total integrated risks of proposed concepts with appropriate criteria, it can be determined whether or not the risk to man exceeds acceptable criteria. If the risk level is unacceptably high, the concept could be rejected or changes could be made in the concept to reduce the risk. If the risk for a concept mèets a 11 criteria, the concept would be considered to have met the safety requirements, although further improvements may still be made in the concept.
Of course, concepts in which the risk is substantially lower than the measurement criteria would be rated as most favorable.

Development of suitable safety criteria is most important in a final evaluation of waste management practices. Development of such criteria was beyond the scope of this study, but the following are proposed as representative of major safety criteria:

1) On a probabilistic basis, the risk to the world population from waste management should represent only a minor increase in the total risk presently assumed by the operation of nuclear power plants. The risk contribution from probabilistic releases from the waste production of a power plant should be no more than a fraction of the risk from chronic effluent releases from the plant.

2) Because the risk to man from waste may exist substantially longer 
than the use of fission reactors as a power source, its risk to future man should compare favorably with other involuntary risks that give little or no benefit. Being struck by lightning, being killed in an earthquake or flood and being hit by a fallen aircraft are examples of involuntary risks with little benefit to those exposed to the risk. Such risks result in about one death per milion population per year. (a) Comparison of the risk from waste management practices would require conversion of radiation dose to deaths to establish a criterion. Several such conversions have been postulated but remain controversial.

3) The dose to the population in the immediate disposal area should not be great enough to put the population at serious immediate risk. This may require that some protective reaction from a release of waste materials be available; for example, the pofulation in the affected area may be evacuated or restricted or the water supplies may be relocated. It is assumed that evacuation may be required if the estimated exposure to a population group were to exceed some maximum standard which could not be decreased through curtailed operation.

The basic problem with this analytical technique is that the values used to describe probabilities of system failures, the actual rates of movement through environmental media to man, and even the population distribution around the release from a plant 1,000 years or more in the future are obviously in question. In addition, information on the interrelationships between dose to man, risk to man in units of potential deaths or dollar costs and acceptable risk were found to be controversial. Information on these subjects must be developed in future studies.

\subsection{FAILURE MODE ANALYSIS AND RELEASE PROBABILITIES}

Evaluation of the safety of any disposal concept requires identification of mechanisms and probabilities of possible releases of radioactive waste constituents to man's environment. The fault tree analysis technique was determined to be the preferred method to provide for achieving these requirements. The method provides for calculating the risk to man (in terms of radiation exposure in this study) on a probabilistic basis.

As an illustration of the method, a generic fault tree was developed for geologic disposal in a mined cavity. In a 11, 77 basic failure events were identified as possible contributors to a waste release from a geologic disposal site.

a. There is a great deal of concern about natural disasters but essentially no concern about accidents caused by lightning. In natural disasters, the concern is high because many people could be exposed to a single event. These simple comparisons show that perception of risk is very complex and that numerous factors must be considered. 
For the fault tree to be fully utilized each failure event must be amenable to analysis. Each must have a predictable failure threshold, and it must be possible either to obtain a reasonable data base for predicting the frequency of the event or else to show that the failure event is not an important safety consideration.

of the 77 failure events in the example studied, over 60 are believed to have predictable failure thresholds; thus it should be possible to develop data base for predicting probabilities. They are fully amenable to analysis.

Of the remaining 17 failure events, the majority were associated with man's future activities. Although man's future activities can never be exactly quantified, the importance of man's presence can be bracketed by first assuming the site is not actively administered and alternatively by assuming that man is actively controlling activities in the area.

Thus the degree of reliance placed on man's presence in the region can be roughly quantified. It is believed that disposal concepts which place minimum reliance on man's presence can be found. Thus, for those concepts the final criterion is met; i.e., the failure events associated with man's activity are not an important safety consideration.

The remaining failure events were associated with future tectonic activity. Areas of high tectonic activity may not be readily amenable to analysis because the forces involved are potentially large, they may not be well known, and they are particularly difficult to quantify. However, areas of high tectonic stability are available, and disposal in these locations should be amenable to fault tree analysis.

The reference noted on paqe 1 in this report shows an approach to evaluating each of the 77 basic failure elements identified by the qeneric fault tree for this example.

\subsubsection{Sample Waste Release} Probability Estimate

The next step of analysis is to follow each release sequence through its pathway to man's environment and ultimately to man. One release sequence, obtained from the geologic fault tree developed in the abovereferenced study, is followed here. The numbers presented in this analysis are based on very 1 imited data. Thus they serve primarily to demonstrate the safety evaluation method.

The example waste release sequence considers the release of waste to man's environment by water. This is considered to be one of the more likely release sequences.

The release sequence starts with the premise of "An Aquifer in the Waste Disposal Region" and requires the following three conditions:

"Water Finds Path into Disposal Site," "Water Is Flowing" and "Water Flow Cannot be Controlled by Man." All three conditions must occur together before a release of waste constituents can take place. Based on present tunneling experience, the probability that an undetected flaw in a barrier exists which will allow water 
entry in a region where there is no detectable aquifer is estimated to occur at a rate of once in $100,000 \mathrm{ki-}$ lometers of tunnel length. Thus the failure element "Water Finds Path into Disposal site" is estimated to occur at a rate of $10^{-5} / \mathrm{km}$ of tunnel constructed for geologic disposal. This and the following numbers are order of magnitude estimates. Based on the description for the mined cavity concept, 90 kilometers of tunnels will be in existence in the year 2000; thus the probability of a defect allowing water entry is expected to be once in every one thousand mines (or $10^{-3}$ ) with 90 kilometers of tunnel.

Conditions which could cause an aquifer in the region in the next year were estimated to be once in one billion $\left(10^{-9}\right)$. After one million years, the probability of an active aquifer in the region is taken to be much greater, $10^{-1}$. At the 1000-year period, an intermediate number was used. It was assumed that man would not be able to control the aquifer and the aquifer would be flowing; thus the failure elements "Water Is Flowing" and "Water Flow Cannot be Controlled by Man" have probabilities of one.

Table 5 summarizes the sample failure event probabilities and the resultant cumulative probabilities obtained by multiplying the individual probabilities in each vertical column. The ranges of probabilities given reflect uncertainty in the above data.

The table summarizes a release probability estimate from one sample failure sequence. To estimate the overall safety, all significant paths must be analyzed and the probabilities times the respective consequences must be summed.

TABLE 5. Sample Components of Release Sequence Probabilities for Geologic Disposal

Failure Event

Aquifer Develops in the Region Where One Did Not Exist Previously

Water Finds Path into Disposal site

Water Flow Cannot Be Controlled by Man

Water Is Flowing

Cumulative Release Probability in the Time Given

\begin{tabular}{|c|c|c|}
\hline $\begin{array}{l}\text { During } \\
\text { Operational } \\
\text { Period }\end{array}$ & $\begin{array}{c}\text { During } 1000 \\
\text { Years }\end{array}$ & $\begin{array}{l}\text { During } \\
1,000,000 \\
\text { Years }\end{array}$ \\
\hline $10^{-10}$ to $10^{-8}$ & $10^{-6}$ to $10^{-4}$ & $10^{-2}$ to $10^{-1}$ \\
\hline $10^{-4}$ to $10^{-2}$ & $10^{-4}$ to $10^{-2}$ & $10^{-4}$ to $10^{-2}$ \\
\hline 1 & 1 & 1 \\
\hline 1 & 1 & 1 \\
\hline
\end{tabular}


5.1.2 Application of Fault Trees to other Disposal Concepts

Preliminary failure modes were identified for seabed, ice sheet and extraterrestrial disposal concepts in the first reference. Fault tree analysis can be applied to these disposal concepts in the same manner as to the gelogic concepts.

The preliminary analysis pointed out how relatively little data are available to assess the seabed and ice sheet environments. For example, in the seabed environment, very 1 ittle information is known about the long-term behavior of ocean sediments. In like manner, there is little experience with drilling, placement and sealing of waste canisters in the seabed. Thus its apparent safety is uncertain, chieflv because of lack of detailed knowledge about it. The same is true of the ice sheet environment except that more known mechanisms for release of waste can be identified.

For the extraterrestrial disposal concepts, NASA has accumulated experience with manned space flights as a basis for estimating the safety which can be achieved. Failures on the launch pad, by burnup in the atmosphere, or meltdown after loss on the earth's surface are the failure elements of greatest concern and can be estimated with improved confidence as the number of launches accumulates.

\subsection{TRANSPORT MECHANISMS}

Al I disposal concepts under study provide substantial containment or isolation barriers to initially separate the constituents of nuclear waste from man's environment. A failure or degeneration of these barriers is required before transport to man's environment can be initiated. However, a barrier failure does not necessarily result in release of waste materials into man's immediate environment where exposure takes place; transport mechanisms are required.

The primary transport mechanisms are naturally occurring water and air. In most cases, transport by water will be through soils and/or rock with extensive chemical interaction (ion exchange) taking piace. The quantities, rate, and timing of radioisotopes entering man's environment will depend on a host of parameters such as the rate of release of radioisotopes at the source (i.e., solubility of waste in groundwater), the flow rate of the water, the distance travelled to reach man's environment, the efficiency of ion exchange, chemical species, etc.

Transport by air could be achieved as a result of either a single or a two-step process. In the first, an accident could both directly expose the waste to air and fracture it to such an extent that air currents would resuspend and transport material. In the two-stage process, it is postulated that naturally occurring water would transport the radioisotopes to a water (or earth)-air 
interface. Resuspension and transport could then occur from the residues of evaporation.

Quantification of the decontamination factors (i.e., radioisotope adsorption and holdup time) in the transport process requires an accurate model of the geologic system.

Sample transport decontamination factors were calculated for an aquifer 16 kilometers in length flowing at $30 \mathrm{~cm} /$ day in typical western soil. This calculation assumed that an aquifer penetrated a failed barrier in a geologic disposal site. Dose reduction factors were in the range of $10^{5}$ to $10^{6}$; that is, the calculated doses to man with soil retention were 5 to 6 orders of magnitude lower than those without soil retention. The significance of this calculation is that for properly sited disposal concepts, the earth itself can provide major safety factors.

\subsection{DOSE TO MAN}

A comprehensive dose computational model, developed and used for other Atomic Energy Commission Studies, was adapted to permit ready calculation of radiation doses to individuals and population groups for alternative waste disposal concepts. Typical inputs include source terms (radionuclide release rates to man's immediate environment), population densities, dilution quantities, and consumption rates of food and water. Outputs include individual pathway doses, total doses to individuals and to specified population groups, and fractional dose contributions of specific nuclides.
To demonstrate the capability, calculated doses are shown in Table 6 for a hypothetical release of radioactive waste from geologic disposal (assuming sorption and retention on soil). Also shown in the table is the limiting individual dose from nonoccupational and non-medical radiation exposure according to the latest recommendations of the National Council on Radiation Protection and Measurements. For comparison, the average annual radiation dose in the United States from natural sources is on the order of 120 to $140 \mathrm{mrem}$. The dose indicated in the table for the Maximum Individual is less than that received during a cross-country jet airplane flight.

The potential doses (following releases from a geologic disposal site) are highly dependent on the sorption capacity of the soil or other receiving media, the characteristics (especially the leach rate) of the waste, and the measures taken to prevent release.

Calculations can be based on postulated release of the waste materials to man's immediate environment at any period after disposal, but calculated doses at periods of 1,000 years or more would be much less due to decay of shorter-lived nuclides. The most significant nuclides in terms of dose would generally be Strontium-90 and Cesium-137 at 100 years, various radionuclides of americium and plutonium at 1,000 to 10,000 years, and uranium daughter nuclides at longer periods.

Doses calculated with the model for various generic cases are primarily valuable for comparative purposes, 
TABLE 6. Calculated Whole Body Radiation Doses from Hypothetic Release of Waste Inventory of Year 2000 in Geologic Disposal

Maximum Annual Dose (mrem)

Maximum Individual

Population

$$
0.4
$$

Annual Dose to Population (man-rem)

30
NCRP Non-Occupationa 1
Guide

500

(a)

Assumptions

- Total waste inventory exposed in the assumed releases is all of the waste resulting from the projected cumulative 167,000 equivalent metric tons of fuel processed in the U.S. through year 2000. (The latest projection is 185,000 equivalent metric tons.)

- Initial release to soil occurs 100 years after disposal.

- Geologic disposal is in arid western region, with release to aquifer.

- Source release rate (or the rate of dissolution of the waste materia 1 ) is $0.3 \%$ per year of total inventory.

- Aquifer is 16 kilometers long; average groundwater velocity is $30 \mathrm{~cm} /$ day.

- Soil is typical western desert soil, with its normally good ion-exchange capacity.

- Population is 180,000 people within an $80-\mathrm{km}$ radius of the point of release to man's immediate environment.

- Aquifer flows into a river which flows through the center of the region and which provides both drinking water and irrigation.

- Average river flow rate is $280 \mathrm{~m}^{3} / \mathrm{sec}$.

a. Guides are not available, but dividing the indicated dose of 30,000 man-rem by the assumed population size of 180,000 gives an average annual dose of 0.16 mrem for comparison with the dose to the hypothetical Maximum Individual.

and such doses would be, at worst, the result of a series of unpredictable or low-probability events leading to the release of radioactivity to man's immediate environment. Detailed analyses will be required to assess the risks to man from specific concepts, sites, and operations.

\subsection{RISK TO MAN}

The sample calculations of probability given in Table 5 can be multiplied by doses such as those shown in Table 6 to obtain a hypothetical risk of radiation dose to man from the disposal concept. The maximum measure of risk to an individual from the given failure mechanisms and pathways would then be in the range of $10^{-14}$ to $10^{-10} \mathrm{mrem} /$ year to the whole body during the operational period, $10^{-10}$ to $10^{-6} \mathrm{mrem} /$ year at 1,000 years after disposal, and $10^{-6}$ to $10^{-3} \mathrm{mrem} /$ year at $1,000,000$ years after disposal. Similarly, the risk to the affected large population 
group would be less than $10^{-8}, 10^{-4}$, and $10^{-1}$ man-rem/year for the same respective three time intervals.

These previous sections demonstrate the methodology for calculating the probabilistic risk to man from radioactive waste disposal. For actual application of risk calculations, analyses will be required for specific concepts, sites, and operations. In addition, the risks from all major mechanisms and pathways must be summed to obtain the total calculated risk.

An alternative measure of risk would be derived from estimation of harmful effects (deaths or illness) on people from the calculated radiation dose increments associated with each disposal concept. Recent studies sponsored by the United Nations Scientific Committee on the Effects of Atomic Radiation and by the U.S.
Environmental Protection Agency address what is known and what is assumed for low-level radiation concerning the radiation dose/radiation effects problem. Considering the large uncertainties in the derived conversions and the problem of making equivalent conversions for radiation doses to different organs of the body, we have chosen not to attempt estimates of harmful effects for these concept comparison studies. Attempts have been made by others to place a dollar value on estimates of increased harmful effects on people to provide a more direct method of comparisons than the above. Such a procedure involves not only still larger uncertainties, but the basic philosphical question of equating dollars to human lives, and is not being considered for these studies. 


\subsection{DISPOSAL CONCEPTS - DESCRIPTION AND SYSTEMS}

Listed in Table 7 are the various waste management concepts. The table highlights key differences of the various alternative system characteristics compared to a reference disposa? concept. The reference concept was arbitrarily selected to be a concept comparable to salt mine disposal: total waste encapsulated as a solid and emplaced in a mined cavity with no auxiliary fluid cooling. The simplified table does not show all the variations studied for each of the generic concepts listed. Brief concept and systems descriptions are presented in the following sections.

\subsection{GEOLOGIC DISPOSAL CONCEPTS}

The basic requirement for any geologic environment to be suitable for disposal of radioactive waste is the capability to safely contain and isolate the emplaced radioactive material until decay has reduced the radioactivity to nonhazardous levels. Geologic environments exist which have been physically and chemically stable for millions of years, would provide isolation from man's environment, and have acted as effective barriers for isolation of naturally occurring radioactive uranium and thorium deposits from man's environment.

Relative to other terrestrial locations, a large amount of information is available on the geology of the conterminous United States, the primary area of interest for this waste disposal study.
A geologic formation can be penetrated and altered in several ways to provide a repository for waste emplacement. This study considers the use of drilling, mining (mechanical and dissolution), exploded cavity formation and hydraulic fracturing. Many combinations of potential geologic environments and methods of their penetration, along with methods for placement of waste within these systems, were studied in an attempt to cover the broad range of potential possibilities.

Ten methods for disposing of waste in geologic formations were considered in this study. Two primary disposal geometries, i.e., cavities and a drilled hole, several means for forming cavities, and several operational modes were examined, as shown in Table 8.

In a 11 concepts the final waste form is a solid. In some concepts, waste is emplaced in the geologic formation as a liquid and converted in-place to a solid form for longterm disposal. For concepts 5, 6, and 9 , the self-generated heat within the liquid waste is used to dry and melt the waste and some of the surrounding rock which, when cooled, forms a solid waste-rock matrix. In concept 10 , the 1 iquid waste is incorporated within a self-curing cement.

Because of the potential hazards of shipping aqueous high-level waste, the liquid emplacement concepts require incating the fuel reprocessing 
Table 7. Summary of System Characteristics for Alternative Waste Management Systems

\begin{tabular}{|c|c|c|c|c|c|c|c|c|}
\hline \multirow[b]{2}{*}{ Concept } & \multicolumn{8}{|c|}{ Requirements for the System } \\
\hline & \multirow{3}{*}{$\begin{array}{c}\text { Interim } \\
\text { Liquid Waste } \\
\text { Storage at } \\
\text { Reprocessing } \\
\text { Plant? }\end{array}$} & \multirow{3}{*}{$\begin{array}{l}\text { Partitioning } \\
\text { of Waste into } \\
\text { Two or More } \\
\text { Fractions? } \\
\text { No }\end{array}$} & \multirow{2}{*}{$\begin{array}{l}\begin{array}{c}\text { Solidification } \\
\text { Into Canned } \\
\text { Silicate Glass } \\
\text { or Special Forms? }\end{array} \\
\text { Glass }\end{array}$} & \multirow{2}{*}{$\begin{array}{l}\begin{array}{c}\text { Interim } \\
\text { Solid Waste } \\
\text { Storage? }\end{array} \\
\text { Optional }\end{array}$} & \multirow{3}{*}{$\begin{array}{c}\text { Overland } \\
\text { Transportation } \\
\text { to Disposal or } \\
\text { Recycle Facility? } \\
\text { Yes }\end{array}$} & \multirow{3}{*}{$\begin{array}{c}\begin{array}{c}\text { Involves Final } \\
\text { Disposal } \\
\text { of Waste } \\
\text { Constituents? }\end{array} \\
\text { Yes }\end{array}$} & \multirow{3}{*}{$\begin{array}{c}\text { Disposal } \\
\text { of Total } \\
\text { High-Level } \\
\text { Waste } \\
\text { Constituents? } \\
\text { Yes }\end{array}$} & \multirow{3}{*}{$\begin{array}{l}\text { Other } \\
\text { None }\end{array}$} \\
\hline $\begin{array}{l}\text { "Reference" Concept (solid waste } \\
\text { emplaced in mined cavity, no } \\
\text { fluid cooling or melting). }\end{array}$ & & & & & & & & \\
\hline Geologic Concepts & & & ies from Above Requiremen & ents are Liste & & & & \\
\hline $\begin{array}{l}\text { 1. Solid waste emplaced in } \\
\text { mined cavity; no fluid } \\
\text { cooling or melting }\end{array}$ & -- & -- & - & -- & -- & -- & -- & $\cdots$ \\
\hline $\begin{array}{l}\text { 2. Solid waste emplaced in } \\
\text { mined cavity; initial } \\
\text { water cooling; melting }\end{array}$ & -- & -- & $\begin{array}{l}\text { Also in-place melt- } \\
\text { conversion to rock- } \\
\text { waste matrix. }\end{array}$ & $\cdot-$ & -- & -- & -- & -- \\
\hline $\begin{array}{l}\text { 3. Solid waste emplaced in } \\
\text { manmade structure in mined } \\
\text { cavity; initial air cooling; } \\
\text { no melting }\end{array}$ & -- & -- & - & -. & -- & -- & -- & -- \\
\hline $\begin{array}{l}\text { 4. Solid waste emplaced in } \\
\text { manmade structure in mined } \\
\text { cavity; initial water cool- } \\
\text { ing; no melting }\end{array}$ & $-\cdot$ & -- & . & -. & $-\cdot$ & -- & $\begin{array}{l}D i \\
\text { op } \\
\text { bi } \\
\text { po }\end{array}$ & $\begin{array}{l}\text { Disposal/processing } \\
\text { operations are com- } \\
\text { bined; extra trans- } \\
\text { port of fuel to re- }\end{array}$ \\
\hline $\begin{array}{l}\text { 5. Liquid waste emplaced in } \\
\text { mined cavity; initial re- } \\
\text { flux cooling; melting }\end{array}$ & $-\cdot$ & -- & $\begin{array}{l}\text { Liquid; in-place melt- } \\
\text { conversion in rock- } \\
\text { waste matrix. }\end{array}$ & . & No & -. & $-\cdot$ & $\begin{array}{l}\text { processing plant. } \\
\text { Disposa } 1 / \text { processing } \\
\text { operations are com- }\end{array}$ \\
\hline $\begin{array}{l}\text { 6. Liquid waste emplaced in } \\
\text { exploded cavity; initial } \\
\text { reflux cooling; melting }\end{array}$ & -- & $-\cdot$ & $\begin{array}{l}\text { Liquid; in-place melt- } \\
\text { conversion to rock- } \\
\text { waste matrix. }\end{array}$ & - & No & - & $\begin{array}{l}\text { bi } \\
\text { po } \\
\text { pr }\end{array}$ & $\begin{array}{l}\text { bined; extra trans- } \\
\text { port of fuel to re- } \\
\text { processing plant. }\end{array}$ \\
\hline $\begin{array}{l}\text { 7. Solid waste emplaced in } \\
\text { matrix of drill holes; } \\
\text { no fluid cooling or } \\
\text { melting }\end{array}$ & -- & -- & -. & -. & $\cdot \cdot$ & $\cdots$ & $\cdot \cdot$ & s. \\
\hline $\begin{array}{l}\text { 8. Solid waste emplaced in } \\
\text { deep holes; no fluid cool- } \\
\text { ing; melting or nonmelting (a) }\end{array}$ & -- & -- & -- & -. & $\cdots$ & -. & -. & (a) \\
\hline $\begin{array}{l}\text { 9. Liquid waste emplaced in } \\
\text { deep holes; initial reflux } \\
\text { cooling; melting }\end{array}$ & $-\cdot$ & -- & $\begin{array}{l}\text { Liquid: in-place melt- } \\
\text { conversion to rock- } \\
\text { waste matric. }\end{array}$ & . & No & -. & $\begin{array}{l}\text { Di } \\
\text { op } \\
\text { bi } \\
\text { po } \\
\text { pr }\end{array}$ & $\begin{array}{l}\text { Disposal/processing } \\
\text { operations are com- } \\
\text { bined; extra trans- } \\
\text { port of fuel to re- } \\
\text { processing plant. }\end{array}$ \\
\hline $\begin{array}{l}\text { 10. Liquid waste emplaced by } \\
\text { hydrofracture; in-place } \\
\text { curing }\end{array}$ & Yes & -. & $\begin{array}{l}\text { In-place curing to } \\
\text { waste-cement matrix }\end{array}$ & 10 & No & -. & $\begin{array}{l}\text { Di } \\
\text { op } \\
\text { bi } \\
\text { po } \\
\text { pr }\end{array}$ & $\begin{array}{l}\text { Disposal/processing } \\
\text { operations are com- } \\
\text { bined; extra trans- } \\
\text { port of fuel to re- } \\
\text { processing plant. }\end{array}$ \\
\hline Ice Sheet concepts & & & & & & & & \\
\hline $\left.\begin{array}{l}\text { 1. Self melt through ice } \\
\text { 2. Anchored storage/disposal } \\
\text { 3. Ice surface storage/disposal }\end{array}\right\}$ & -- & -. & $\cdots$ & - & $\begin{array}{l}\text { Also over-sea, } \\
\text { over-ice transport }\end{array}$ & - & -- & $-\cdot$ \\
\hline$\underline{\text { Seabed Concepts }}$ & & & & & & & & \\
\hline $\begin{array}{l}\text { 1. Subduction zones and other } \\
\text { deep-sea trenches }\end{array}$ & & & & & & & & \\
\hline $\left.\begin{array}{l}\text { 2. Stable deep-sea floors } \\
\text { 3. Rapid sedimentation }\end{array}\right\}$ & -- & -. & -- & .. & $\begin{array}{l}\text { Also over-sea } \\
\text { transport }\end{array}$ & -. & -. & -- \\
\hline Extraterrestrial Concepts & . & & & & & & & \\
\hline $\left.\begin{array}{l}\text { 1. Solar and Earth Orbits } \\
\text { 2. Solar impact } \\
\text { 3. Solar escape }\end{array}\right\}$ & Desired & Yes & $\begin{array}{c}\text { Special } \\
\text { capsule forms }\end{array}$ & No & -. & -- & $\begin{array}{l}\text { No, transuranic } \\
\text { only }\end{array}$ & incs. \\
\hline Transmutation Concepts & & & & & & & & \\
\hline 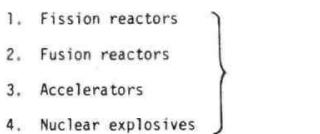 & Desired & Yes & $\begin{array}{c}\text { Special } \\
\text { capsule forms }\end{array}$ & No & $-\cdot$ & $\begin{array}{l}\text { Recycle/ } \\
\text { elimination }\end{array}$ & $\begin{array}{l}\text { No, actinides } \\
\text { only and } \\
\text { selected } \\
\text { fission products }\end{array}$ & ts \\
\hline
\end{tabular}

a. For deep drill hole, both prior solidification and in-place solidification were studied. 
TABLE 8. Characteristics of Geologic Disposal Concepts

\begin{tabular}{|c|c|c|c|c|}
\hline Concept & Type of Cavity & $\begin{array}{l}\text { Waste Form } \\
\text { at Time of } \\
\text { Emplacement }\end{array}$ & $\begin{array}{l}\text { Fluid } \\
\text { Cooling }\end{array}$ & $\begin{array}{r}\text { Waste-Rock } \\
\text { Reactions } \\
\end{array}$ \\
\hline 1 & Mined & Solid & No & No \\
\hline 2 & Mined & Solid & Water & Melt \\
\hline 3 & Mined $^{(a)}$ & Solid & $\operatorname{Air}(c)$ & No \\
\hline 4 & Mined (a) & Solid & Water (c) & No \\
\hline 5 & Mined & Liquid (b) & No & Melt \\
\hline 6 & Exploded & Liquid (b) & No & Melt \\
\hline 7 & $\begin{array}{l}\text { Matrix of } \\
\text { Drilled Holes }\end{array}$ & Solid & No & No \\
\hline 8 & Deep Hole & Solid & No & No/Melt ${ }^{(d)}$ \\
\hline 9 & Deep Hole & Liquid (b) & No & Melt \\
\hline 10 & Hydrofracture & Liquid (b) & No & No \\
\hline
\end{tabular}

\footnotetext{
a. Includes underground manmade structures.

b. All liquid emplacement concepts involve in-place conversion to a solid form.
c. Cooling is provided for an interim period of tens of years until the heat generation rate has decreased to a point that melting will not occur.

d. This deep hole concept is studied for both melting and non-melting cases.
}

\begin{abstract}
plant at the disposal site. (a) The solid emplacement concepts involve transportation of the waste, already converted to a solid at the fuel reprocessing plant, cross-country to a central Federal disposal site, assumed to be separate from the reprocessing plant. (b) These basic systems requirements for high-level waste management in terrestrial locations (geologic formations, ice sheet, and seabed) are shown in Figure 4.

It was assumed in this study that geologic disposal options are aimed
\end{abstract}

\begin{abstract}
at managing the total high-level waste, including the long-lived radionuclides, without preconditioning or partitioning of the aqueous waste.

The ten geologic disposal concepts are shown schematically in Figures 5 through 14 and discussed below.
\end{abstract}
6.1.1 Solid Waste Emplaced in Mined Cavity - No Fluid Cooling or Melting
The concept depicted in Figure 5 shows previously solidified waste buried in the floor of rooms or tun- nels that have been excavated in the

a. It may be possible to ship calcined waste to the repository and dispose of it as an aqueous slurry by any of the liquid waste disposal concepts. This concept may be looked at as a variation of the liquid waste disposal concept.

b. A Federal repository, the Retrievable Surface Storage Facility, is planned for interim retrievable storage of solidified waste until a disposal concept is ready for use. 


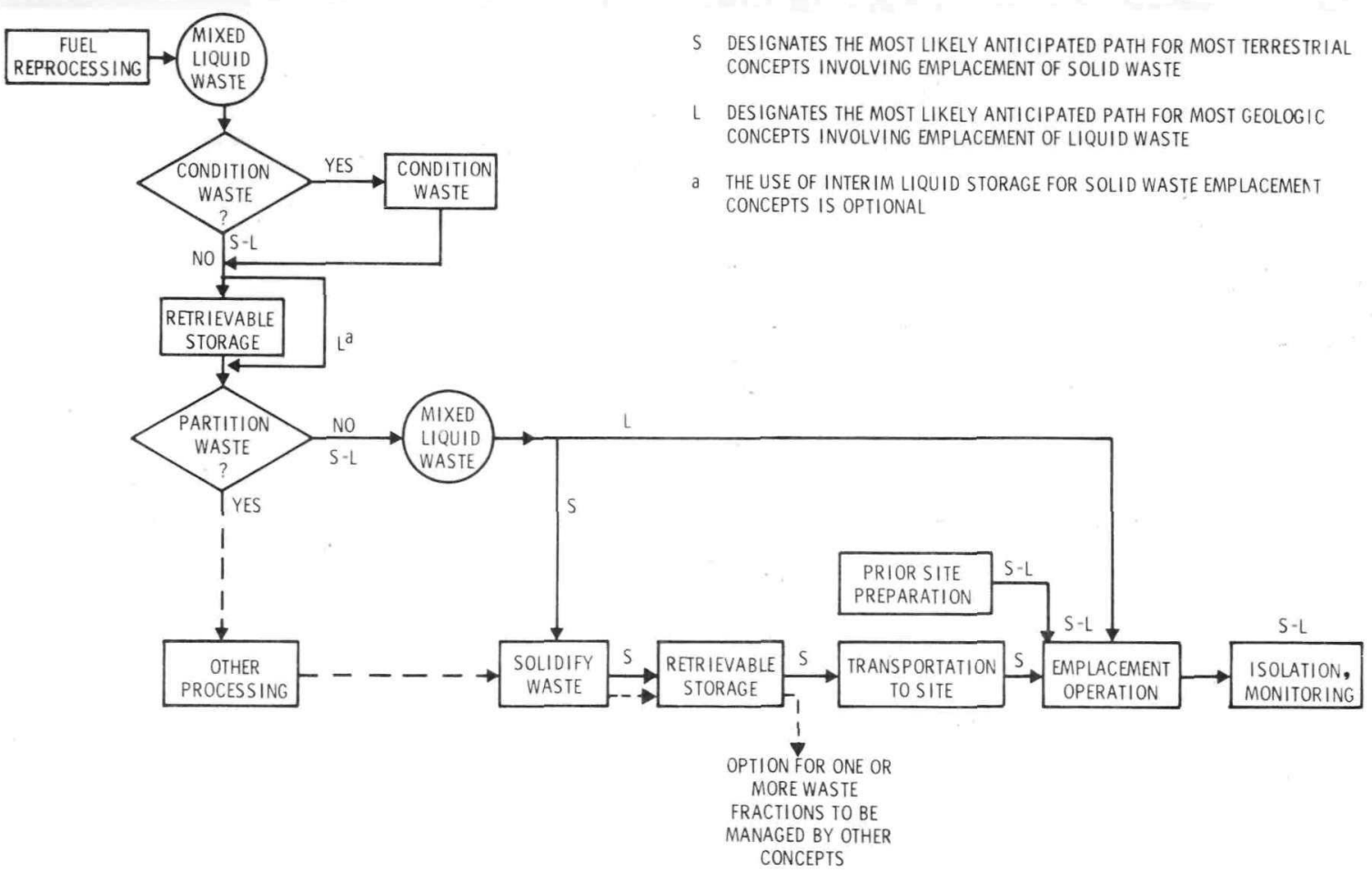

FIGURE 4. System Requirements for High-Level Radioactive Waste Management in Terrestrial Locations

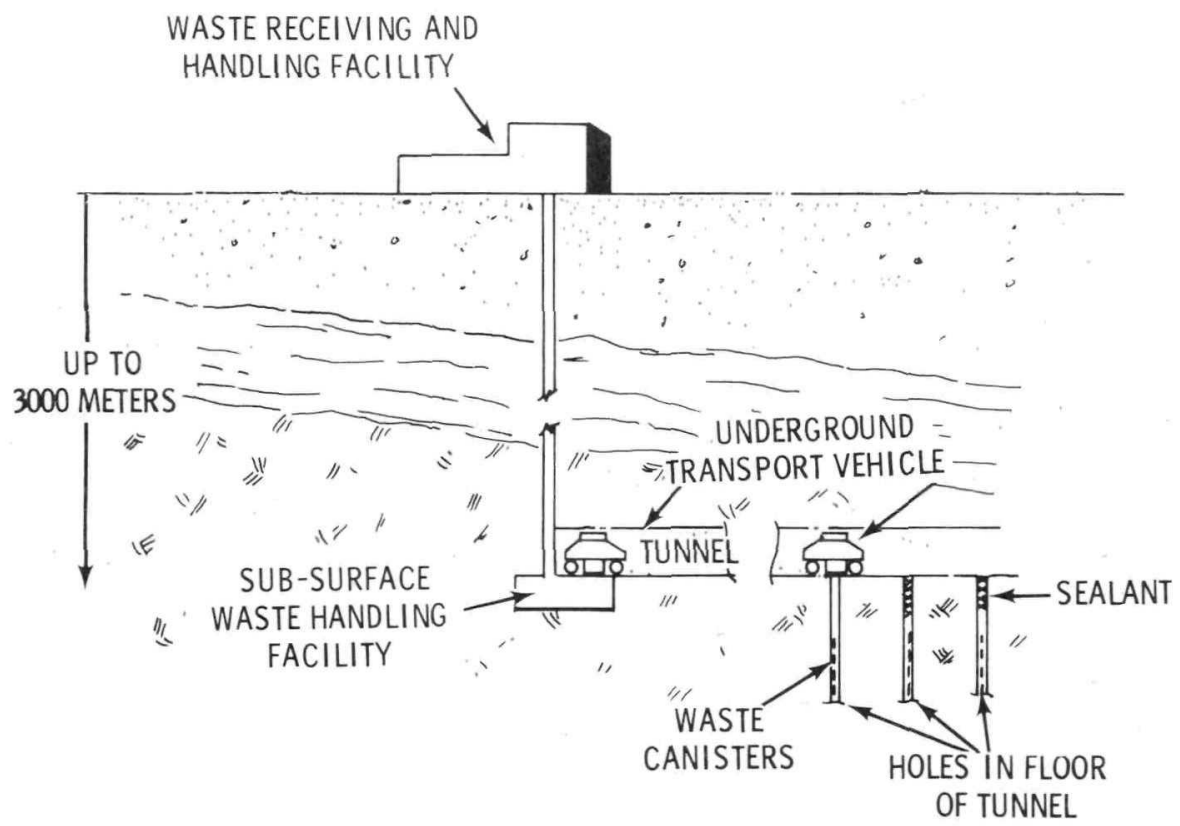

FIGURE 5. Solid Waste Emplacement in a Mined Cavity No Fluid Cooling or Melting 
geologic formation. This generic concept includes the bedded salt disposal concept that has received emphasis in major Research and Development studies sponsored by the Atomic Energy Commission over the past 15 years. Studies on the bedded salt concept were initiated based on recommendations of the National Academy of Sciences - National Research Council.

Upon arrival at the repository, the shipping cask and transport vehicle are moved into a cask unloading area which is inside a building. The cask is removed from its carrier and lowered into a shielded handling cell. Individual canisters are removed from the cask and transported to a shaft where they are lowered by cable into the subsurface complex. The lower end of the shaft terminates in a transfer vault or shielded handling cell located in the geologic formation at the mine level.

At the mine level, individual waste canisters are moved from the sub-surface shielded cell into a shielded transfer vehicle. After receiving the canister, the subsurface transfer vehicle transports the waste package to a previously mined and prepared burial tunnel or room with predrilled holes in the floor. The transfer vehicle is located over a hole, and the waste package is lowered into the hole. The hole may be backfilled with material to provide some shielding to the tunnel area and to act as a partial barrier against escape of radionuclides into the tunnel area in the event a can fails. After the last can is lowered into a hole, the top 1.8 to 2.4 meters ( 6 to 8 feet) of the hole are filled with a sealant to provide isolation and shielding. The system is designed so that the heat from the waste will be conducted through the geologic formations without causing melting or deterioriation of the geologic media.

After all the holes have been filled and sealed, individual burial tunnels or rooms are sealed from the rest of the repository by a bulkhead. The tunnel or room will eventually be backfilled.

It is estimated that about $90 \mathrm{kilo-}$ meters of burial tunnel, 4.6 meters on a side, would be required to dispose of the 14,700 canisters of highlevel waste produced by the reference reprocessing plant. In addition, nearly 11 kilometers of access tunnel will be required.

6.1.2 Solid Waste Emplaced in Mined Cavities - Interim Liquid Cooling and Waste-Rock Reaction

A pictorial description of this concept is shown in Figure 6 . Waste canisters are removed from shipping casks in a waste receiving facility, lowered through a drill hole into a lined cavity, and deposited on the cavity floor in a random array. Waste within the cavity is immersed in a boiling water bath. Steam generated is condensed in a surface facility and returned to the hole for cooling the waste. Operation of the surface cooling system will be continued until the cavity contents are permitted to melt by allowing the cooling water to boil away.

The reference case for this concept assumes eventual waste-rock me1ting after shutdown of the water 


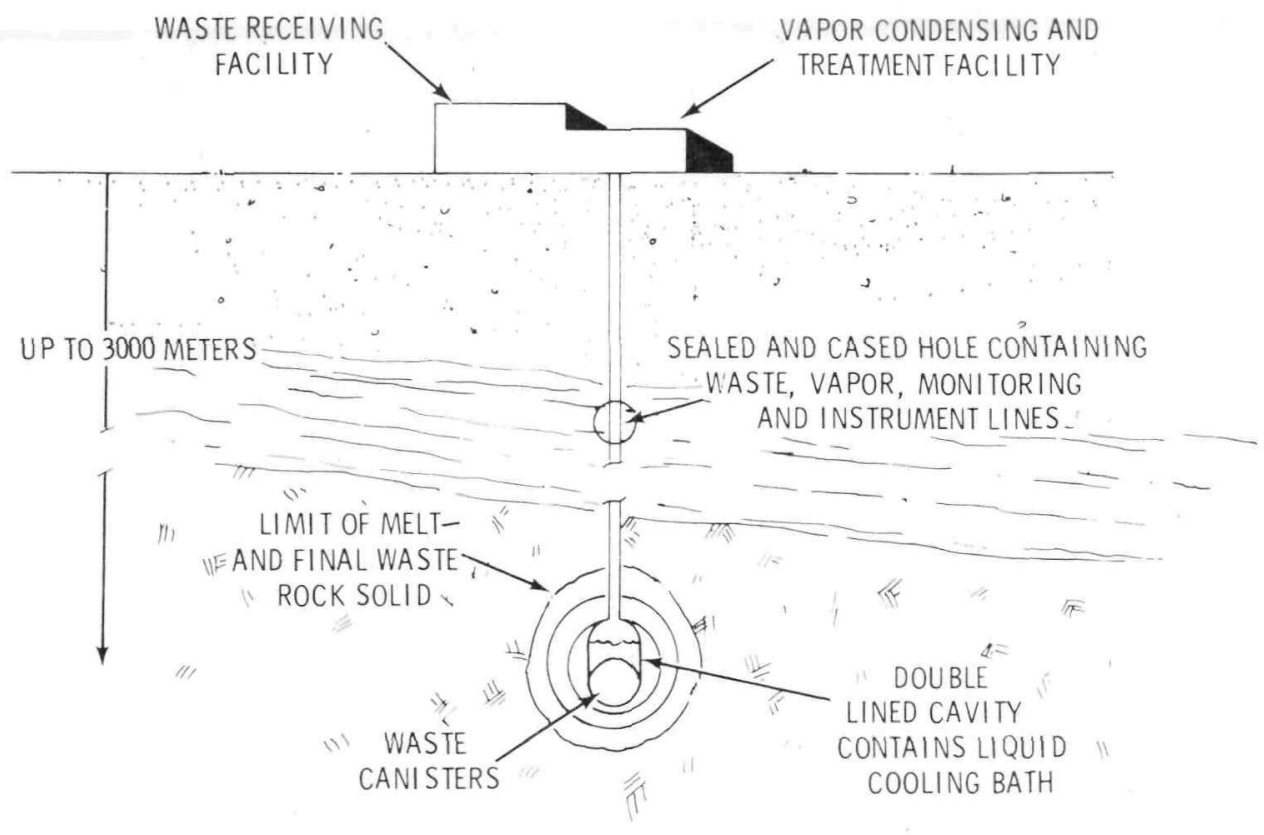

FIGURE 6. Solid Waste Emplacement in a Mined Cavity Interim Liquid Cooling and Waste-Rock Melting

cooling phase of cavity operation. Cavity shutdown is started by stopping return of the condensed steam. The cavity begins to dry and the temperature of the contained materials starts to rise. The cased hole is sealed by plugging at an appropriate time, and the waste is allowed to melt. The waste will melt from its own heat within a few days because it is concentrated in a small volume with little cooling by the surrounding rock. Over a few tens to one hundred years the heat from the waste will melt some of the surrounding rock and form a larger molten mass which dilutes the waste concentration. After a few hundred years, the molten rock-waste mixture will cool and solidify into a rockwaste matrix as the heat provided by radioactivity diminishes.
A cavity volume of about 13,000 cubic meters would be required to receive and serve as a repository for the high-level waste generated by the reference reprocessing plant.

\subsubsection{Solid Waste Emplaced in Man-} made Structures in Geologic Formations - Interim Air Cooling

Figure 7 is a graphic description of a concept using natural convection air cooling of waste canisters inside individual pods designed to conduct the heat to the air coolant. A canister of waste is sealed inside the bottom of a thick-walled metal pod buried in the floor of the tunnel to shield operating personnel from radiation. Radioactive decay heat is conducted through the metal pod wall and is dissipated from the finned surface to 


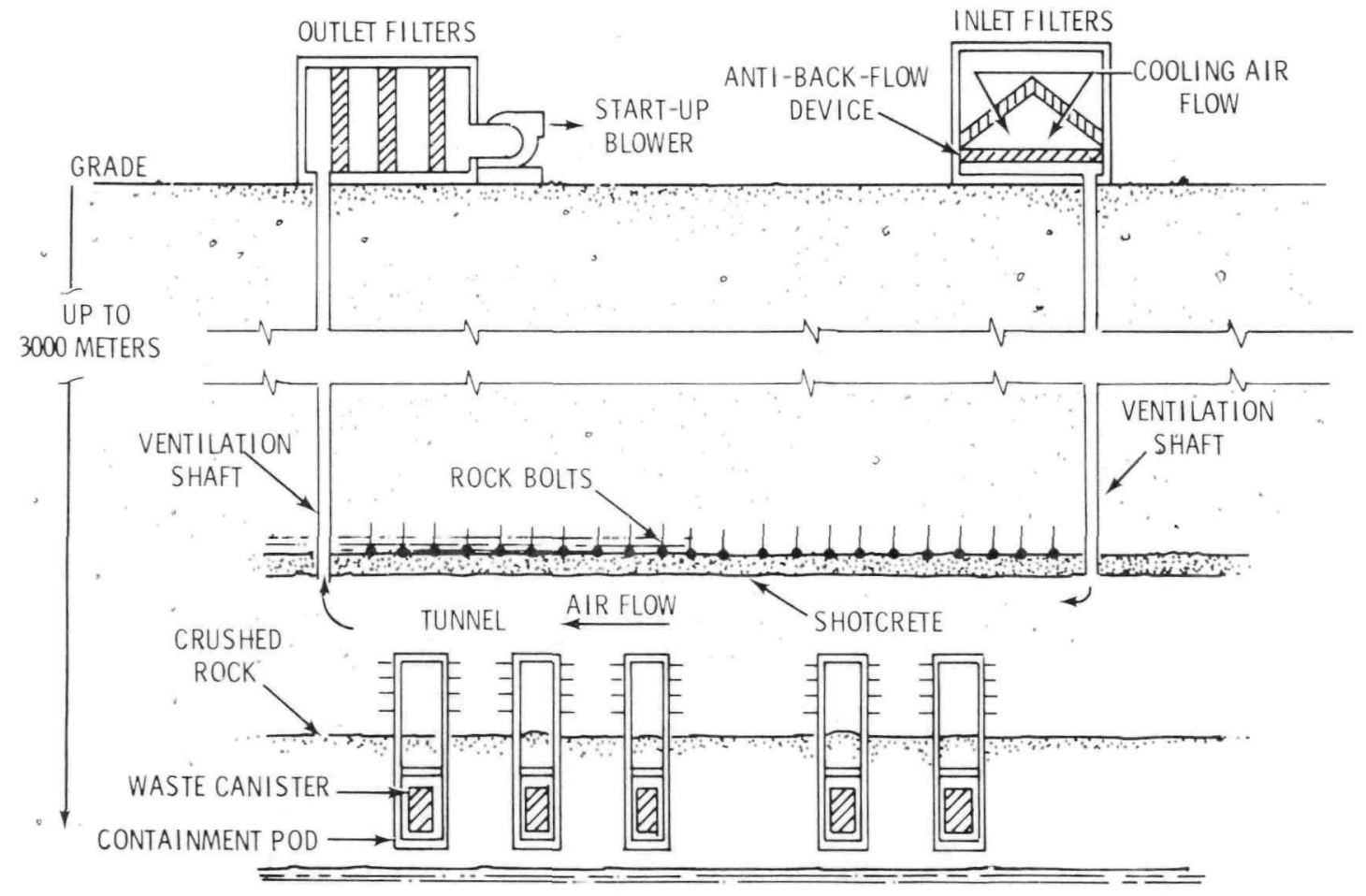

FIGURE 7. Solid Waste Emplacement in a Mined Tunnel - Interim Natural Convection Air Cooling, No Melting.

the flowing cooling air. The single pass cooling air flows by natural convection once the draft has been initiated. After a predetermined time, the access areas are sealed and the waste heat is transferred to the surrounding rock as in concept 1 .

Upon arrival at the repository, a waste canister is unloaded inside a building and transferred to the belowground facilities much as in concept 1 (see Figure 5). At the mine level, the waste canister is placed in the containment pod. The pod is placed in a hole or trench within a tunnel, the hole is backfilled with crushed rock, and the top of the pod is sealed. Other emplacement operations are similar to those for concept 1 .
About 5.5 kilometers of burial tunnel, 9 meters in diameter, would be required to dispose of the highlevel waste produced by the reference reprocessing plant.

\subsubsection{Solid Waste Emplaced in Man- made Structures in Geologic Formations - Interim Water cooling}

A schematic diagram of a watercooled system is shown in Figure 8 . This is a typical cross-sectional view of a tunnel containing the underground facility, a manmade structure designed to withstand earthquakes and shifting of the rock formation. Upon arrival at the repository, the waste 
NON-

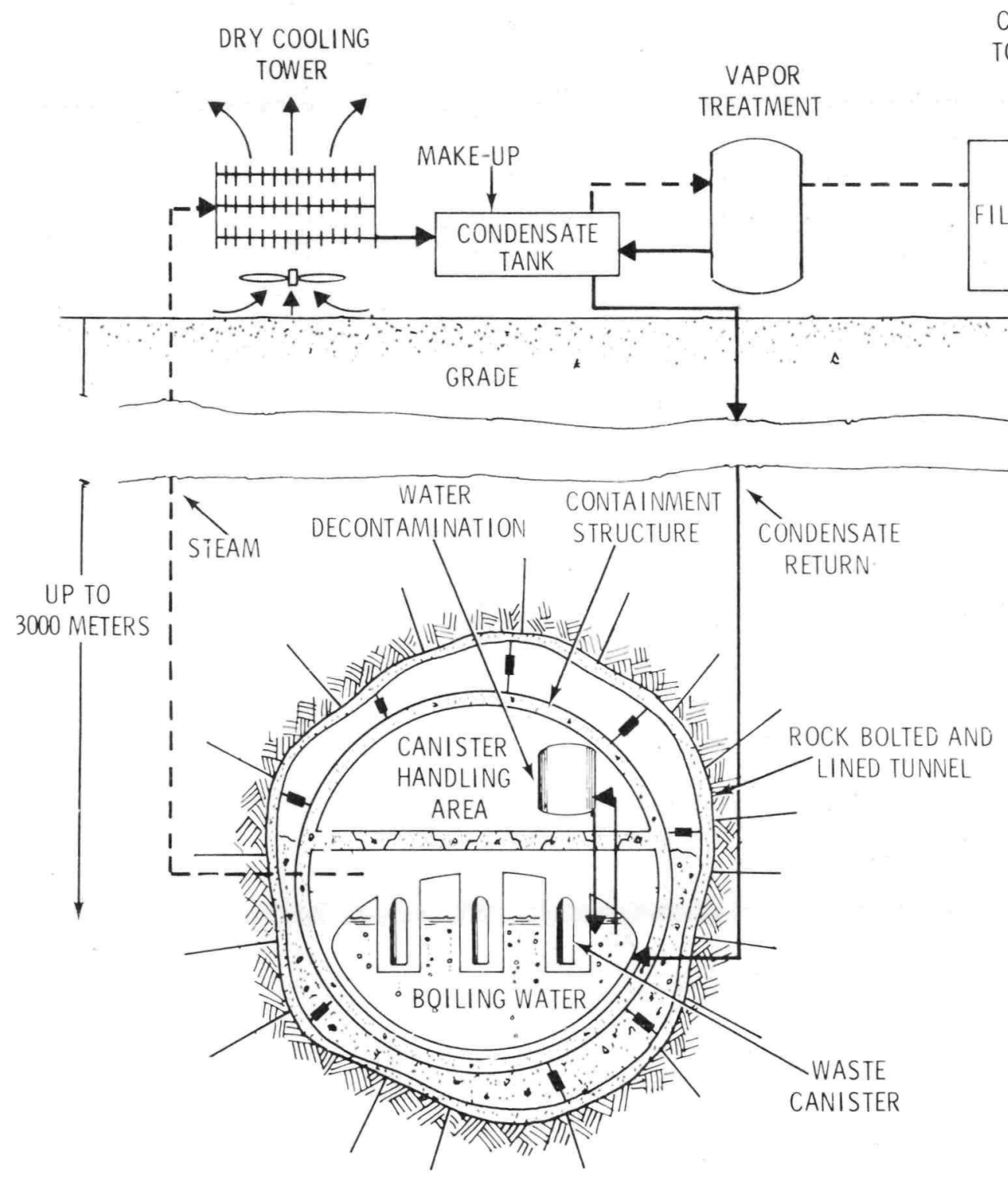

CONDENSABLES TO ATMOSPHERE

FIGURE 8. Solid Waste Emplacement in Manmade Structure with Interim Boiling Water Cooling, No Melting

canister is unloaded inside a building, transferred to the below-ground facilities, transported to the disposal location through the waste canister handling area of the tunnel and lowered into the hole, similarly to other concepts. The waste is placed in the shielded lower part of a cylindrically-shaped water-filled storage vessel in the mined cavity. Typically the concrete shell would be 30 feet in diameter and the tunnel would be 50 feet in diameter. Steam generated by the waste is piped to a heat-exchange system at the earth's surface where it is condensed and returned to the waste storage area. A side stream of the coolant is 
treated to remove radioactivity which may be present from leaking or externally contaminated canisters. After a predetermined time the cooling water is removed from the system. The access areas are sealed, and the waste heat is transferred to the surrounding rock without melting as in concept 1. Tunnel requirements would be about the same as in the previous concept. Auxiliary facilities such as personnel access shafts, air locks and waste transfer shafts are not shown in Figure 8 but would be similar to those in concept 1 .

6.1.5 Liquid Waste Emplaced in a Mined Cavity - In-Place Drying and Conversion to Rock-Waste

\section{Matrix}

Figure 9 shows this concept. Liquid waste is stored in a mined cavity below the fuel reprocessing plant. The cavity contains a high-integrity liner or tank connected through highintegrity piping to a specially designed condensing and treatment facility for the radioactivity-containing vapor, located adjacent to the fuel reprocessing plant at the surface. Liquid waste is continuously added to the cavity and cooled by recycling condensed vapors from the surface facility. When the reprocessing plant is to be shut down or the cavity is to be converted to its permanent disposal mode, recycle of the condensed coolant is stopped and the cavity contents are allowed to boil to dryness and to melt. When it is certain that no excessive pressure will build up in the cavity, the access shafts and piping are sealed. During a few tens to one hundred

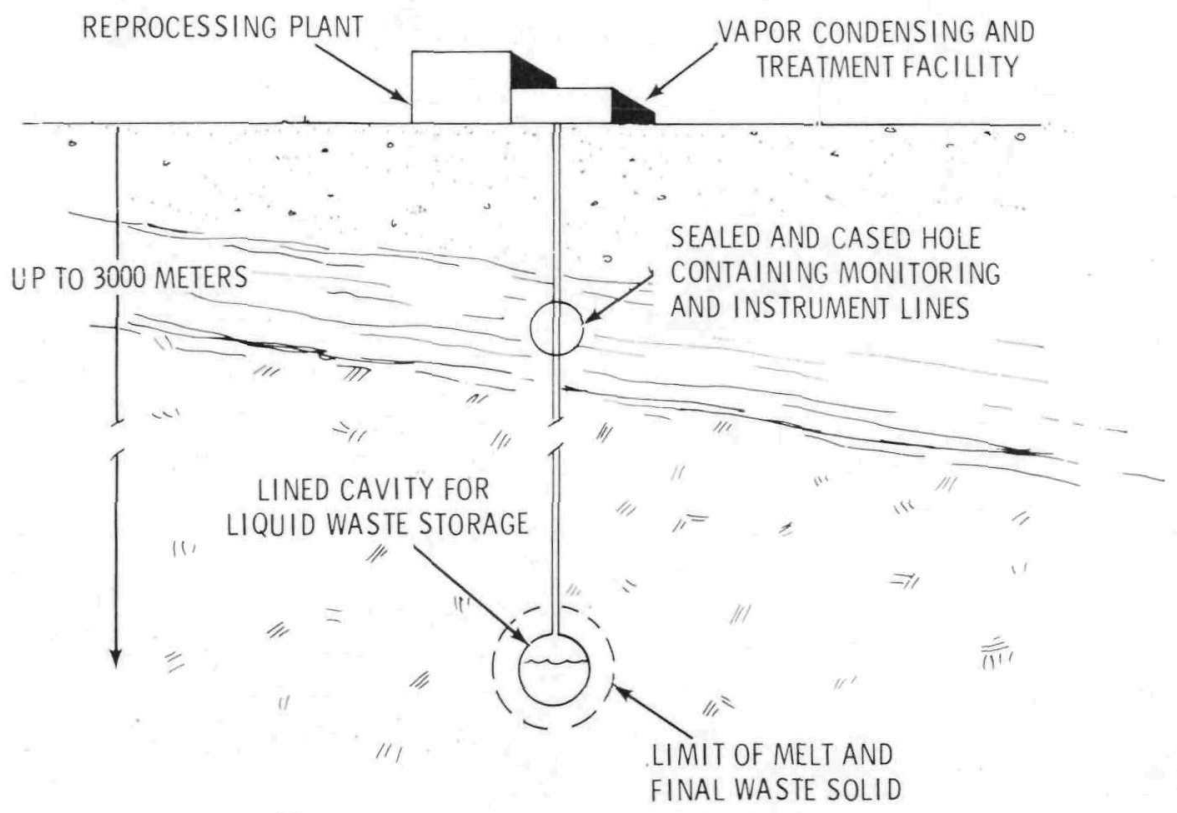

FIGURE 9. Liquid Waste Emplacement in a Mined Cavity In-Place Drying and Conversion to Rock-Waste Matrix 
years the waste will melt the liner and some of the surrounding rock. After a few hundred years the molten rock-waste mixture will cool and progressively solidify into a rock-waste matrix.

About 4,000 cubic meters are required for the cavity volume to dispose of the high-level liquid waste generated by the reference reprocess ing plant.

This concept has some similarities to that studied at AEC's Savannah River site for storage of aqueous alkaline waste in bedrock without inplace solidification. The National Academy of Sciences concluded that such long-term storage disposal of aqueous waste in bedrock would re- quire substantial research and development before it could be implemented.

\subsubsection{Liquid Waste Emplaced in Ex- ploded Cavities - In-Place Drying and Conversion to Rock- Waste Matrix}

This concept, shown in Figure 10 , is similar to concept 5 (see Figure 9) except that an unlined, rubble-filled cavity is formed by nuclear explosion (or possibly by conventional explosive). The rock rubble filling the cavity provides the material for initial formation of the rock-waste matrix. The rubble-filled hole must provide about 4,000 cubic meters of free volume to contain the high-level 1 iquid waste discharged by the reference reprocessing plant.
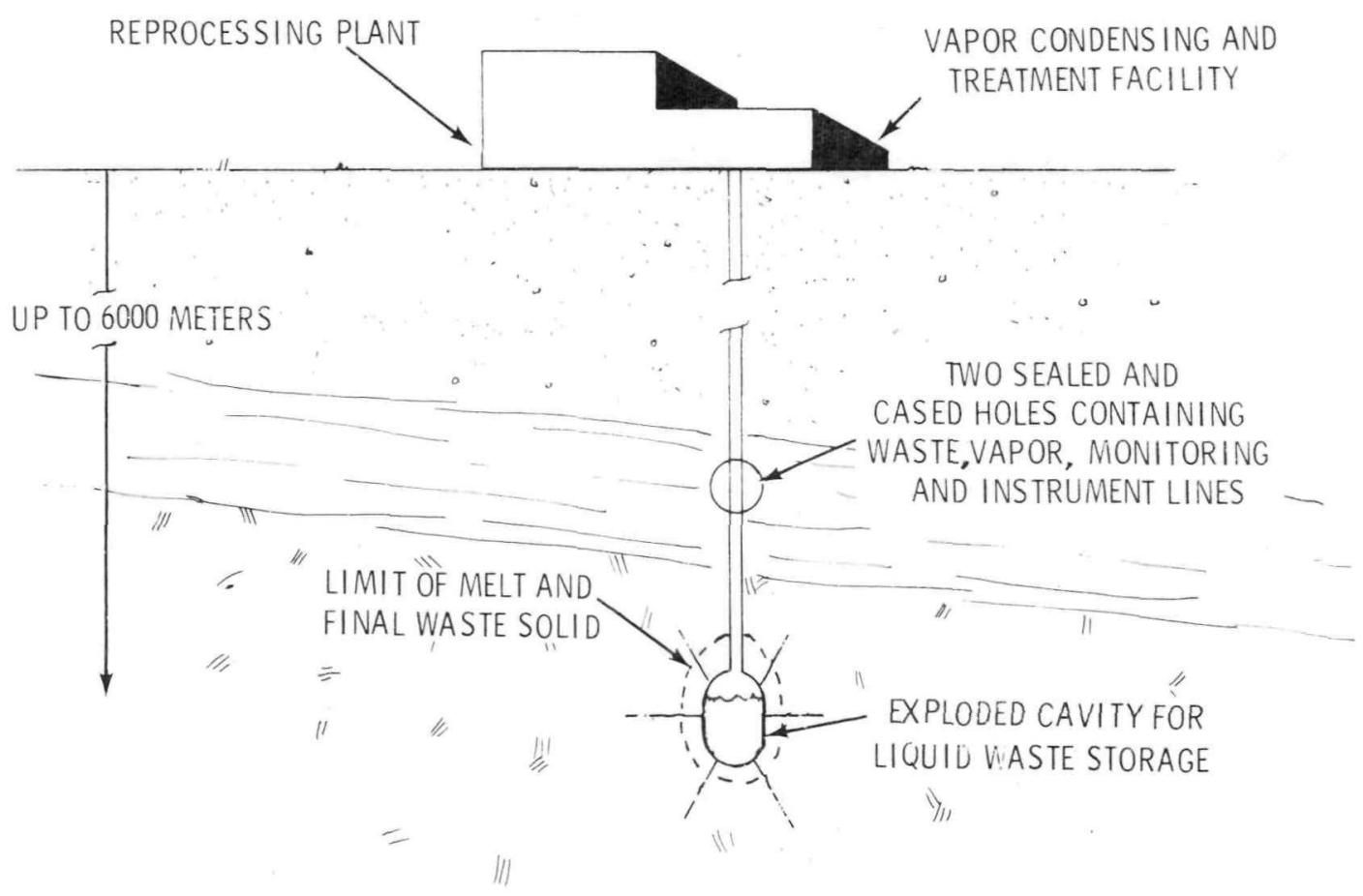

FIGURE 10. Liquid Waste Emplacement in an Exploded Cavity - In-Place Drying and Conversion to Rock-Waste Matrix 


\subsubsection{Solid Waste Emplaced in a}

Matrix of Drilled Holes

In this concept all operations are performed from the earth's surface, as show in Figure 11. Canisters full of solidified high-level waste are brought to the handling facility where they are transferred to a specially designed transfer and emplacement (charging) vehicle. The vehicle moves to a previously drilled hole where each waste canister is carefully lowered into the hole and placed on the preceding canister. When the hole is filled with waste canisters to a predetermined level, it is sealed, and waste is emplaced in the next hole of the array. For the reference case in this study, 300 canisters were assumed to be contained in the lower portion of each 4500 -meter-deep hole.
6.1.8 Solid Waste Emplaced in a Deep Hole

This concept, shown in Figure 12 , is similar to the previous drilled matrix hole concept except that each drill hole penetrates to an extreme depth, nominal1y 16 kilometers

(10 miles) deep. The concept can be designed for a nonmelting or a melting case (the latter is shown in Figure 12). For the me1ting case, the capability for handling vapors from volatilization of small amounts of water in geologic formations may be necessary within the surface facility. The waste in the lower portion of the hole will be molten while waste is added from above. After each hole is filled to the predetermined level with waste canisters, the hole is sealed. A few hundred years after emplacement of the waste,

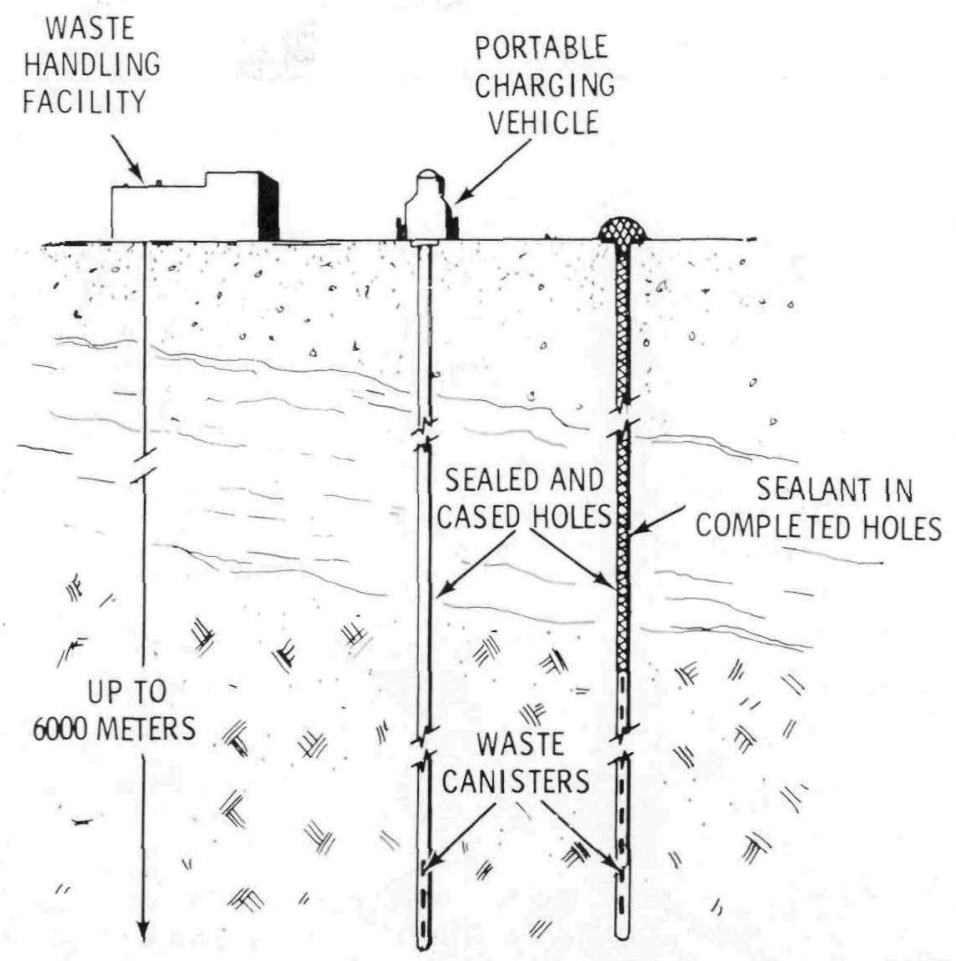

FIGURE 11. Solid Waste Emplacement in a Matrix of Drilled Holes - No Melting 


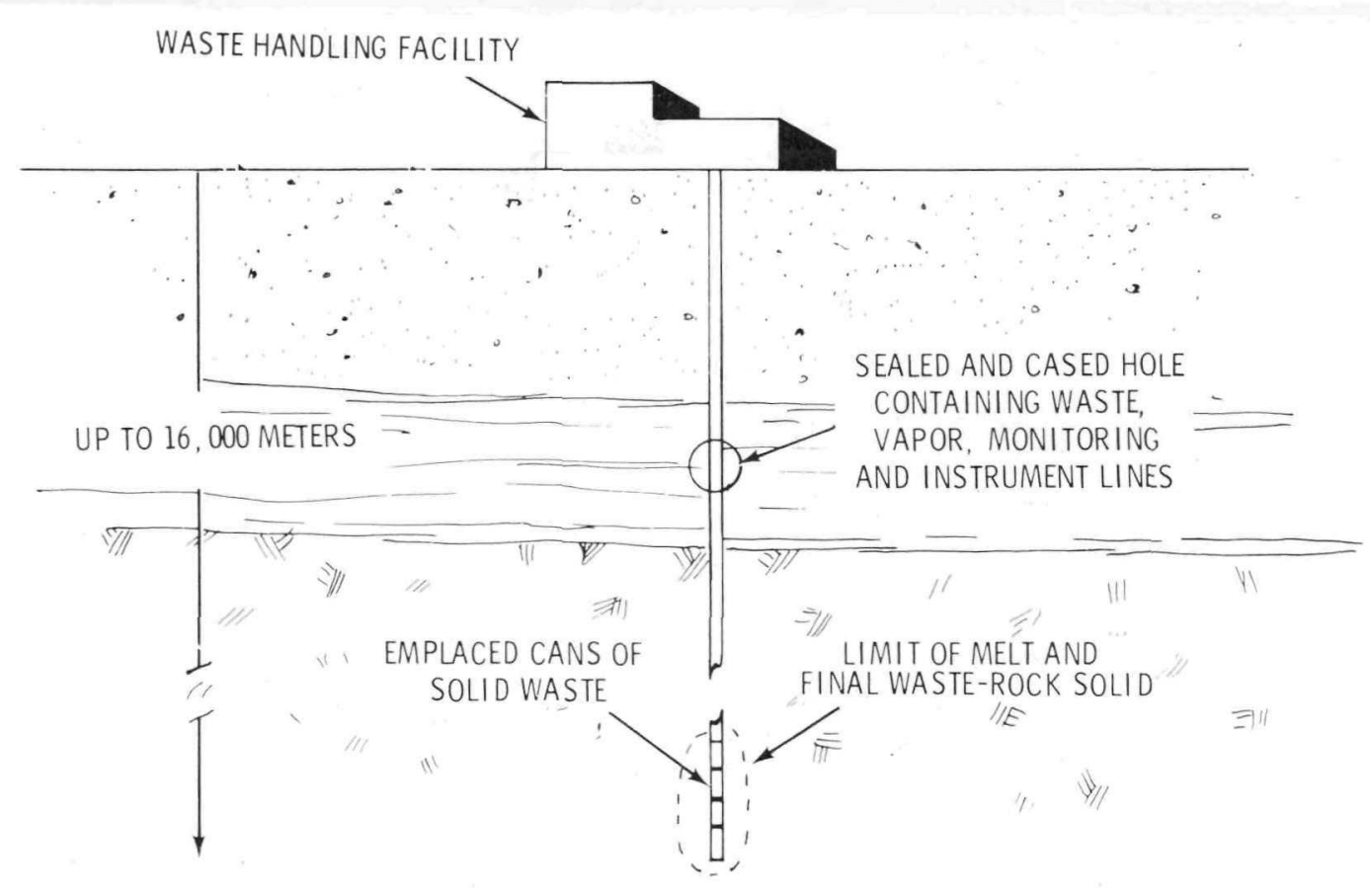

FIGURE 12. Solid Waste Emplacement in a Deep Hole with In-Place Conversion to a Rock-Waste

the molten waste-rock mixture will cool and solidify into a tall column of rock-waste matrix. For the reference case in this study, 2,500 canisters were assumed to be in the lower 7,500-meter portion of each hole.

\subsubsection{Liquid Waste Emplaced in a} Deep Hole - In-Place Drying and Conversion to a Rock-Waste Matrix

This concept, shown in Figure 13 , is somewhat similar to concept 5 , but uses very deep (16-kilometer) holes. The deep hole is drilled at the reprocessing plant site. Liquid waste is continually added to the hole, and the vapor from the hot waste is removed in a vapor condensing facility at the surface. Below the small pool of boiling aqueous waste is a layer of dried and calcined waste. Below this layer is one of molten waste and melting rock. When the hole is

filled to the predetermined level (assumed in this study to be the lower 7,500-meter portion of the hole), a second hole is then used, the waste in the first hole is allowed to dry and the hole is sealed. After a few hundred years the molten waste-rock mixture will cool and form a wasterock matrix.

It is estimated that three deep holes with high-level waste filling the bottom 7,500 meters would be required to contain the waste produced by the reference reprocessing plant. 


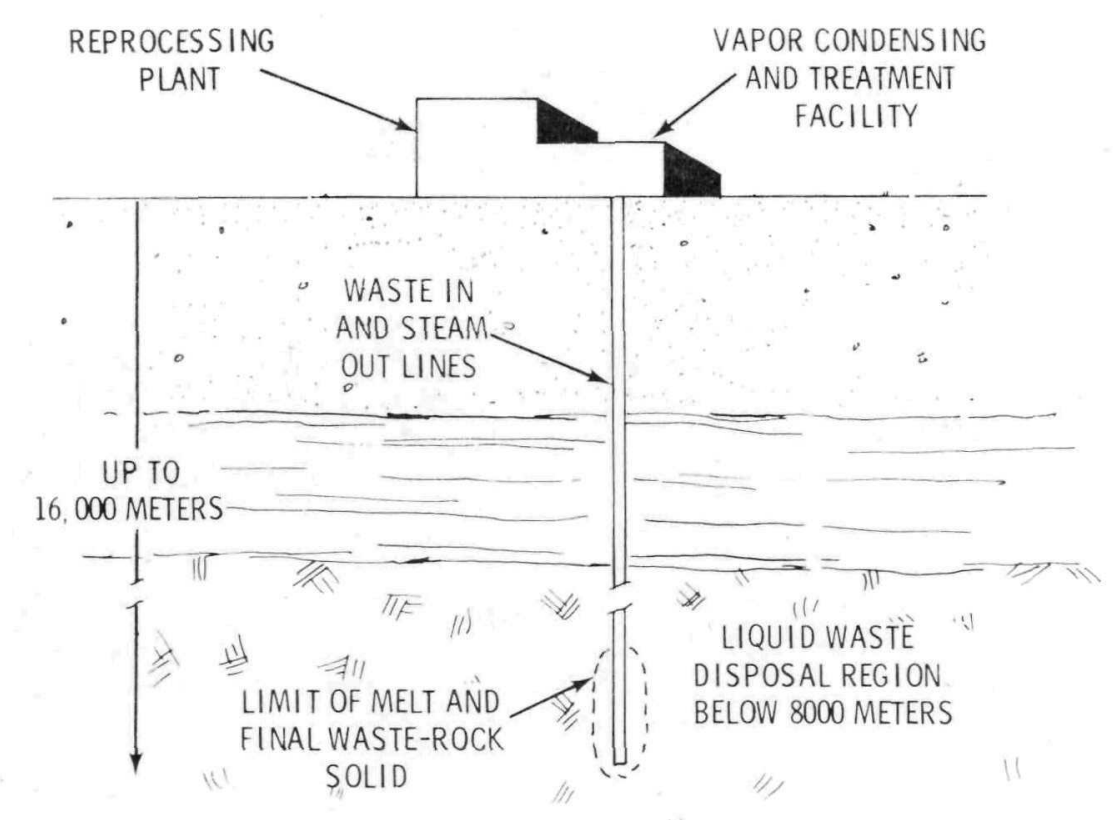

FIGURE 13. Liquid Waste Emplacement in a Deep Hole In-Place Drying and Conversion to RockWaste Matrix

\subsubsection{Liquid Waste Emplaced by Hydraulic Fracturing - In- Place Conversion to a Solid}

In this concept, showr in

Figure 14, liquid waste is mixed with cement grout to form a slurry which is pumped under pressure into a well. The pressurized slurry spreads out to form and fill thin horizontal fractures in the geologic formation which were initiated previously by forcing water at high pressure to fracture the rocks along the bedding planes. The slurry cures in-place within a few days to form a sheet of solid waste-cement mixture typically $3 \mathrm{mil}$ 1 imeters in thickness and 350 meters in diameter around the well. Several layers of the sheets of waste-cement can be emplaced one above the other, before sealing the access hole and moving to another well location. 0perations are all conducted at the surface from a shielded cell facility. The dilution and heat transfer conditions are designed to keep the waste and rock at low temperatures $\left(100^{\circ} \mathrm{C}\right.$ or less).

About thirty disposal wells would be required to accept the waste discharged by the reference reprocessing plant.

\subsection{ICE SHEET DISPOSAL CONCEPTS}

Ice sheets are large permanent masses of ice overlying continental land masses. They have several potential advantages as a disposal medium. The Antarctic ice sheet, which is international territory, has 


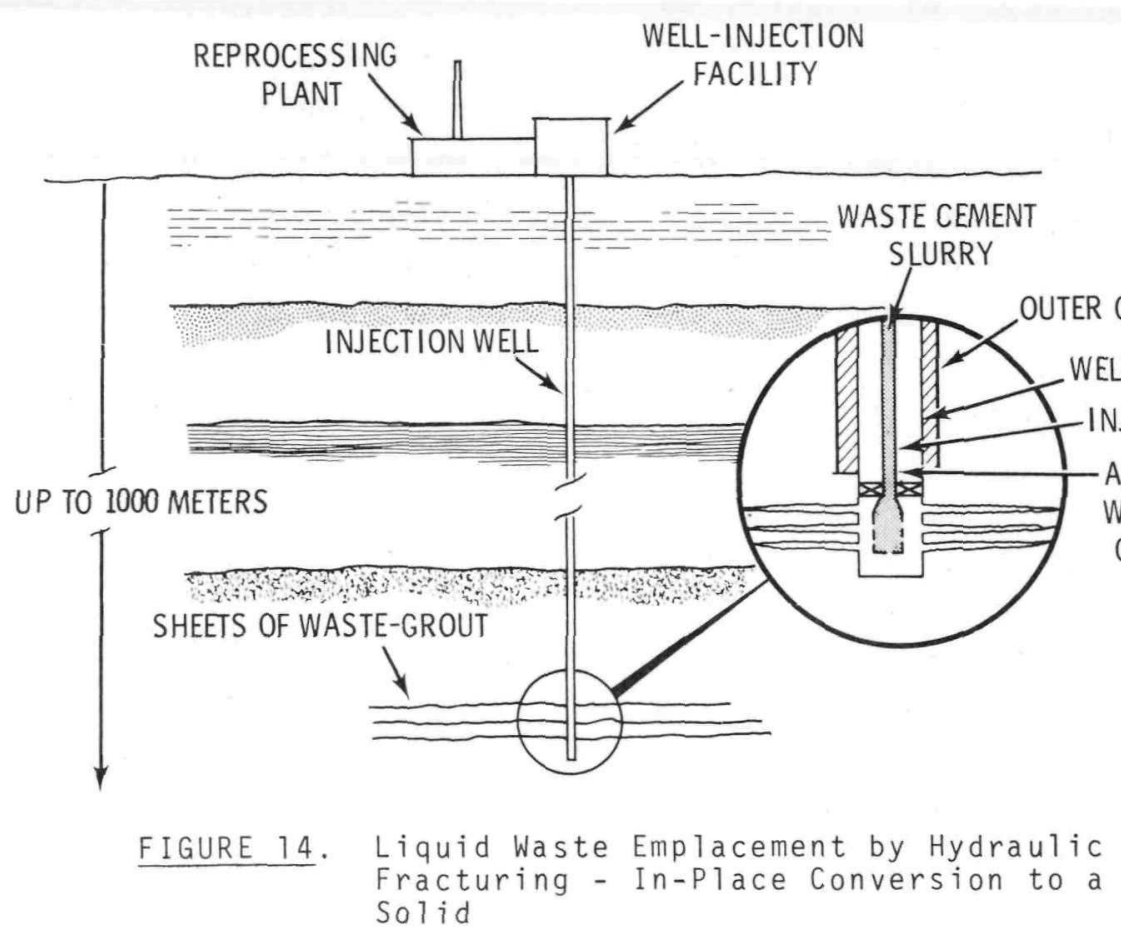

the potential to provide an international repository. Large quantities of ice with great thickness are available at locations remote from man's activities and with low likelihood for future developments. Ice, if its average temperature remains well below the freezing point, selfheals fractures. It has low permeability to water and has a thermal conductivity comparable to common rock types. Biological activity is low. The natural capability of the ice sheets to dissipate heat from radioactive waste canisters at low temperatures is conducive to maintaining integrity of the waste materials.

Three potential disposal concepts were developed for the ice sheet areas such as Antarctica or Greenland. These concepts, aimed at managing the solidified high-level waste without partitioning, are:
1) Meltdown or free flow--the waste canister is placed in an individual shallow drilled hole in the hole in the ice and allowed to melt down through the ice sheet to bedrock.

2) Anchored emplacement--the waste canister is placed in an individual shallow drilled hole in the ice but connected to surface anchors by cables or chains, which stop its descent and maintain its position for some extended period, perhaps on the order of 100 years.

3) Surface storage/disposal--the waste canisters are placed in a shielded cell storage facility with jack-up piers on the ice sheet surface to provide heat removal to the ambient air and to prevent covering over by further ice accumulation. After about 50 years, the facility is allowed to become covered by accumulating snow and is eventually 
buried in the ice sheet for final disposal.

The waste management system for all ice sheet concepts (shown diagrammatically in Figure 4 and pictorially in Figure 15) consists of transporting previously solidified and canned bulk waste in protective casks from the reprocessing plant to special embarkation ports; transporting the waste in protective casks by ships (equipped to monitor and examine the waste canisters) to harbor facilities adjacent to the ice sheet; offloading the waste canisters and casks at a debarkation facility on land in an ice-free area or near the edge of the ice; over-ice transporting by surface vehicles (envisioned as tractor-sled trains or surface-effect vehicles); and emplacing at the disposal site. The area around the disposal site would be monitored for a yet undetermined time.

The embarkation port would contain a receiving facility for inspecting the canisters and placing them individually in special casks for loading onto the transport ship.

Sea transport would be by specially designed ship(s) with facilities for cooling, inspecting, and handling the waste canisters. The hull would be designed for protection against damage due to pack ice. Ice-breaker escorts would be used for routine operation. The transport ship would operate outside normal sea lanes to

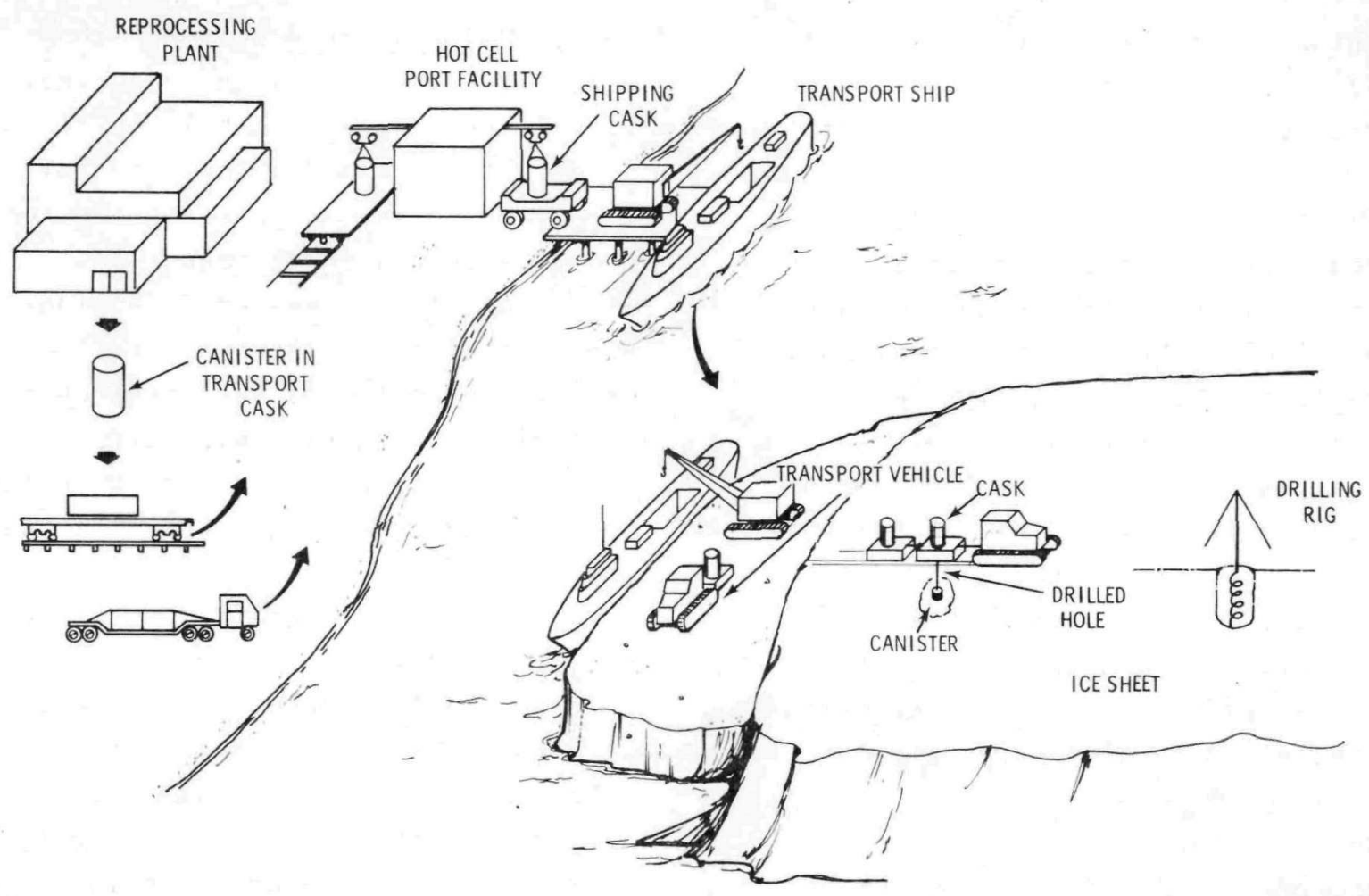

FIGURE 15. Operations in Ice Sheet Disposal 
reduce the risk of collision at sea and would dock and unload the casks onto the over-ice transport vehicles.

Crawler-type tractors pulling sleds are at present probably the most dependable means of over-ice transport under the severe operating conditions of the ice sheet areas. However, other types of transportation may be used such as aircraft or surface effect vehicles (hovercraft), with fuel supplied by aircraft fuel drops. Hovercraft would require further development and testing to prove their capability for routine operation.

For the meltdown and anchored emplacement concepts, shown in Figure 16, the canister is placed in a drilled hole 50 to 100 meters deep and released to begin its descent by self-melting. Cables or chains, 200 to 500 meters long and attached to surface anchors, are fastened to the canister for the anchored emplacement concept. The canisters are emplaced one per hole on l-kilometer centers. This spacing should maintain separation between canisters during descent. Disposal would be accomplished by self-melting and refreezing of the ice above the canisters as they descend. The waste canister must be encapsulated to accommodate high pressures and contain the waste.

In the surface storage facility disposal concept, storage would be accomplished by placing the canisters in a surface facility on the ice sheet. Disposal would occur when the facility is eventually covered by accumulating snow and ice.

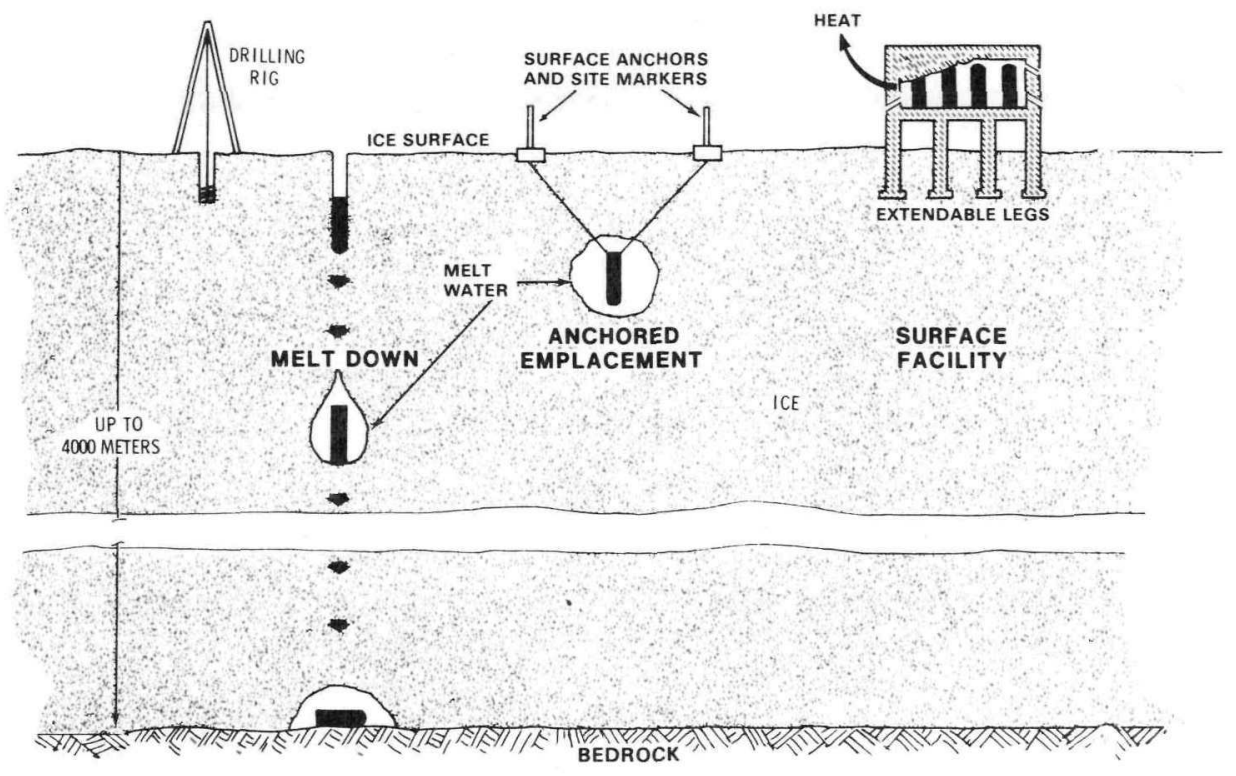

FIGURE 16. Ice Sheet Disposal Concepts 


\subsection{SEABED DISPOSAL CONCEPTS}

Disposal of high-level waste within the floor of the world's oceans has a number of potentially attractive features. Since disposal of nuclear waste is a multinational problem, consideration of a "common territory" as an international solution appears to have merit. The oceans comprise a large fraction of the earth's suface. There are areas of extreme remoteness that have not been identified with resources of significant use to man, that are biologically nonproliferating, and that are geologically stable. Large areas are available at depths that would provide isolation and safety from natural disasters such as storms, as well as from sabotage or accidental disturbance. The high ion-exchange capacity of sea floor sediments could provide additional isolation barriers. Large volumes of seawater may help cool the waste and would provide very high dilution of any material which accidentally escapes.

Geologic settings and certain areas of the sea floor were studied, i.e.:

1) Stable Deep Sea Floor--areas such as deep ocean basins and abyssal plains, which are considered geologically stable. The waste would be placed in the bedrock below the unconsolidated sedimentary cover.

2) Subduction Zones/Deep Sea Trenches--areas where, according to crustal plate tectonics theory, one edge of certain crustal plates is moving under the other crustal plates and down into the earth's mantle. The waste would be placed in these trench areas to be carried down, or subducted, into the earth's mantle with the crustal plate. (a)

3) High Sedimentation Rate Areas-areas where major rivers are building deltas into the ocean. The waste would be placed in the bedrock below the accumulating deltaic sediments.

It is assumed that the seabed disposal concepts are aimed at disposal of all solidified high-level waste without partitioning. The waste must be encapsulated to accommodate the high pressures and potential corrosion during emplacement.

Waste management systems for all seabed disposal concepts, identical except for the site, are shown diagrammatically in Figure 4 and are presented pictorially in Figure 17. The concepts would consist of transporting the previously solidified and canned bulk waste from the reprocessing plant in protective casks to special ports of embarkation for short-term storage of the waste and for integrity of the waste canister to be checked; transport in protective casks by ship (equipped to monitor and examine the waste canisters) to the disposal site; disposal of a number of waste canisters into each predrilled hole in the basement rock from a special drilling platform; and filling the upper part of each hole

a. It should be noted that the detailed mechanism for this geologic activity is not well known. The descriptions in this report are based upon inferred and generally acceptable hypotheses, but the actual circumstances of geologic activity of this type have not been confirmed in any area. 


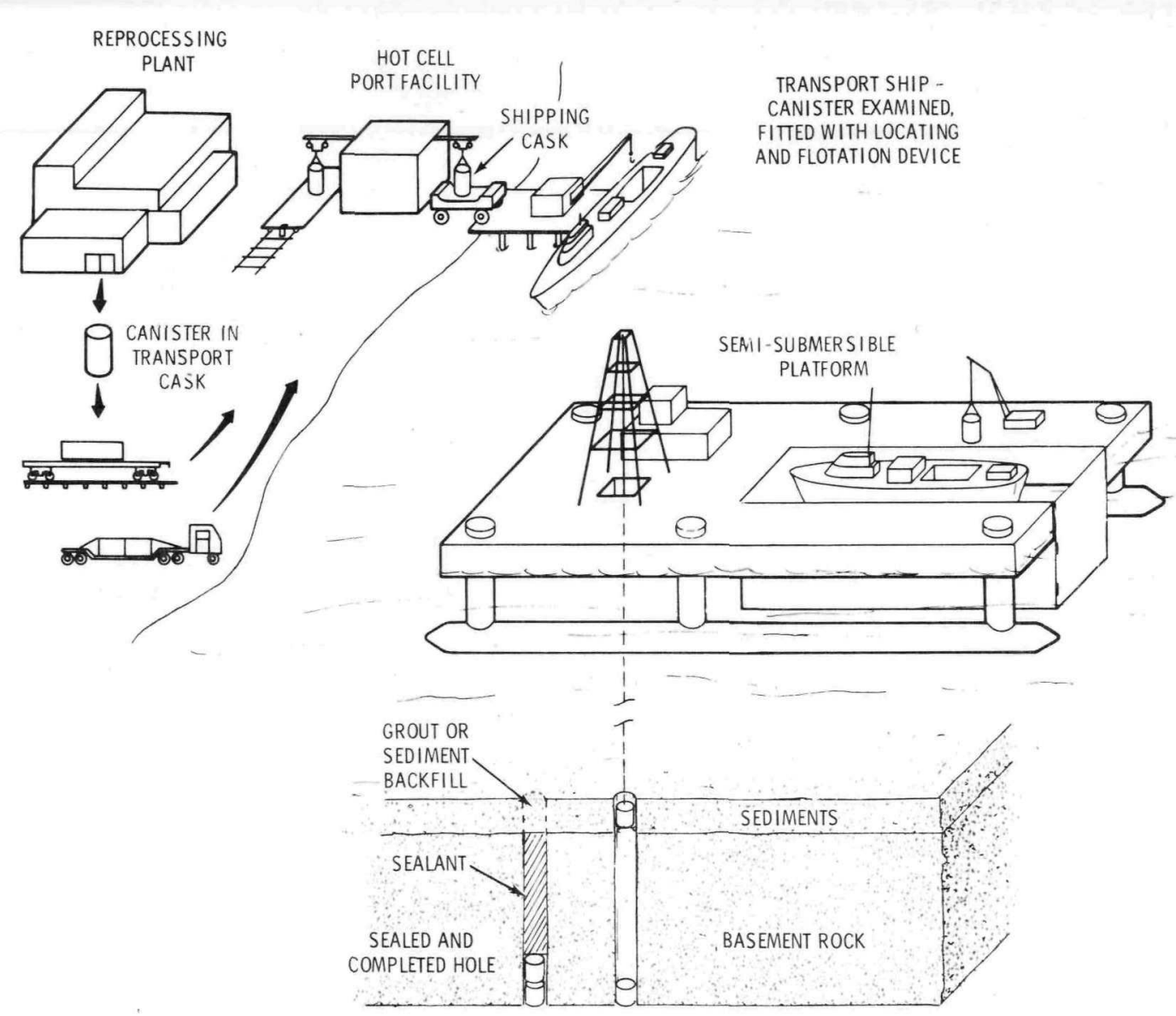

FIGURE 17. Operations in Seabed Disposal

with a sealant. The area around the waste disposal holes would be monitored for a yet undetermined time.

Emplacement in all cases is considered to be in the dense basement rock of the seabed, underlying the unconsolidated softer sediments of the sea floor, as shown in Figure 18. The waste is thus removed from direct contact with the seawater, is less likely to be exposed by submarine geologic processes and may be further isolated from seawater by the high ion-exchange capacity of the sediments.
The embarkation port would consist of a receiving facility for handling and final inspecting of the waste canisters before they are placed individually in special casks and loaded aboard a transport ship.

Sea transport would be by conventional surface ships equipped to provide cooling of the waste and facilities for monitoring and inspection during transport. The transport ship would be docked within a chamber of the emplacement platform, where the waste canisters would be unloaded, removed from the cask and emplaced 


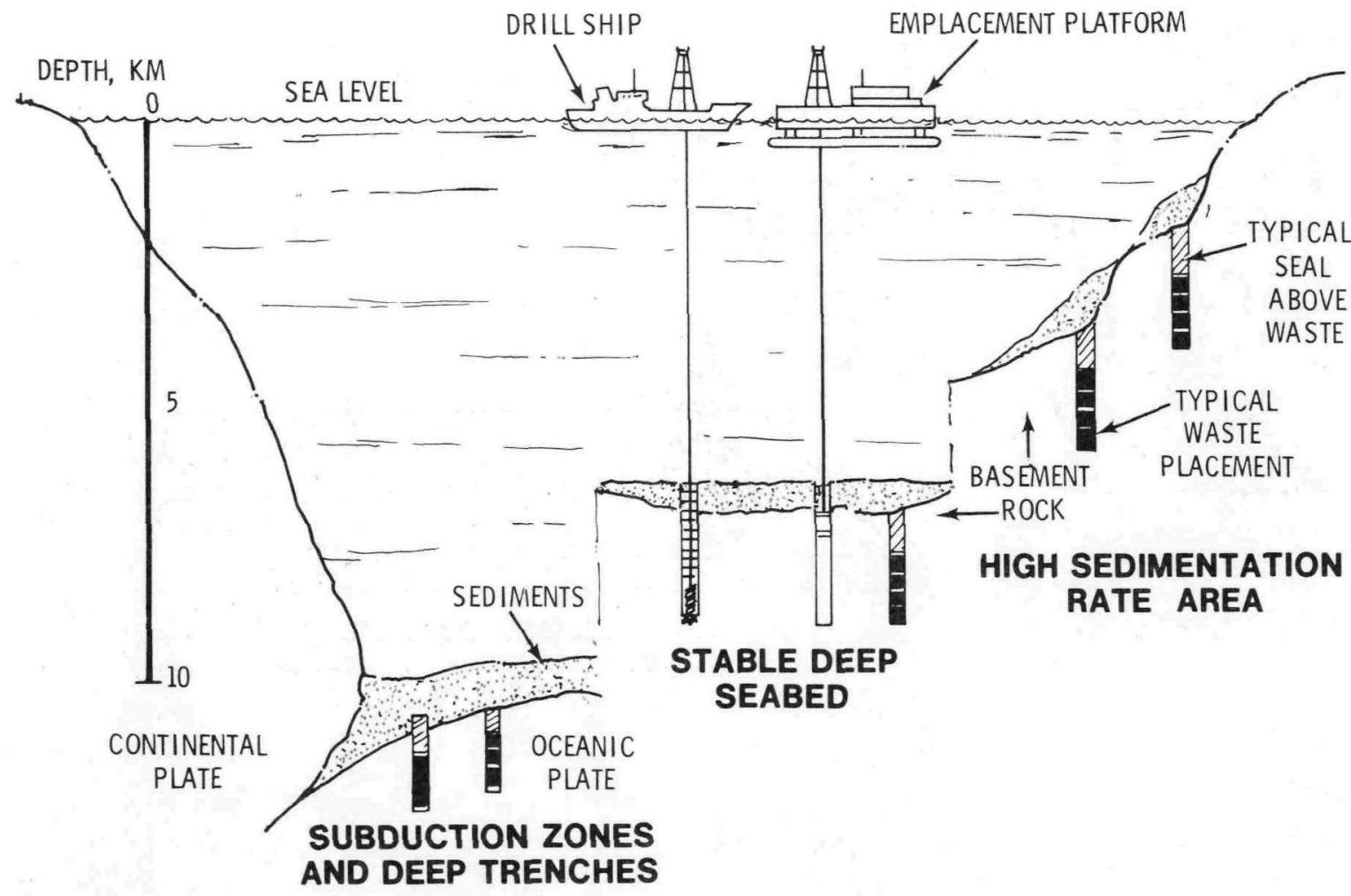

FIGURE 18. Seabed Disposal Concepts

from a semi-submersible drillingemplacement platform. The waste canisters are assumed to be emplaced 100 per drilled hole. The holes would be about 800 meters in depth and drilled on about 1.6-kilometer centers to compensate for limitations on hole locating accuracy and for heat dissipation. Disposal is completed by filling and sealing the top 200 meters of the holes with cement or grout and by replacement of the sediment.

\subsection{EXTRATERRESTRIAL DISPOSAL} CONCEPTS

If a stable non-earth intercept trajectory or orbit can be assured, extraterrestrial disposal offers the complete removal of long-lived nuclear waste constituents from the earth and the potential for an international solution to waste management. The primary unfavorable features are that the concept deals with only part of the waste, there are possible launch safety problems, retrievability and monitoring, if necessary, are difficult and the concept will require international agreements.

Extraterrestrial disposal of the total waste constituents and of only the transuranic elements were both considered. However, space disposal of the transuranics only is believed to be the most practical scheme, primarily because of the very high space transport cost per unit of weight (at 
least $\$ 2000 / \mathrm{kg}$ of waste material). Because of the high shielding weight and cooling systems required for space disposal of the total high level waste, disposal of transuranic element waste separated from the other waste constituents received primary emphasis and is used as the base case in this study. The remaining waste must be disposed of by some other means.

The overall waste management system, shown in Figure 19, consists of likely interim aqueous waste storage to allow for decay and simplification of partitioning; partitioning of the aqueous waste into a transuranic element fraction contaminated by no more than $1 \%$ of the fission products and the remaining waste which must be disposed of by an alternative method; converting the actinide waste at the reprocessing plant to a refractory oxide and encapsulating this into high-integrity, multiple-barrier capsules; transporting the capsules overland to a space launch site; launching the waste into space to an initial low-earth orbit with a reusable space shuttle, followed by space tug transport to the final destination; and monitoring for control to destinations and for off-standard events and radioactivity in the upper atmosphere.

The launch deployment sequence using a shuttle and a tug is shown in

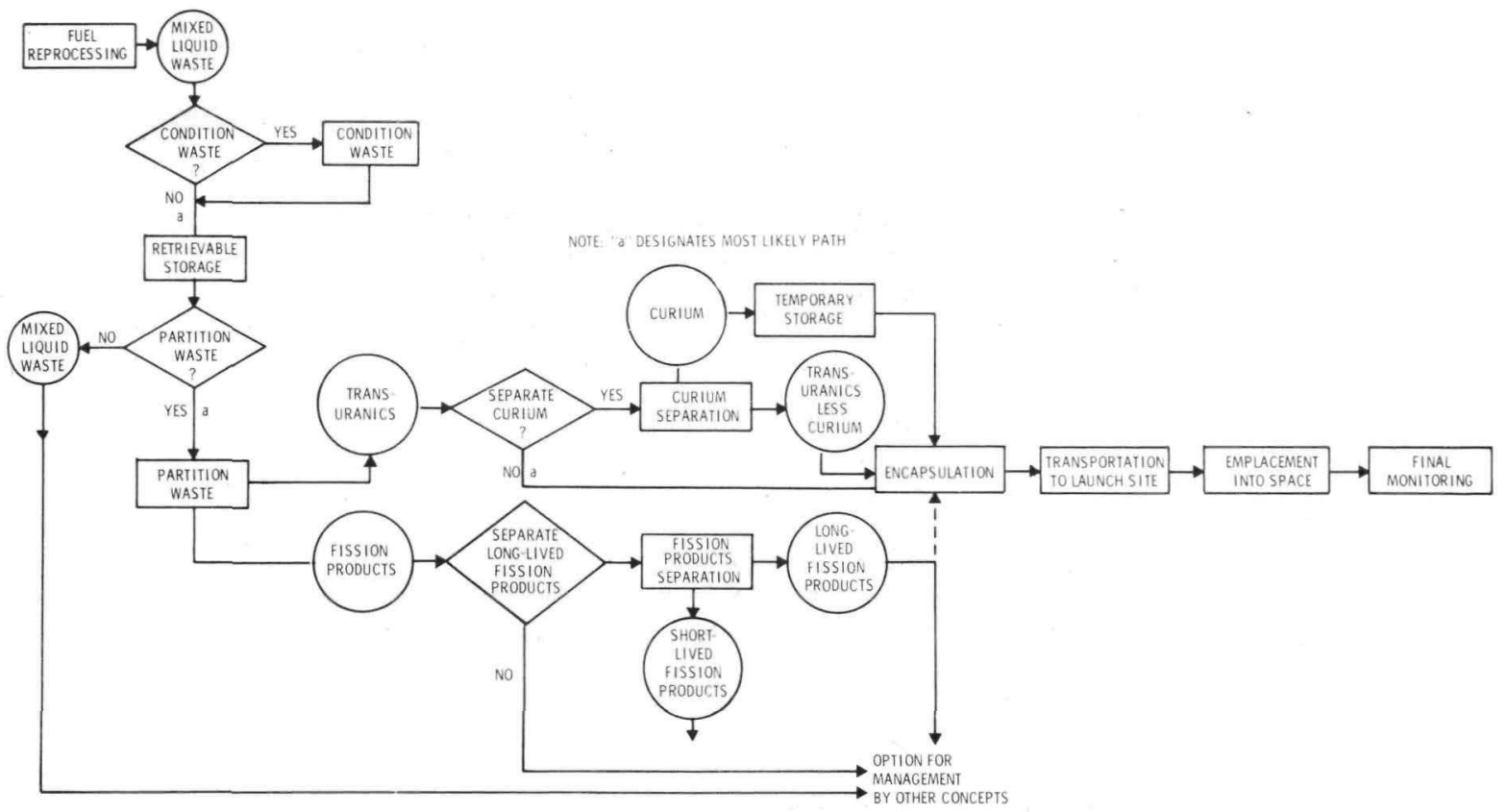

FIGURE 19. System Requirements for Managing HighLevel Radioactive Waste by Extraterrestrial Disposal 
Figure 20. Typically, the shuttle is first launched into a low circular earth orbit (150 to 500 kilometers above the earth). From this orbit, the tugs or upper stage(s) are launched to carry the waste package to its final destination. In some cases, the launch system can inject the waste to its final destination without subsequent course correction. In other cases, the waste tug will require subsequent mid-course corrections or propulsion.

\subsection{TRANSMUTATION ELIMINATION}

Transmutation is the changing of one isotope into another by any means whatsoever. For waste management, transmutation results in a product isotope having a lower toxicity and/ or a shorter half-life than its predecessor. Ideally, radioactive constituents in high-level waste could be eliminated by using nuclear processes themselves to achieve the transmutation. More practically, the transmutation process can accelerate the decay rate of radioactive waste by converting long-lived radioisotopes to other isotopes which have shorter decay times. If this can be achieved, the quantity of waste containing long-lived radionuclides could be reduced significantly and the time required for safely storing treated radioactive waste may be significantly shortened.
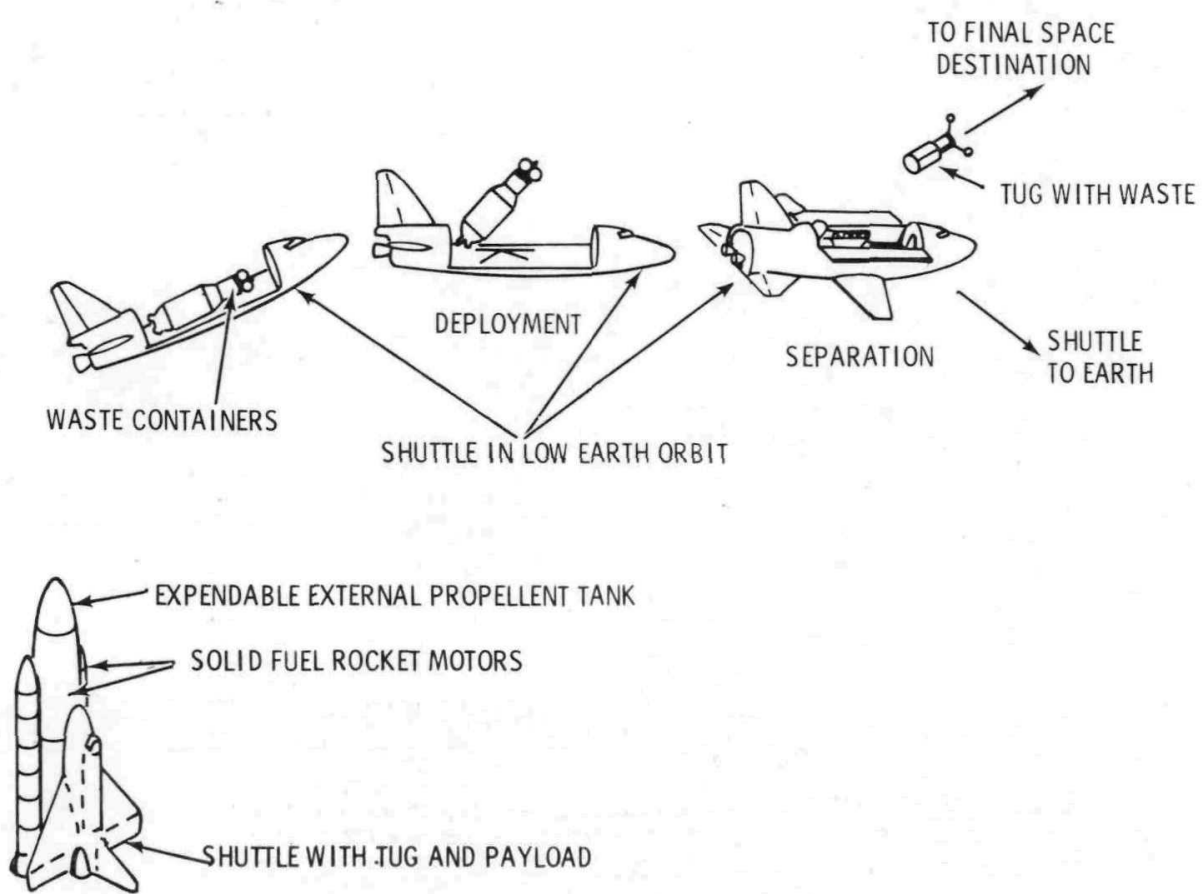

LAUNCH

FIGURE 20. Shuttle Launch Deployment Sequence for Extraterrestrial Disposal 
System requirements for managing high-level radioactive waste by transmutation are shown in Figure 21. The overall waste management system using fission reactors for waste actinides includes a period of interim aqueous waste storage to allow for decay and to permit improved partitioning; partitioning of the aqueous waste into an actinide waste stream and a shortlived residue; converting the actinides at the reprocessing plant to oxides; transporting the oxide to a facility for fabricating it into special recycle fuel forms; and transporting the actinide fuel form to a fission reactor for irradiation. The short-1ived fraction must be disposed of by other means.
For the transmutation strategy using fusion reactors, the concept would be similar except that the aqueous waste stream would be partitioned into two or more streams containing waste actinides, possibly selected fission products, and a residual waste stream to be disposed of by other methods. The two waste streams for transmutation would be converted into solid fuel materials (probably oxide) at the reprocessing plant; the fuel materials would be transported to a facility for fabrication into special target elements; and the special targets would be transported to and inserted into the blanket of a fusion reactor for irradiation as

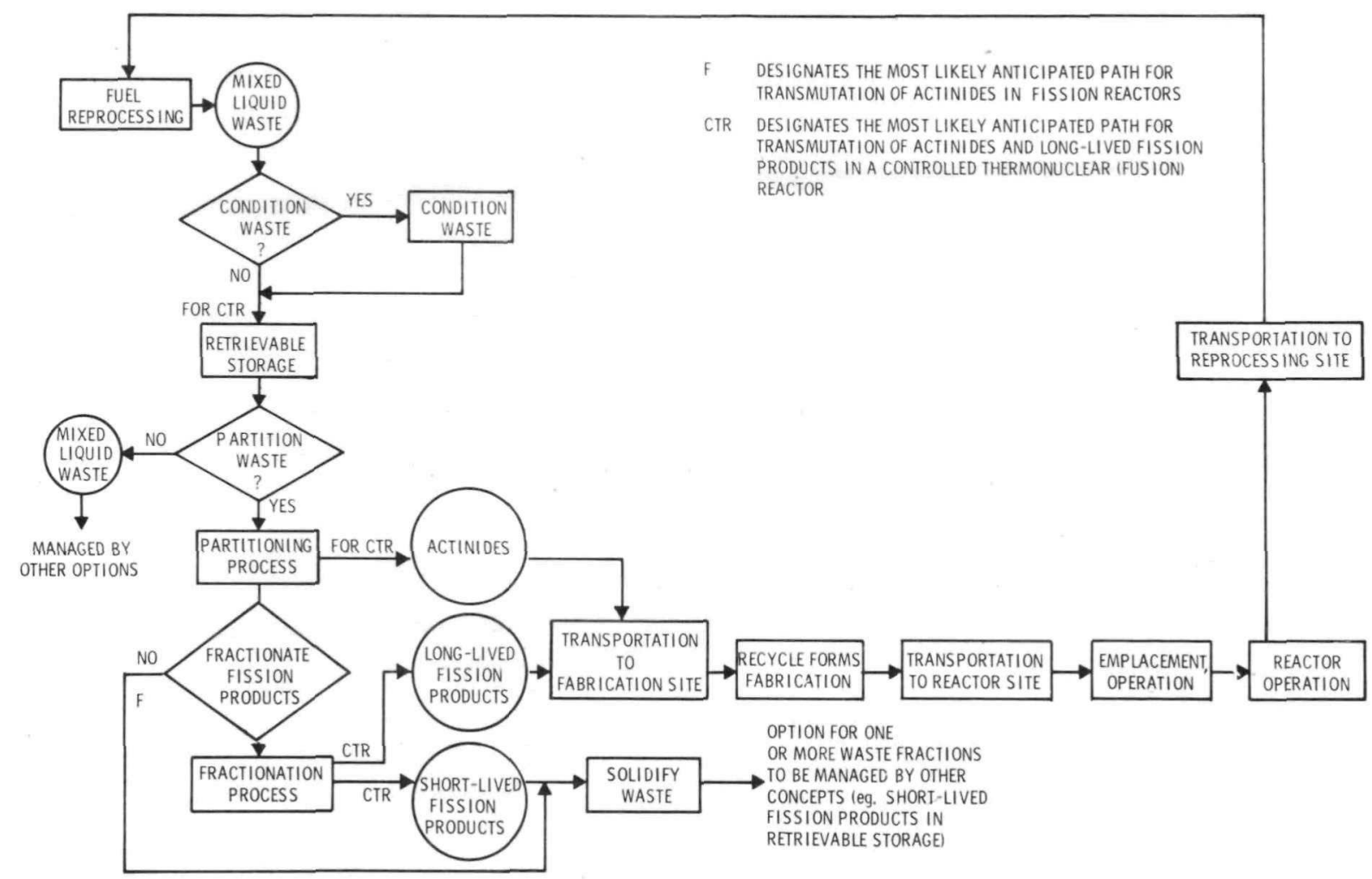

FIGURE 21. System Requirements for High-Level Radioactive Waste Management Using Transmutation 
part of the reactor fuel cycle. Continued recycle of material which undergoes transmutation would also be a part of this section.

The waste streams not sent to transmutation must be disposed of by other means. In addition, the "heel" of untransmuted actinide waste at the termination of a nuclear plant era must be disposed of by other means.

The strategy envisioned for using transmutation in the management of high-level waste is shown in Figure 22 , assuming a three-phase development scheme:

- Phase 1 converts 1ong-1ived actinides to short-lived fission products. This phase uses the normal nuclear fuel cycle of the fission reactor industry to retain all actinides in this fuel cycle and thereby convert a significant part of them into fission products by transmutation. The most significant modification to the fuel cycle is to partition the waste. - Phase 2 involves temporary retrievable storage of fission products for ultimate use in Phase 3 .

- Phase 3 transmutes in a fusion reactor the equilibrium inventory of long-lived fission products and actinides accumulated from the fission reactor cycle. This final phase results in the ultimate elimination of nearly all long-lived radioactive waste constituents.

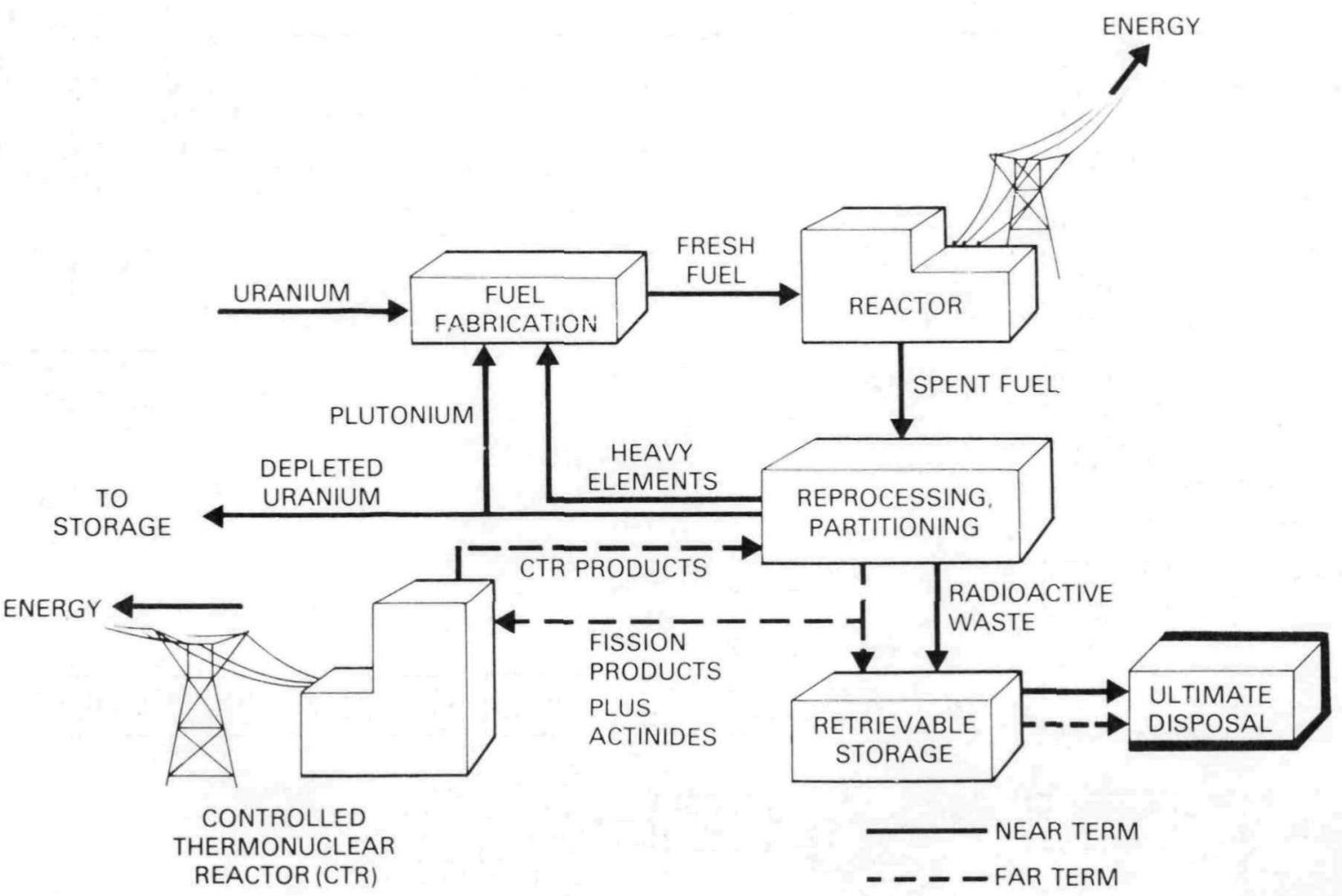

FIGURE 22. Transmutation Waste Management Strategy 
The transmutation of certain fission products as well as actinides would require further separation of the waste to obtain additional trans mutation process feed streams. In addition, fabrication of the target elements for transmutation in fusion reactors and the special fuel elements for transmutation in fission reactors will require special remote facilities because of the high dose rate of the materials handled. 


\subsection{TECHNICAL FEASIBILITY}

The technical feasibility of the potential disposal concepts was determined in this study by responding to the following primary questions:

1) Can the disposal concept be implemented using today's technology? (This does not imply that additional development is unnecessary to adapt existing scientific and engineering technology to the implementation of these disposal concepts. It assumes that we have enough information to assess the overall development requirements.)

2) Can the disposal concept be implemented with future technology based upon current theory? (Is it theoretically possible?)

3) Can the disposal concept provide the potential for confining or eliminating the waste over the time period of concern? (Truly quantified answers to this point require very extensive study, and only qualitative indications were developed for this study.)

4) Does the concept have a favorable energy balance? (Is the energy consumed in the implementation of the disposal concept less than the electrical energy obtained from the nuclear fuel represented by the waste?)

The responses to these questions from this study are summarized in Table 9. To highlight the differences among the concepts, only the variations from the same previously described "reference" concept (geologic mined cavity) are shown. Also summarized in Table 9 are the inherent favorable and unfavorable characteristics of the concepts. In gen- eral, it can be seen that all concepts studied appear technically feasible (with some limitations) within the extent of this study, with the probable exception of transmutation using accelerators.

The information in Table 9 is discussed in the subsections which follow.

\subsection{GEOLOGIC DISPOSAL CONCEPTS}

All geologic concepts appear to be technically feasible. Cavities and holes could be made today with the possible exception of the very deep hole. A deep hole could probably be drilled today in areas with very low geothermal gradients, but a question remains as to whether the lower portion of the hole can be kept open at these depths during the time period required for emplacement of the waste. New technology is required for the moderately large holes needed at the great depth (16 kilometers or 10 miles) and for the high down-hole temperatures encountered at great depth.

Nuclear explosive technology is available, whereas chemical explosives appear impractical for exploded cavities. In either case, evaluation of the significance of fractures that will be produced by the detonation would be most difficult. It is not certain whether sufficient technology exists today for implementing the waste-rock melting concepts. Melting can certainly be accomplished, but the conduct of the molten mass and its effect on the surrounding media are not yet certain. 
TABLE 9. Summary of Technical Feasibility for Alternative Waste Management Systems

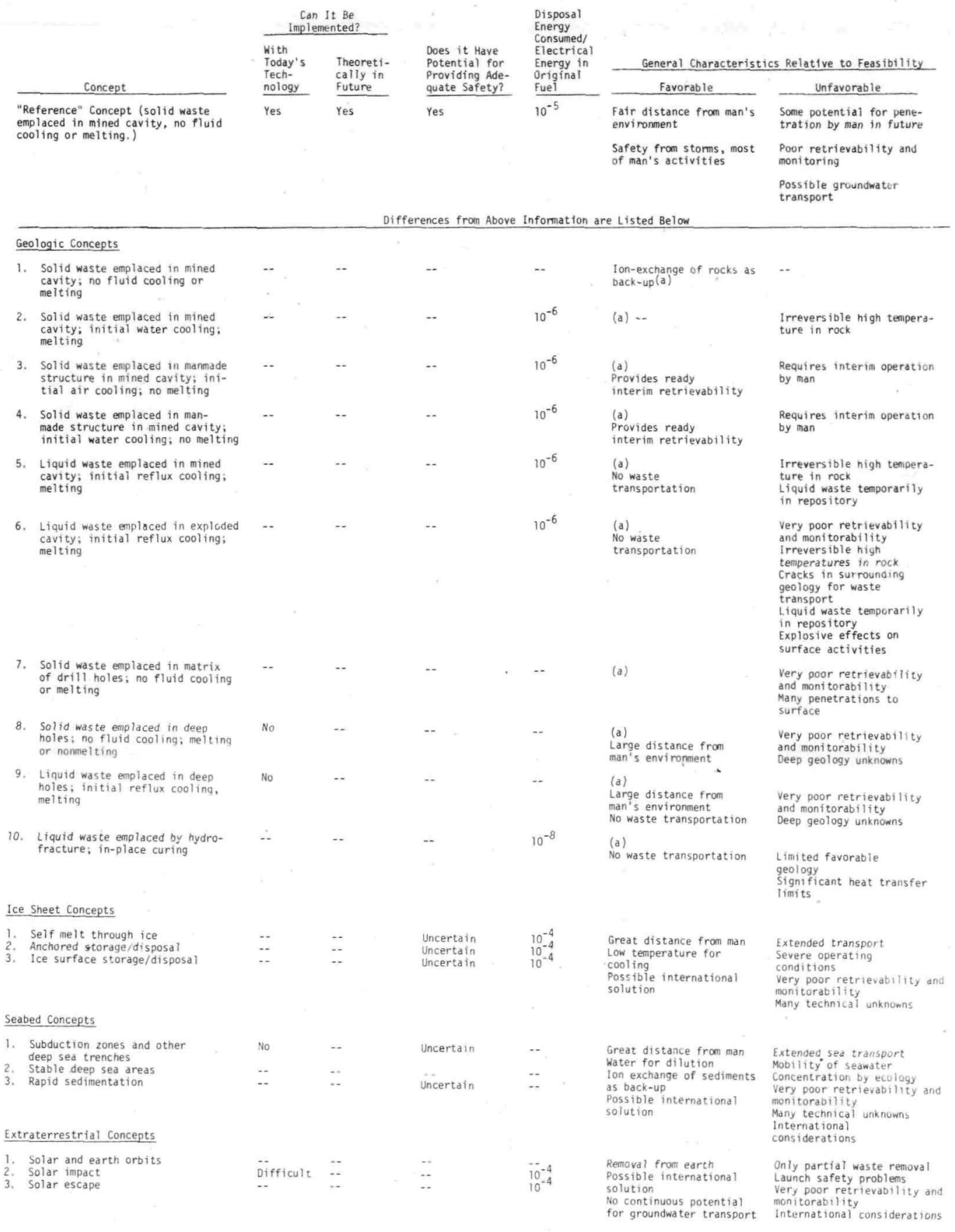

Iransmutation concepts

1. Fission reactors

2. Fusion reactors

3. Accelerators
4. Nuclear and explosives

Today's

cally in

Potential for

quate Safety?

lectrica

to Feasibility

Fair distance from man's
environment

Safety from storms, most

Some potential for pene-
tration by man in future

Poor retrievability and

Possible groundwate
transport

ifferences from Above Information are Listed Below

Solid waste emplaced in mine

structure in mined cavity;

Solid waste emplaced in man-

Liquid waste emplaced in mined

Liquid waste emplaced in explade

cavity; initial reflux cooling

Solid waste emplaced in matrix

andaced in deep

(solid waste
colud 
The technology for other related needs in geologic disposal systems is generally in-hand. These technologies include interim aqueous waste storage if desired, conversion to stable solid waste forms, interim solid waste storage if desired, transportation to the disposal site if needed, emplacement of the waste, and interim operation of the disposal facility as needed. Successful emplacement of an intermediate-level liquid wastecement mixture using hydraulic fracturing techniques has been practiced by Oak Ridge National Laboratory since 1965.

Final sealing of the access holes is required for geologic concepts for the long time period of concern. Such high-integrity sealing, necessary to maintain long-term isolation of the waste from man's environment, has not been considered heretofore by industry. Existing sealing techniques must be tested (and improved if necessary) for radioactive waste disposal.

General heat transfer modeling technology is available for use in geologic systems, but the methodology must be modified for application to geologic waste disposal concepts.

The various geologic disposal schemes involve short-term operational, safety and retrievability differences. However, in the context of providing adequate long-term isolation, the major factors are in differences in the geologic settings relative to the different emplacement modes.
Key factors to avoid in siting are areas with: 1) potential for hydrologic transport; 2) usable groundwater; 3) seismic potential, including fault densities; 4) resource potential; and 5) significant population density.

of the various geohydrologic factors considered in evaluating potential sites for disposal the most important is hydrologic isolation; this is to assure that the waste will be effectively contained within an acceptable radius of the emplacement zone. To achieve this degree of hydrologic isolation, the host rock for the waste should exhibit a very low permeability and the site should be virtually free of geologic faults.

A potential disposal site should be in an area of gentle relief to minimize any accelerated erosion or denudation that might occur because of natural climatic changes or changes brought about by the preparation for disposal operations. The most suitable geographic location for a disposal site is also one that is as far removed from major drainages, lakes, and oceans as possible and where the intrusion of man in a manner that will change the condition is minimal.

Areas considered generally unsuitable for waste disposal are those where seismic risk is high, (a) where possible sea-level rise or changes in drainage patterns (a) could inundate potential sites, where high topographic relief coincides with high fault densities (a) and/or unfavorable

a. Generalized maps of the conterminous United States showing these areas are included in Appendix. B. 
hydrologic conditions, where no suitable rock media are known to be present to reasonable depths, where a possible return of glacial or high rainfall climate will cause undesirable changes in the geology, where there is danger of exhumation by erosion, and where the area contains us$\overline{a b l e}$ volumes of groundwater $(a)$ or has hiah oil, gas, or other mineral potential.

In lieu of more comprehensive seis mic risk studies and criteria for acceptable ground motions, this investigation considered that areas of seismic risk zone 3 are unsuitable for underground as well as surface facilities. Areas in seismic risk zone 2 and less are considered potentially suitable if zones of active fautting are avoided.

Sea-level rise as a result of future climatic changes could drastically alter the present-day hydrologic regime. A lack of firm factual data for predicting climatic change makes it necessary at this time to consider the possibility that large parts of the coastal areas and some inland areas of the United States could be inundated during the next million years. This consideration is a very conservative one, because future inundation of a disposal site by sea water may well have no effect on the integrity of the site and its waste contents. With this in mind, a 11 potential sites for waste disposal that could be inundated by $60-$ to 150-meter sea level rises, especially those below the 60-meter level, should be reviewed critically.

Faults and fractures, along which there has been a relative displacement of the rocks, can either be conduits for flow of water between impermeable zones or be obstructions to flow of water in an aquifer. These faults are undesirable because they could serve as connections between burial sites and man's environment. Therefore, any site selected for disposal of waste should be virtually free of faults, especially in the disposal zone.

In any terrestrial concept for disposal of high-level waste, a conflict will arise between the use of the earth for disposal and for development of the resource potential that could be available in other forms such as geothermal energy, minerals, surface space and subsurface space.

The most suitable rock media for the various concepts considered appear to be (b) 1) intrusive igneous rocks $(c)$ (e.g., granite) or crystalline metamorphic rocks $(\mathrm{d})$ (e.g., quartzite) because of their low permeabilities and high mechanical strengths, 2) salt, either in stable domes or thick beds because of its

a. Generalized maps of the conterminous United States showing these areas are included in Appendix B.

b. No order of preference was established in this study nor is it implied here. Much more information is available regardino disposal in salt than in these other rock media.

c. Intrusive igneous rocks are those formed by cooling and solidification of a molten rock mass that invaded the earth's crust but did not reach the surface.

d. Crystalline metamorphic is a general term used here for the more granular, coarsegrained rocks that have been changed in texture or composition by heat, pressure, or chemically active fluids after their formation. 
low permeability and self-sealing property, and 3 ) tuff (welded volcanic ash) and shale (a) because of their very low permeabilities and high ionexchange capacities. Sedimentary rocks other than shale and salt, and volcanic rocks, exclusive of tuff, are considered generally unsuitable for waste emplacement because of their potential for high permeabilities.

Areas appearing potentially suitable as waste repositories based on this study have not been defined. However, simple overlaying has been done of maps showing some geologic characteristics pertinent to waste disposal. These maps, shown as Figures 23 and 24 , can be used as gross indicators of where to start looking for possible disposal sites. Excluded from the figures are areas of seismic risk zone 3 and areas which would be inundated by a rise in sea level of about 150 meters. Yet to be removed from consideration are areas such as those with high resource potential (including productive aquifers and areas of possible geothermal development), high population density, high fault density, and high topographic relief.

Potentially suitable media for the deep dri11-hole method appear to be crystalline rocks, either intrusive igneous (e.g., granite) or metamorphic (e.g., quartzite). Possible areas, shown in Figure 23, include areas in the continental interior where the sedimentary cover over the crystalline rocks is generally thin.

Areas potentially suitable for consideration as cavity and matrix hole disposal sites are presented in Figure 24. The designated areas include essentially the same igneous and metamorphic rocks considered for the deep drill-hole, salt beds and stable salt domes, and granitic stocks in the Basin and Range area. Additionally, in the case of the mined cavity concepts, tuff and shale are potentially suitable formations for above-thewater-table emplacement in arid and semi-arid climates; and for the exploded cavity and matrix hole concepts, pending proof of hydrologic isolation, shale in some sedimentary basins below 2000 meters is a possibly suitable formation.

The sample risk evaluation in Section 5 indicated the high potential for geologic disposal to provide safety and isolation of waste from man. With proper site selection for geologic disposal in general, even in the event of a release, the surrounding rocks will still permit a high degree of protection to man's environment by sorption of radionuclides.

The major energy consumption in geologic disposal is in mining and drilling. This energy consumption is about 5 to 6 orders of magnitude lower than the electrical energy from the original nuclear fuel from which the waste was derived.

a. Shale is rock composed of laminated layers of clay-like, fine-grained sediments. 


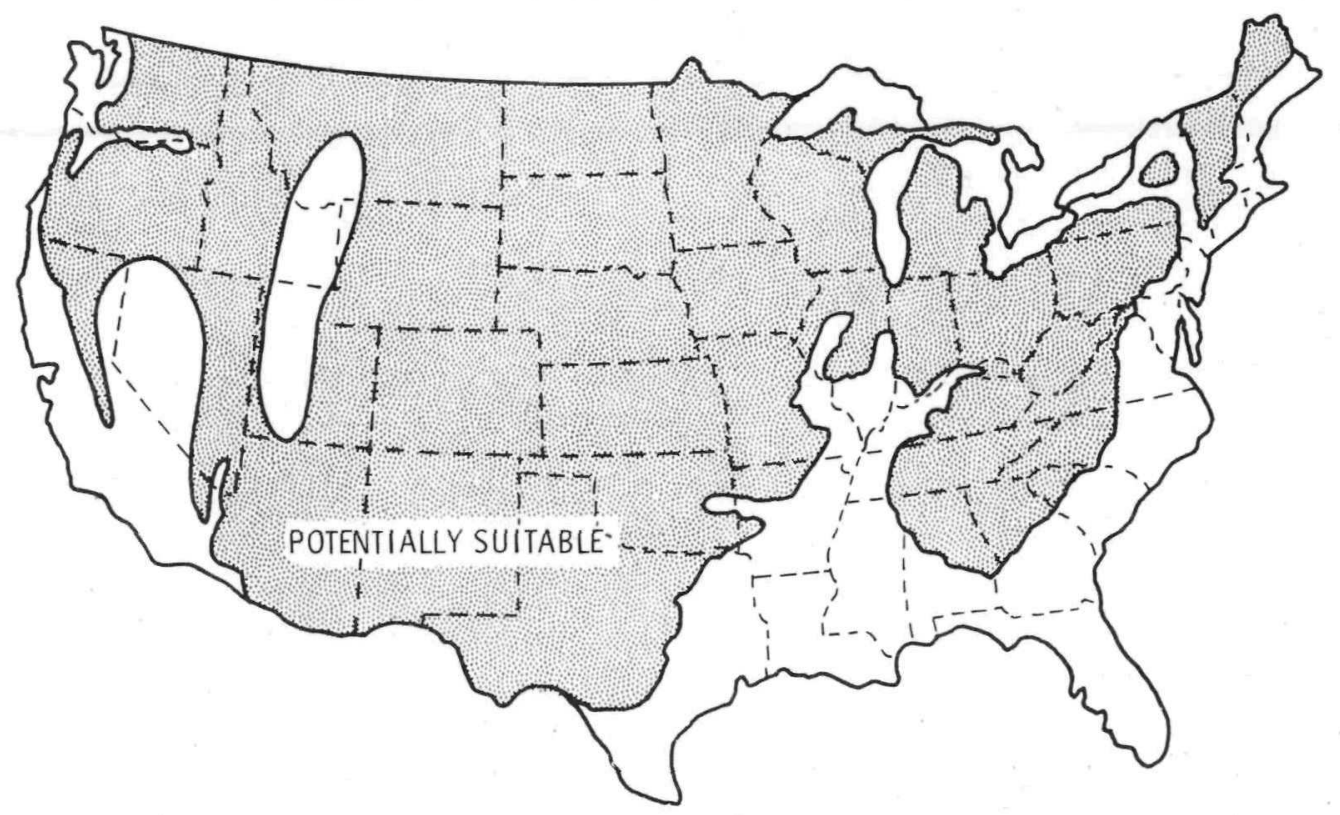

FIGURE 23. Potentially Suitable Areas for Geologic Disposal Sites Using the Deep Hole Concept

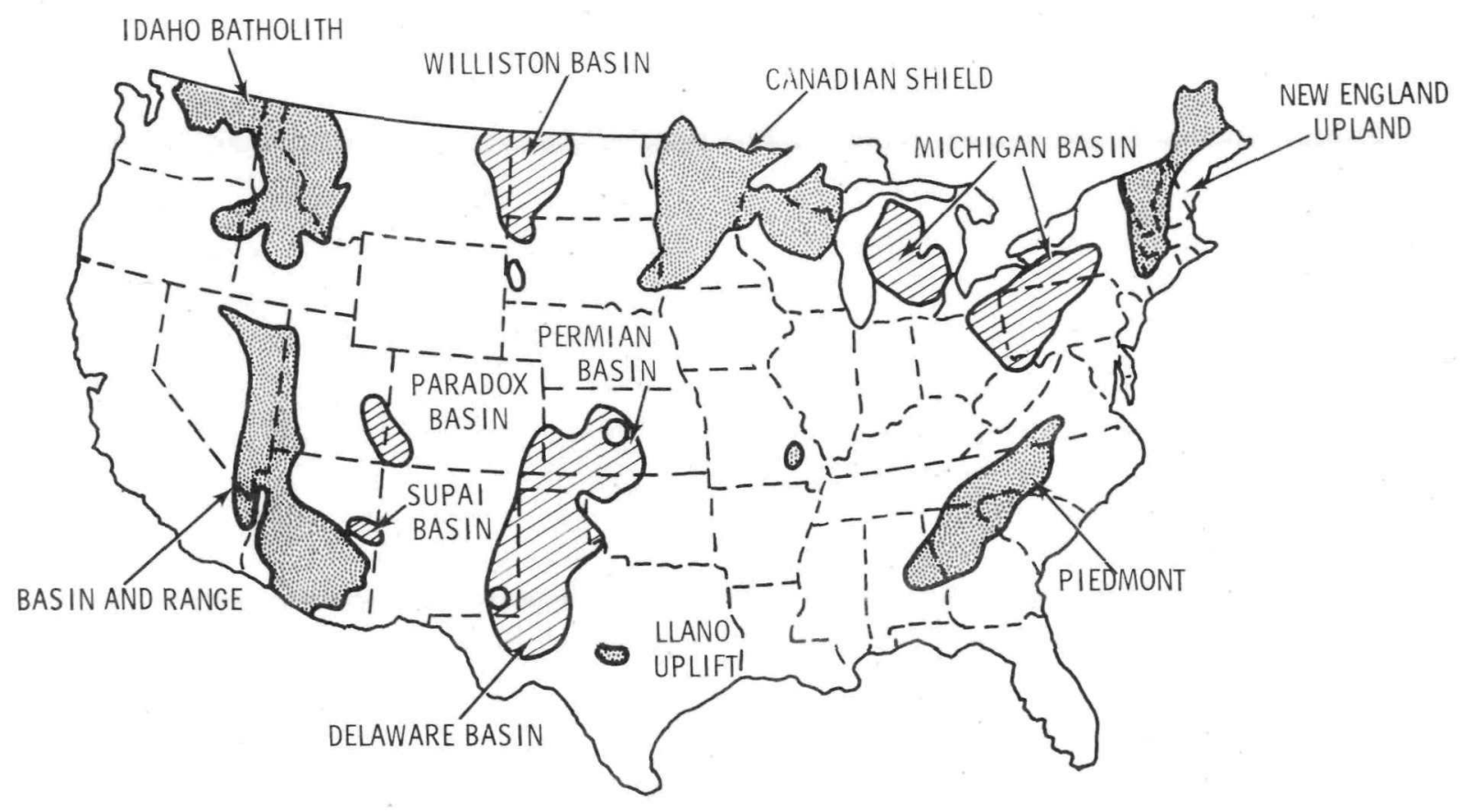

ZS SALT

IGNEOUS AND METAMIORPHIC

FIGURE 24. Potentially Suitable Areas for Geologic Disposal Sites Using the Cavity and Matrix Hole Concepts. 
Overall, disposal of radioactive waste in geologic formations has the potential of isolating the waste from man's environment for extended time periods (millions of years). Geologic environments exist which have been physically and chemically stable for such periods, are isolated from man's immediate environment, and can potentially provide effective barriers between waste and man's environment for the time periods required.

Generally favorable characteristics of geologic waste disposal are:

1) waste is reasonably distant from man's environment;

2) safety is provided from climatic phenomena such as surface storms and from man's destructive activities; and

3) significant backup isolation can be provided by favorable ionexchange characteristics of many rocks and soils.

The primary unfavorable characteristics of geologic waste disposal are:

1) there is always some finite potential for man to inadvertently penetrate the disposal area at some time in the distant future;

2) groundwater is an ever present means for transporting waste constituents to man's environment;

3) for in-place melting concepts, localized melting and high rock temperatures cannot be reversed by man; and

4) retrievability and monitoring over long time periods is difficult.

\subsection{ICE SHEET CONCEPTS}

The implementation of all ice sheet disposal concepts could be done with today's technology. The disposal system aspects of containerization, transportation, and emplacement can all be accomplished by modification of current technology. Final sealing of the waste would be performed by natural refreezing of the water around the waste in all concepts.

Major technical uncertainties exist as to the potential for ice sheets to provide long-term isolation. Relatively little is known about ice sheets with respect to history, movement, and conditions at depth. Subglacial lakes are known to exist but their number and extent are not well known. Projections regarding future conditions and even the continued existence of the ice sheet can be inferred only from highly speculative, theoretical, or limited knowledge.

A most important question is the prediction of the future existence of the ice sheets. Present knowledge of climatology is not sufficient to assure that an ice sheet will be present more than a thousand years or so in the future.

\section{Another key question is the ice} flow rate. If the ice flow rate at depth is 0.1 centimeter per day (a value hypothesized as being a minimum for a few select locations), it would take about 2,000,000 years for the ice in the center of a large ice 
sheet (and an entrapped waste canister) to reach the edge of the ice sheet. If the ice flow rate is similar to measured values of surface flow rates toward the ocean (5 to 15 centimeters per day in Antarctica), a waste canister emplaced 1000 kilometers inland could reach the edge of the ice sheet in 20,000 years or less.

other questions are unanswered such as whether the melt water surrounding the waste will travel quick$7 y$ down through the ice to form a "pipe" for rapid communication of the waste to potential flowing water at the base of the ice sheet. In addition, the effects of the heat from the waste on the stability of the ice sheet is unknown.

Disposal sites would be selected with maximum travel distance to the ocean and minimum ice flow rates. These sites would be in the interior of the continent over ice-basin areas or possibly over "ice divides," where the underlying topography divides the ice flow into different directions and the time for ice (and waste) to flow to the ocean is maximized.

For emplacement of waste canisters within the ice, the hole depth for initial emplacement must be sufficiently great to assure that the interconnecting air spaces are sealed off to form bubbles. This placement is done to quickly remove the waste from surface exposure and to place it in the dense ice $\left(0.8 \mathrm{gm} / \mathrm{cm}^{3}\right)$ where the meltdown trajectory would be expected to be more stable. The canister would melt through the 3000 to 4000 meters of ice in an estimated 5 to 10 years. The time estimated for the canister to reach its anchored depth in the anchored emplacement concept is 6 to 18 months. The anchors and also the surface storage facility would be covered slowly (2 to $10 \mathrm{~cm} /$ year) as the snow accumulated.

The major energy consumption in ice sheet disposal is for fuel needed for transportation. This energy consumption is about four orders of magnitude lower than the electrical energy from the original nuclear fuel from which the waste was derived.

Overall, disposal of radioactive waste in ice sheets is considered to have an uncertain potential for isolating waste from man's environment, depending largely on ice flow rates and lack of certainty that the ice sheet will remain in existence for 1000 to $1,000,000$ years. Assuming the key questions can be answered favorably, disposal of radioactive waste in ice sheets could have the potential for isolating waste from man's environment for long time periods.

Generally favorable features offered by ice sheet waste disposal are:

1) waste can be deposited at great distance from man and his immediate environment;

2) a low temperature environment is provided for cooling the waste;

3) safety is provided from surface storms and man's destructive activities; and

4) a possible solution to the waste disposal problem is offered on an international basis.

The primary unfavorable features of ice sheet waste disposal are: 
1) extended transport over sea and ice is required;

2) operation is performed under severe climatic conditions;

3) monitoring and retrievability of waste is difficult; and

4) international political factors must be accommodated.

\subsection{SEABED CONCEPTS}

Implementation of the seabed disposal concepts in the stable deep sea areas or rapid sedimentation areas could be attained with today's technology. However, significant development of drilling and emplacement technology is required to implement disposal in the very deep sea areas of the trenches and the subduction zones. Final sealing of the disposal holes to maintain isolation for the long time periods of concern will need to be tested (and improved if necessary) for radioactive waste disposal.

Knowledge is limited about the seabed and overlying sediments with respect to history, movement, geology, and tectonic stability over extended time periods. Projections regarding future conditions can be inferred only from highly speculative, theoretical, or limited knowledge.

The unconsolidated sediments on the sea floor are not currently considered adequate in total for long-time isolation of waste canisters, since the sediments are subject to slumping, erosion, and possibly liquifaction. These occurrences could expose waste canisters unless they are emplaced in the underlying basement rock. Sedimentation rates (from less than one to possibly ten meters per million years) in all seabed areas except large river delta areas would provide insufficient cover to assure waste isolation. Sedimentary cover, however, could provide an effective secondary barrier between waste in the basement rock and the ocean water. The high geologic instability of areas with high sedimentation rates precludes assurance of waste isolation unless waste is emplaced in the underlying dense seabed.

Because of their relative geologic stability, the stable deep areas are considered the preferred areas for seabed disposal, based upon present knowledge. Proper selection of sites in these areas could provide potential isolation of radioactive waste for very long time periods. These stable seabed areas are considered to be among the most stable geophysical features in the earth. Isolation of the waste would depend on the stability of the seabed and to some degree the integrity of the man-emplaced overlying sealant.

The major energy consumption in seabed disposal is for fuel needed for transportation and drilling. This energy consumed is about five orders of magnitude lower than the

lectrical energy obtained from the corresponding nuclear fuel.

Overall, disposal of radioactive waste in the seabed has the potential for isolating waste from man's environment for periods in the order of millions of years, depending upon confirmation of inferred information by future seabed exploration. 
Generally favorable characteristics of seabed waste disposal are:

1) waste can be deposited at great distance from man and his environment;

2) unconsolidated sediments offer high retention capability for radionuclides in event of their release from the basement rock;

3) safety is provided from surface storms and man's destructive activities;

4) large volumes of water are available for dilution in event of release of waste constituents; and

5) a possible solution to the waste disposal problem is offered on an international basis.

The generally unfavorable characteristics of seabed waste disposal are:

1) extended transport and precise placement operations are required over the seas;

2) mobile seawater provides a ready mechanism for transport of released waste constituents;

3) plant and animal life in seawater offers potential means for reconcentration of released waste constituents;

4) knowledge of the seabed relative to waste disposal is inadequate; and

5) international political factors must be accommodated.

\subsection{EXTRATERRESTRIAL CONCEPTS}

The implementation of space disposal of transuranic waste could be achieved with current technology.

This technology is considered to include the space shuttle and the space tug, which are advanced vehicles but which will use existing engineering technology.
Some consideration was given to potential advanced space propulsion systems such as solar sails, nuclear propulsion, ion propulsion, and acceleration of waste particles electrically from an orbiting platform. Advantages appear possible with most of these advanced schemes in regard to more flexibility in achieving destinations, larger payload, or improved flight economics. However, they are undefined and insufficiently advanced to permit the analysis required by this study.

\section{Space trajectories considered} include:

1) Solar system escape

2) Solar impact

3) A high-earth orbit on the order of 100,000 miles $(160,000$ kilometers)

4) A solar orbit other than that of the earth and planets.

Information on these destinations is shown in Table 10.

Solar system escape càn be achieved directly by a single propulsion burn from the low-earth orbit with all propulsion and guidance provided by the launch vehicle. Solar system escape can be achieved with somewhat less energy expenditure by a properly designed swingby of Jupiter, using a single propulsion phase (tug) from low-earth orbit. However, either case requires multiple shuttles per waste package to supply the necessary sequential propulsion energy.

Direct solar impact with a single propulsion phase would require vehicles using advanced technology. Solar impact can be achieved by a swingby of Jupiter, using a single 
TABLE 10. Summary of Potential Space Destinations

\begin{tabular}{|c|c|c|c|}
\hline Destination & $\begin{array}{l}\text { Delta-V, } \\
\mathrm{km} / \mathrm{sec}(a)\end{array}$ & Advantages & Disadvantages \\
\hline High-Earth orbit & 4.11 & $\begin{array}{l}\text { Low Delta-V } \\
\text { Launch any day } \\
\text { Passive waste package } \\
\text { Can be retrieved }\end{array}$ & $\begin{array}{l}\text { Long-term container integrity } \\
\text { required. } \\
\text { Orbit lifetime not proven. }\end{array}$ \\
\hline $\begin{array}{l}\text { Solar orbits via: } \\
\text { Single burn beyond } \\
\text { Earth escape }\end{array}$ & 3.65 & $\begin{array}{l}\text { Low Delta-V } \\
\text { Launch any day } \\
\text { Passive waste package }\end{array}$ & $\begin{array}{l}\text { Long-term container integrity } \\
\text { required. } \\
\text { Earth re-encounter possible (may } \\
\text { not be able to prove otherwise) } \\
\text { Abort gap past Earth escape } \\
\text { velocity. (b) }\end{array}$ \\
\hline $\begin{array}{l}\text { Circular solar } \\
\text { orbit }\end{array}$ & 4.11 & $\begin{array}{l}\text { Low Delta-V } \\
\text { Launch any day }\end{array}$ & $\begin{array}{l}\text { Long-term container integrity } \\
\text { required. } \\
\text { Orbit stability not proven. } \\
\text { Abort gap past Earth escape } \\
\text { velocity. (b) }\end{array}$ \\
\hline $\begin{array}{l}\text { Venus or Mars } \\
\text { swingby }\end{array}$ & 4.11 & Low Delta-V & $\begin{array}{l}\text { Long-term container integrity } \\
\text { required. } \\
\text { Limited launch opportunity ( } 3 \text { to } \\
4 \text { months every } 19 \text { to } 24 \text { months) } \\
\text { Requires midcourse systems. } \\
\text { Need space propulsion or have } \\
\text { possibility of unplanned } \\
\text { encounter. }\end{array}$ \\
\hline $\begin{array}{l}\text { Solar system escape: } \\
\text { Direct }\end{array}$ & 8.75 & $\begin{array}{l}\text { Launch any day } \\
\text { Passive waste package } \\
\text { Removed from solar system }\end{array}$ & $\begin{array}{l}\text { High Delta-V } \\
\text { Abort gap past Earth escape } \\
\text { velocity. (b) }\end{array}$ \\
\hline Via Jupiter swingby & 7.01 & Removed from solar system & $\begin{array}{l}\text { High Delta-V. } \\
\text { Limited launch opportunity (2 } \\
\text { to } 3 \text { months every } 13 \text { months). } \\
\text { Requires midcourse systems. } \\
\text { Abort gap past Earth escape } \\
\text { velocity. (b) }\end{array}$ \\
\hline $\begin{array}{l}\text { Solar impact: } \\
\text { Direct }\end{array}$ & 24.08 & $\begin{array}{l}\text { Package destroyed } \\
\text { Launch any day } \\
\text { Passive waste package }\end{array}$ & $\begin{array}{l}\text { Extremely high Delta-V. } \\
\text { Abort gap past Earth escape } \\
\text { velocity. (b) }\end{array}$ \\
\hline Via Jupiter swingby & 7.62 & Package destroyed & $\begin{array}{l}\text { High Delta-V. } \\
\text { Limited launch opportunity ( } 1 \\
\text { to } 2 \text { months every } 13 \text { months). } \\
\text { Requires midcourse guidance } \\
\text { systems. } \\
\text { Abort gap past Earth escape } \\
\text { velocity. (b) }\end{array}$ \\
\hline
\end{tabular}

a. Delta-V is the incremental velocity required to leave a low-earth orbit and is a direct indication of the size and propulsion energy of the rockets required.

b. An abort gap is a short time period wherein a controlled abort of the mission cannot be accomplished if the flight is off-course. 
tug phase from low-earth orbit. However, the complexities of course control in a swingby mission may make this mission impractical.

For high-earth orbit, the tug first places the payload into an elliptical orbit. Another tug places the payload into the final circular orbit. The stability of the highearth orbit cannot currently be as sured for times greater than a few thousand years. Furthermore, the orbiting destinations are currently believed to require that the capsule integrity be maintained for time periods approaching those of the need for isolation from man, because waste released in earth orbit could return to the earth.

Solar orbit possibilities include (1) those closely associated with the earth's orbit by injecting the waste to earth escape velocity or slightly beyond, (2) circular orbits slightly inside or outside the earth's orbit, achieved by additional propulsion after escaping the earth, and (3) solar orbits achievable by swingby of Mars or Venus. However, solar orbits, like high-earth orbits, cannot yet be assured stable enough so that the waste could not impact the earth before radioactive decay is complete.

Use of the moon as a repository was not analyzed in this study because of future scientific interest, future potential value, and space environmental considerations.

The destination considered most likely is direct solar system escape. About 190 kilograms of transuranic waste can be transported in each flight to direct solar system escape with the proposed space vehicles. This capacity provides for disposal of the transuranics from about 280 metric tons of spent LWR fuel in each flight.

A conceptual design of a highintegrity capsule has been developed for space disposal of waste transuranics. This spherical capsule, 1.5 meters in diameter, contains transuranic oxide particles inside individual coated tungsten spheres containing a void for buildup of helium from alpha particle decay; these spheres are within a solid aluminum matrix which also contains lithium hydride particles for slowing down the neutrons and boron particles to absorb neutrons. These capsules can be fabricated using current technology.

The safety aspects for space disposal include primarily safety during launch and control of the extraterrestrial destination of the waste constituents. The potential for an abort which could cause a release of radionuclides during any one space launching is moderately high, but relatively small amounts of waste constituents are associated with each launch, and package integrity is high even in an abort.

The major energy consumption in space disposal is for propelling the waste to its final destination. This energy consumption for disposal of transuranic waste is about 4 to 5 orders of magnitude less than the electrical energy from the original nuclear fuel, depending upon the final space destination. 
Overal1, extraterrestrial disposal has the potential for permanent removal of radioactive waste constituents from the earth, depending largely on incentives and improved knowledge of deep space travel.

Generally favorable features of space disposal are:

.1) potential for complete removal of selected waste constituents from the earth;

2) safety is provided from earth's climatic phenomena, both short and long-term, and from man's destructive activities; and

3) a possible solution to the waste disposal problem is offered on an international basis.

Generally unfavorable features of space disposal are:

1) disposal of only part of the waste constituents appears to be economically feasible with present technology;

2) safety associated with multiple launches is questionable;

3) monitoring and retrievability of the waste constituents is very difficult; and
4) international political factors must be accommodated.

\subsection{TRANSMUTATION ELIMINATION CONCEPTS}

Elimination of a substantial fraction of the waste actinides via transmutation could be achieved by recycling in fission reactors. Elimination of larger fractions of waste actinides and selected fission products appears feasible by recycling in fusion reactors.

To establish the relative merits and specific technical feasibility of the transmutation approaches, special criteria were developed and applied which are unique to transmutation. These related to overall waste balance, specific transmutation rate, and total transmutation rate.

The results of the feasibility investigations are summarized in Table 11. The accelerator devices fail to meet the criteria for transmutation for almost all categories of radioactive waste. The possible exceptions are the use of a spallation neutron source for transmutation of

IABLE 11. Summary of Transmutation Device Feasibility

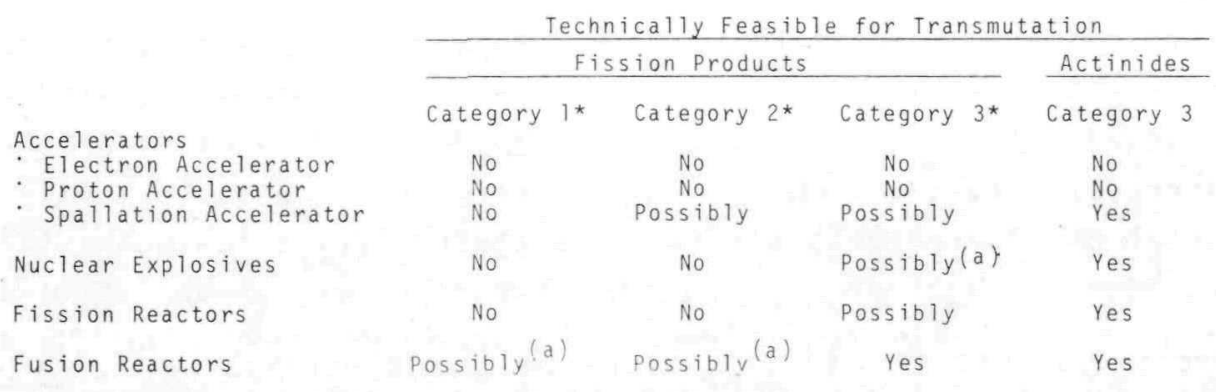

*Category 1: Storage required for 100 years

Category 2: Storage required for 100-1000 years

Category 3: Storage required for 1000 years

a. Separated isotopes 
long-lived fission products or actinides. The use of neutrons from a nuclear explosion does not appear technically feasible except for actinides or separated fission product isotopes. The use of fission and fusion reactors (when they exist) meet the selection criteria for transmutation of actinides. Fusion reactors also may transmute selected fission products.

The transmutation concept of continual recycle of actinides in fission reactors appears to have merit. Calculations by Claiborne at $0 a k$ Ridge National Laboratory, by Kubo and Rose at the Massachusetts Institute of Technology, arid at PNL for this study indicate that significant reductions are possible in the cumulative toxicity index (a) of actinides. The calculations indicate that using existing separations efficiencies with recycling of actinides in light water power reactors could achieve an order of magnitude decrease in the short-term actinide toxicity index and about a factor of fifty decrease in the long-term toxicity index.

These reduction factors may be significantly improved by achieving higher separations efficiencies, better optimization of the reactor irradiation, or by recycling in LMFBRS or HTGRS.

The calculations of the neutroninduced transmutation of actinides and fission products in the blankets of hypothetical Controlled Thermonuclear Reactors (CTRs or fusion reactors) have demonstrated that reductions of cumulative toxicity index of actinides by a factor of 10 or more below those achievable in fission reactors could be obtained in the high neutron flux levels proposed for CTRs. The limitations on efficiency of actinide transmutation in CTRs are primarily practical problems such as radiation damage to materials. These studies have also shown that large reductions in the total radioactive toxicity are possible for some fission product elements (e.g. $10^{8}$ for I-129). For others, notably strontium and cesium, the degree of toxicity reduction is minimal ( 2 to 5 for $C_{S}-137$ ). The calculated values are also uncertain by a factor of about two because of uncertainty in nuclear reaction data for these elements. Thus, the projected transmutation of some fis sion product elements in CTRs may not be decided until improved estimates of rates are possible and the actual characteristics of a CTR have been established. All considerations of radionuclide transmutation in CTRS, of course, presuppose the successful accomplishment of controlled thermonuclear fusion.

The primary beneficial safety aspect of transmutation is the inventory reduction of most of the longlived radionuclides. Safety considerations during the operational phase

a. Toxicity index is defined as the amount of air or water required to dilute the present amount of a given isotope to levels defined in the Code of Federal Regulations ( 10 CFR - Part 20) as the maximum permissible concentration. The toxicity index provides only an approximate comparison of radiological risk, since it does not allow for accumulation or reconcentration of a nuclide in environmental media, nor for the total impact of a number of nuclides. For limited comparisons, it is an acceptable alternative to dose calculations if used with caution. 
are primarily concerned with the incremental burden of processing, handling, and transporting the transmutation materials. While the possibility for release of radionuclides during operation is relatively high, the amount of materials involved in a release should normally be small. For the long time periods the safety concerns are dictated by the means used for disposal of the untransmuted waste.

The energy consumption in transmutation is essentially that associated with increased enrichment for transmutation in Light Water Reactors, chemical partitioning and handling, and transportation costs. The energy consumed and the additional energy developed due to transmutation processes in the nuclear devices are considered to be essentially at the break-even point. The total incremental energy consumed from the processing and handling operations is three to four orders of magnitude less than the electrical energy from the original nuclear fuel. The added enrichment cost for Light Water Reactors would not be present if recycle were done in fast fission reactors.

Overall, elimination of a substantial fraction of actinides and selected fission products appears to be technically feasible by recycling in fission and fusion reactors.

Generally favorable features offered by transmutation processing are:

1) the inventory of actinides and certain fission products is reduced markedly;

2) improved use of resources from fission reactors is effected; and
3) the waste being transmuted is readily monitored and retrieved.

Generally unfavorable features offered by transmutation processing are:

1) elimination of only part of the radioactive waste constituents is feasible;

2) the waste constituents undergoing transmutation are subject to effects of all other nuclear materials in man's environment such as earth's storms and man's destructive activities;

3) significant additional handling and processing is required for the waste being transmuted; and

4) additional waste is formed in the processing and transmutation steps.

\subsection{WASTE PARTITIONING}

The extraterrestrial and transmutation schemes require partitioning (separation) of actinides from the remaining waste constituents. The main extraterrestrial study case also requires further separation of the uranium from the remaining actinides; and if transmutation of selected fission products is done in a fusion reactor, these selected fission products must also be separated from the other waste streams.

Partitioning, if used, must result in a bulk fission product waste fraction which has very little of the actinides remaining so that this waste stream need by managed for only about 1000 years, and result in an actinide or transuranic fraction which has low enough fission product content to minimize interference with the transmutation or space disposal. 
For the latter need, allowable fission product content in the actinide fraction for transmutation is estimated to be about $1 \%$ of the total waste fission products; and that for space disposal is in the range of 0.1 to $1 \%$ of the total waste fission products. This performance is considered to be technically feasible by extension of existing chemical separations technology.

For removal or actinides from the fission products, the separation requirements are not clear because the ultimate answer to the question of "at what radioactivity level can a material be considered as not radioactive" depends highly on the specific disposal technique and site. It is also complicated by the need for higher decontamination (separation) factors for some actinides than for others. The required separation factors can range from as low as 10 to as much as $10^{6}$ to $10^{8}$, depending upon assumptions and specific case conditions. The more likely case is somewhere in the middle of the range and is believed to be between 100 and 10,000 .

An overview study was made of all chemical separations processes which might be applicable to partitioning of actinides from bulk liquid waste. The conclusions, summarized in Table 12, indicate that solvent extraction and ion exchange have the best capa bility for achieving the required separation factors. Other separa-

tions processes have uncertain capabilities, even for low decontamination factors. Also shown on the table is the need for analytical capability. The existing analytical technology is probably adequate for

TABLE 12. Partitioning Feasibility Study Conclusions: Adequacy of Existing Technology(a)

\begin{tabular}{|c|c|c|c|}
\hline & \multicolumn{3}{|c|}{ Actinide Separation (DF) ${ }^{(b)}$} \\
\hline & $10-100$ & $1,000-10,000$ & $10^{6}-10^{8}$ \\
\hline Solvent Extraction & Yes & Yes & Possibly \\
\hline Ion Exchange & Yes & Possibly & No \\
\hline $\begin{array}{l}\text { Other Separation } \\
\text { Techniques }\end{array}$ & Possibly & No & No \\
\hline Analytical Capability & Yes & Possibly & No \\
\hline
\end{tabular}

a. Existing separations technology needs adaptation to the objectives of partitioning.

b. This study was concerned primarily with the adequacy of existina technology for obtaining adequate separation of actinide elements from the short-lived waste fraction. Adequate technology exists for obtaining needed purity of the separated actinide fraction. 
low separation factors but is probably not adequate for higher separation factors.

The overview study also developed the following conclusions with respect to partitioning:

- Solids present in all high-level radioactive waste will complicate separations process development. Solids composed of large particle sizes may contain long-lived nuclides and have to be treated to remove them. Very small or colloidal solids may contain long-lived nuclides, particularly plutonium, and interfere with separations processes.

- A large amount of technology exists pertinent to the separations needed, but it has never been applied to this particular problem. Addi- tional research and development is needed to adapt it to achieve the needed separation factors.

- To accomplish actinide element separation completely within a typical purex reprocessing plant by process and equipment modification is not practical. Major process and equipment changes would be required. - Because of potential radiation damage to solvents or ion-exchange media, there may be a processing incentive to include interim aqueous waste storage for improved partitioning.

Overall, it is concluded that partioning of the waste is feasible for low to modest separation factors and is uncertain for high separation factors. 


\subsection{RESEARCH, DEVELOPMENT, AND TIMING}

All of the potential alternative concepts require kesearch and Development before they can be implemented. The time requirement to complete the Fesearch and Development in al 1 concepts is the orimary controlling factor in the time that the concepts can be implemented. A summary of the estimated Research and Development needs and the estimated nearearly time for implementation of the disposal concepts on a routine production basis is presented in Table 13. The Research and Development studies for al1 concepts are assumed to terminate upon successful completion of pilot-scale demonstrations.

A reference point for comparison of Research and Development costs is the Research and Development cost for nuclear reactors to date. The total cumulative Research and Development cost for nuclear reactors is on the order of $\$ 5$ bilition. The capital value of nuclear power reactors anticipated through the year 2000 and the value of the associated electricity may also be used for comparison. At $\$ 400 /$ installed kilowatt, the capital cost of nuclear power reactors through the year 2000 is $5 \times 10^{11}$ dollars ( $\$ 500$ bi11ion); at $10 \mathrm{mills} / \mathrm{kWhr}$, the value of nuclear electricity through the year 2000 is about $\$ 1000$ billion.

\subsection{GEOLOGIC CONCEPTS}

Research and Development requirements for the geologic concepts are primarily associated with the analysis and prediction of geological events and the definition of the effects resulting from the emplacement of waste in a geologic formation. In addition, significant drilling Research and Development is required for the deep-hole concepts, and significant thermal and chemical behavior studies are needed for the in-place melting concepts.

Some of the specific areas for study are:

1) Migration of radionuclides in geologic formations

2) Rock-waste chemical reactions

3) Rock mechanics of candidate geologic formations in the presence of waste

4) Sealing of access areas to disposal sites

5) A11 aspects of in-place fixation for certain concepts

6) Deep-hole drilling technology for deep-hole concepts

7) Deep geologic studies for deephole concepts

8) Improved survey and monitoring methods.

Major Research and Development problems are posed when considering disposal of an intermediate liquid phase and, in the melting concepts, assuring the behavior of a molten region.

Total Research and Development costs for the geologic concepts were estimated to range from $\$ 50$ to $\$ 200$ million, depending on the specific 
TABLE 13. Estimated Research and Development Needs and Timing to Routine operation

Research and Development

\section{Geologic Concepts}

1. Solid waste emplaced in mined cavity; no fluid cooling or cavity; initial water cooling; melting

3. Solid waste emplaced in manmade structure in mined cavity; initial air cooling; no melting

4. Solid waste emplaced in manmade structure in mined cavity; initial water cooling; no melting

5. Liquid waste emplaced in mined cavity; initial reflux cooling; melting

6. Liquid waste emplaced in exploded cavity; initial reflux cooling; melting

7. Solid waste emplaced in matrix of drill holes; no fluid cooling or melting

8. Solid waste emplaced in deep holes; no fluid cooling; melting or nonmelting

9. Liquid waste emplaced in deep holes; initial reflux cooling: melting

10. Liquid waste emplaced by hydrofracture; in-place curing

Ice Sheet Concepts

1. Self melt through ice

2. Anchored storage/disposal

3. Ice surface storage/disposal

Seabed Concepts

1. Subduction zones and other deep sea trenches

2. Stable deep sea areas

3. Rapid sedimentation

Extraterrestrial Concepts

1. Solar and Earth Orbits

2. Solar impact ${ }^{(c)}$

3. Solar escape

Transmutation Concepts

1. Fission reactors

2. Fusion reactors $(\mathrm{e})$ melting

2. Solid waste emplaced in mined

3. Accelerators $(f)$

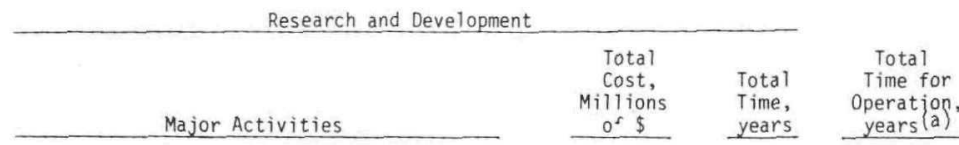

Basic geological, geophysical studies; site

50

15

$20-25$

evaluation; emplacement systems develop-
ment; thermal and radiation effects; con-

ment; thermal and radiation effects; con-
tainment/confinement integrity; instrumen-

tation auxiliaries; rock sealing;

demonstration

Same as 1 above; also, in-place conversion

90

25

Same as 1 above

50

Same as 1 above

50

Same as 1 above; also, in-place conversion

160

20

25

Same as 1 above; also, in-place conversion

170

20

Same as 1 above

200

20

30

Same as 1 above; also, in-place conversion and deep hole drilling techniques

160

25

$30-35$

Same as 1 above; also, in-place conversion and deep hole drilling techniques

Same as 1 above; a1so, rock hydrofracture studies

$\begin{array}{lll}180 & 25 & 30-35 \\ 50 & 10 & 15-20\end{array}$

Basic geological/geophysical studies; site evaluations; sea and ice transport; emplacement system development; instrumentation and auxiliaries; demonstration

$600-1000^{(b)} \quad 25$

Basic geological/geophysical studies; site evaluations; sea transport; drilling and sealing; emplacement system development;

instrumentation and auxiliaries;

demonstration

Partitioning development; disposal priority; capsule design, testing; encapsulation

development; flight vehicle, auxiliary

development; testing; safety evaluation

Partitioning development; neutronics data analysis and measurements; fuel development; safety evaluation; demonstration

Includes Research and Development time.

b. Ice sheet and seabed costs are very difficult to estimate. The estimated ranges given are highly speculative About four times the estimated costs shown here will be required for basic geological/geophysical and related earth science studies; the costs estimated in this table would be aimed specifically toward waste disposal.

c. Space Research and Development costs do not include costs for basic flight vehicle and auxiliaries development; these costs (in many millions of dollars), are assumed to be borne by NASA for other space flight activities. Costs include an estimated $\$ 100 \mathrm{million}$ for space vehicle and trajectory development specific to waste disposal, and disposal of remaining waste fraction by the terrestrial concept with lowest Research and Development cost (\$50 million). Costs and timing for solar impact were not estimated; these do not apply to solar impact.

d. Includes industrial participation estimated at 50 million dollars and disposal of remaining waste fraction by the terrestrial concept with the lowest Research and Development cost (\$50 million).

e. Research and Development for fusion reactors was not evaluated. Requirements are dictated by advent and engineering of fusion reactors.

f. Research and Development for accelerator transmutation was not evaluated. Feasibility of concept is uncertain. 
concepts. (a) Estimated time through full demonstration to beneficial occupancy of committed facilities for routine operation varies between 15 and 35 years.

\subsection{ICE SHEET CONCEPTS}

Primary Research and Development needs for the ice sheet disposal of high-level waste are concerned with understanding and evaluating the factors affecting long-term containment and isolation of the wastes. Rates of movement within the ice sheet, its long-term stability, and physical conditions at the ice-bedrock interface are essentially unknown. Research in climatology would be necessary to permit estimates of the expected 1 ife of the ice sheet. To collect and evaluate data to assure long-term isolation would require tens of years of extensive effort in many fields of science.

Transportation of the waste from the edge of the continent to the disposal sites would require considerable development of both equipment and supply methods to establish a practical, highly safe system. Surface-effect vehicles offer the possibility of more rapid transport than conventional tracked vehicles but would require more development and testing to prove their usefulness under severe ice sheet conditions.

A pilot-scale demonstration would be needed to prove the effectiveness of meltdown and anchored emplacement concepts. Laboratory studies, transport, and embarkation port design and construction, concept demonstration and pilot-scale demonstration would require an estimated ten years concurrent with ice sheet studies.

Total Research and Jevelopment costs for ice sheet disposal concepts are most difficult to estimate but are expected to be in the range of $\$ 3$ to $\$ 5$ bi11ion, and those specifically aimed toward waste disposal are expected to be in the $\$ 600$ to $\$ 1000$ million range. Research in the ice sheet areas is very expensive because of the high cost of logistics and supplies. Time requirements are estimated to be about 25 years for Research and Development before routine operation would be in effect.

More than three-fourths of the estimated Research and Development costs are for basic geological/geophysical studies of the ice sheet areas. The level of research effort would be several times that currently applied to these basic studies.

\section{3 SEABED CONCEPTS}

Extensive geological/geophysical/ oceanographic/biological studies would need to be conducted on the sea and seabed to determine more the location and specific features of suitable areas for waste disposal. Knowledge of the composition and physical characteristics of the seafloor material, deep currents and geologic stability is necessary to determine how

a. The major Research and Development efforts expended to date on disposal of radioactive waste in mined cavities in geologic salt formations would likely result in significantly lower future costs for development of this concept. 
successfully isolation of the waste could be maintained.

Present transportation systems and equipment could be modified to transport the waste. Establishing embarkation ports would be essentially a design problem but would require some research for site selection.

Waste canister materials resistant to corrosion during emplacement and able to accommodate the hydrostatic pressures would need to be developed. The thermal and radiation effects of the waste canisters on seabed material would need investigation, which could be performed, in part, in laboratories once seabed material had been obtained.

Drilling equipment capable of operating through 10 kilometers of water would need to be developed. Existing semi-submersible drilling platforms would need further development and modification for stable positioning and for firm docking of transport ships.

A pilot-scale demonstration would be needed to establish the viability of the waste management system and of the equipment, once developed.

Total kesearch and Development costs for seabed disposal concepts are quite difficult to estimate, but are expected to be in the range of $\$ 400$ to $\$ 1000$ million specifically for waste disposal, with a total of about $\$ 2$ to $\$ 5$ billion. Near-minimum time requirements are estimated to be 20 to 25 years. More than 75 percent of the total effort would be applied to geological/geophysical studies aimed at a basic knowledge of the seabed. The expenditure rate would be several times the current rate for seabed Research and Development studies.

\subsection{EXTRATERRESTRIAL CONCEPTS}

Research and Development items specific to extraterrestrial waste disposal include waste partitioning, waste capsule materials and form development, encapsulation process development, handling techniques, disposal trajectory studies, special instrumentation, and safety evaluations.

The estimated Research and Development costs of $\$ 50$ million for space disposal of transuranic element waste includes a 11 costs except those for the basic flight vehicles and their auxiliaries. Overall flight development costs, expected to be many millions of dollars, are assumed to be part of the space development program conducted by government agencies other than the Atomic Energy Commission. Costs for space vehicle and trajectory development specific to waste disposal are estimated by the Pacific Northwest Laboratory to be in the range of $\$ 100$ million. An additional $\$ 50$ million of Research and Development is assumed to be needed for terrestrial disposal of the waste fraction not sent to space. This cost is the minimum estimated for terrestrial disposal concepts. Thus the total direct Research and Development costs for space disposal are esti-

mated at about $\$ 200$ million.

The timing for routine operation of space disposal, estimated at about 20 years, is controlled largely by the schedule for development and 
achievement of reliable operational status of the basic space shuttles and tugs by other government agencies.

\subsection{TRANSMUTATION EL IMINATION} CONCEPTS

It was assumed for this study that transmutation would be accomplished in commercially owned facilities and the Research and Development needs, costs, and timing for implementation were estimated on this basis.

The Research and Development needs to develop the fission reactor transmutation concept are estimated to require between 10 and 15 years (depending upon using either LWRS or LMFBRS) and cost 130 million dollars. The cost includes $\$ 3$ to $\$ 5$ million for partitioning, $\$ 50$ milition for terrestrial disposal of the waste fraction not transmuted and $\$ 75$ milition for actinide recycle engineering (assuming $\$ 20$ million of government funding and $\$ 50$ million of industrial funding).

The potential near-term feasibility of fission reactor transmutation of the actinides suggests major Research and Development emphas is in that area. Since the development of a viable fusion reactor remains to be proven, a modest analytical research and development effort is projected for studying transmutation in fusion reactors. No specific Research and Development effort is recommended for accelerator transmutation at this time. However, it may be worthwhile to consider a modest effort to better ascertain the accelerator requirements for transmutation in order to determine the breakthrough necessary in acceleration technology for this alternative to represent a technically feasible transmutation concept.

Specific Research and DeveTopment items for the fission reactor transmutation concept include development and evaluation of nuclear data, reactor and fuel cycle calculations, experimentation and evaluation, and evaluations of special fuel handling systems, waste management schemes, and safety evaluations.

\subsection{WASTE PARTITIONING}

A Research and Development program was outlined to develop waste partitioning to the state of readiness for commercial application. The program is planned to obtain representative high-level waste and characterize it with respect to solids content and composition; to develop separations flowsheets through laboratory scale testing; to provide cost estimates on various separations processes for economic comparison; to select promising separations processes for pilot plant testing; to design, construct and operate pilot plant facilities for demonstration of processes and resolution of problems posed by large scale operation; and to develop and test analytical procedures as required for process control. The program is estimated to require about five years and cost $\$ 3$ to $\$ 5$ million, not including the cost of the pilot plant facility. (Pilot plant facilities exist which should be, with some modifications, usable for these studies.)

The AEC is currently embarked on a program of study of the partitioning of high-level radioactive waste. 


\subsection{WASTE MANAGEMENT COSTS}

An analysis of waste management costs for each disposal concept was developed by taking into consideration. all of the necessary components of a complete waste management system. The system cost includes, for example, any added spent fuel transport, interim liquid waste storage, waste solidification, interim solid waste storage, and transport of solid waste canisters to the disposal site or port of embarlation in the case of seabed or ice sheet concepts. The cost estimates are highly preliminary, based on limited concept definition, but are believed to be sufficiently detailed to establish the general magnitude and a relative comparison of disposal costs for each concept. The concept costs considered here include only the costs directly related to implementing each concept. They do not include research and development costs nor any estimated external or indirect societal costs.

Disposal costs were developed in terms of levelized unit charges--the single charge that could be assessed over the entire life of a project against each unit processed that would, regardless of fluctuations in processing rates and expenditure patterns, recover all operating expenses as well as the initial investment plus a specified rate of return on the investment. A $10 \%$ interest rate was employed. The final waste disposal facility was assumed to be a federal government operated facility, while all operations prior to this were assumed to be performed by a fuel reprocessor who must pay taxes on his profits.
Levelized unit charges were developed for each concept based on handling all of the waste generated by the nuclear power industry for a 25year period starting in 1980. It was assumed that new facilities would be added at 10-year intervals with sufficient capacity to handle the next ten years of waste generation. The levelized charges are based on assumed payment at the time of fuel reprocessing when the waste is generated. When disposal operations are deferred several years after reprocessing, the payment is credited with interest up to the time the actual operation is carried out. The payment at the time of reprocessing is the discounted present worth at the time of reprocessing of the cost at the time the operation is carried out.

For partitioning, total costs of $\$ 10,000$ to $\$ 20,000$ per metric ton of irradiated fuel were estimated for relatively low separations requirements (actinide elements only, separation factors on the order of 100) depending on the purity of the longlived fraction. If higher separation factors are required, separation costs would probably equal or exceed current total fuel reprocessing costs (about $\$ 30,000$ per metric ton).

The resultant preliminary cost estimates for each of the disposal concepts are shown in Table 14. Estimates are shown for both the direct concept costs and for the waste management system costs. The direct concept costs are shown in terms of estimated total capital and operating expenditures for waste generated over 
TABLE 14. Summary of Concept Cost Evaluations

\section{Geological Concepts}

1. Solid waste emplaced in mined cavity; no fluid cooling or melting; granite.

600 meters deep 1,500 meters deep

2. Solid waste emplaced in mined cavity; initial water cooling; melting; granite.

3. Solid waste emplaced in manmade structure in mined cavity; initial air cooling: no melting: granite.

one tunne?

two tunnels

4. Solid waste emplaced in manmade structure in mined cavity; initial water cooling; no melting; granite.

one tunnel

two tunnels

5. Liquid waste emplaced in mined cavity; initial reflux cooling, melting; granite.

6. Liquid waste emplaced in exploded cavity; initial reflux cooling; melting; granite.

7. Solid waste emplaced in matrix of drill holes; no fluid cooling or melting; granite.

8. Solid waste emplaced in deep holes no fluid cooling; melting or nonmelting granite.

9. Liquid waste emplaced in deep holes; initial reflux cooling; melting; initial

10. Liquid waste emplaced by hydrofracture; in-place curing: shale.

Ice Sheet concepts

1. Self melt through ice.

2. Anchored storage/disposal.

3. Ice surface storage/disposal. Seabed Concepts

1. Subduction zones - deep sea trenches.

2. Stable deep-sea areas.

3. Rapid sedimentation.

Extraterrestrial Concepts ${ }^{(b)}$

1. Solar and earth orbits. )

2. Solar escape.

Transmutation Concepts $(b)$

1. Fission reactors.

\begin{tabular}{c} 
Direct Concept \\
Cumulative for \\
1980-2004 Period \\
Capital \\
SMillions $\quad$ Operating \\
\hline
\end{tabular}

$\begin{gathered}\text { Levelized }(a) \\ \text { Unit Charges }\end{gathered}$
$\begin{gathered}\text { \$/MT Re- } \\ \text { processed }\end{gathered}$

Total Waste Management System Costs (d) Levelized Unit Charges (a) \$/MT Reprocessed

$\begin{array}{rrrrr}1,100 & 300 & 3,700 & 12,000 & 0.046 \\ 1,200 & 300 & 3,900 & 12,000 & 0.046 \\ 140 & 130 & 700 & 9,000 & 0.034\end{array}$

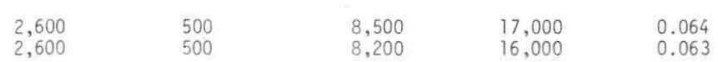

\begin{tabular}{|c|c|c|c|c|}
\hline $\begin{array}{l}1,200 \\
1,100\end{array}$ & $\begin{array}{l}400 \\
400\end{array}$ & $\begin{array}{l}4,000 \\
3,700\end{array}$ & $\begin{array}{l}12,000 \\
12,000\end{array}$ & $\begin{array}{l}0.047 \\
0.046\end{array}$ \\
\hline 110 & 740 & 1,400 & 6,400 & 0.024 \\
\hline 100 & 140 & 1,300 & 6,300 & 0.024 \\
\hline 640 & 140 & 2,100 & 10,000 & 0.039 \\
\hline 700 & 150 & 2,300 & 11,000 & 0.041 \\
\hline 340 & 100 & 3,000 & 8,000 & 0.030 \\
\hline 2,470 & 110 & 700 & 11,000 & 0.043 \\
\hline
\end{tabular}

a. Cost present worthed to time of reprocessing.
b. In the case of Transmutation and Extraterrestrial disposal concepts, the concept cost given in this table includes the cost of disposing actinides and transuraniums only. Additional costs of disposing of the remaining waste must be added to obtain total waste management costs. A representative cost for terrestrial disposal of the remaining waste fraction of $\$ 10,000 / \mathrm{MT}$ or $0.04 \mathrm{mi} 1 \mathrm{ls} / \mathrm{kW}$-hr is added to the transmutation and extraterrestrial costs and 1 isted in the last column to show a total waste management system cost

c. Costs for Transmutation and Extraterrestrial disposal concepts were obtained somewhat differently than for terrestrial concepts. Comparable data for the headings shown are not available. Transmutation costs assume the use of cormercially owned facilities.

d. System cost includes extra transport costs, interim liquid storage, partitioning, solidification, etc. 
the 25-year period from 1980 to 2004 and in terms of levelized unit charges present worthed to the time of reprocessing. The present worthing somewhat obscures the relationship between capital and operating costs and the levelized unit charges because of differences in elapsed time from reprocessing to final disposal for some of the concepts. The waste management system costs include the costs of other essential waste handling components. Relative costs for different concepts are more realistically stated in terms of total system costs.
These estimates conclude that the levelized unit cost for the most expensive concept (extraterrestrial solar escape disposal) is less than five percent of current nuclear electric power costs; most concepts are in the range of 0.4 to 1.0 percent; and two concepts are in the range of 0.2 percent. Consequently, none of the disposal concepts is estimated to increase the cost of nuclear electric power by major amounts. 


\subsection{ENVIRONMENTAL CONSIDERATIONS}

Exclusive of the possible dose consequences of radionuclide release from the waste, there were only a few specific cases in which any significant environmental effects were indicated. Environmental effects are estimated for disposal in the year 2010 for the waste accumulated in the U.S. through the year 2000.

Geologic concepts would commit typically about 130 square kilometers of land(a) but have little other impact. Some care would be required in disposing of the mining spoils of some 2.3 million cubic meters. There would be some small transportation impact resulting from an estimated 12,500 shipments to the disposal site by the year 2010 .

The ecology of the ice sheet regions is fragile, and care would be required to ensure that the transportation and emplacement operations did not seriously disrupt it. The heat rejected by the nuclear waste would have a small but finite probability of accelerating ice sheet movement towards the sea. Such an event could have a profound effect on the entire world. In addition to overland trips to the embarkation point, the noise, possible oil spills, and disruption of the surface resulting from surface transport, air, and water support operations would cause most of the expected impact. Total ice sheet area used would be about 80,000 square kilometers. Up to ten trips per year would be required for over-ocean ship transport.

Seabed concepts would require the isolation of an area of some 2,000 square kilometers from other seabed activities. Some disruption of the ocean bottom environment can be anticipated during the drilling operations, but little disturbance of the marine ecology would be anticipated during other phases of the management operation. Truck or rail shipment would be required to the port of embarkation. An estimated 60 annual round trips to the drilling platform would be required for movement of personnel, small materials, and supplies. Up to ten trips per year would be required for transporting waste to the platform.

Extraterrestrial launches of transuranic elements entail some environmental impact. Probably the most severe of these is the noise level during launch and re-entry of the shuttle. Sonic booms with overpressures of about 0.014 atmospheres over the ocean and 0.001 atmospheres over land can be anticipated. The environmental effects from the launch operations will be only part of the total, since the remaining waste will have to be disposed of by some other method. The ground transportation impact

a. The land use is generally controlled by the size of the "buffer" or zone of isolation around the actual disposal site. In this study, this zone was assumed to be 3.2 kilometers wide, which is in the range of 1.6 to 8 kilometers studied at ORNL for a bedded salt pilot plant repository. 
will be considerably greater from the large launch components than from the "payload" capsules for the launches required each year. Another launch site comparable to the existing Kennedy Space Center will be required.

The incremental environmental impact of actinide transmutation in LWRs would be minimal. Most effects can be attributed to the additional load on the nuclear fuel cycle. Since more fissile material is required to transmute the actinide elements, more uranium must be mined, more enrichment and processing facilities are required, etc. As in the case of extraterrestrial disposal, additional environmental impacts would be involved in the disposal of the fission products. The transportation impact would be increased by a few percent in all phases of the fuel cycle. The fuel elements containing the actinides would require large shielded containers comparable to those used in the shipment of irradiated fuel. 


\subsection{POLICY CONFLICTS}

Both national and international policies which might apply to the disposal of nuclear waste were examined. Although the results of these studies were not factored into the final program analysis, some interesting conclusions were reached.

The rules and regulations as estab1 ished by the Atomic Energy Commission in 10 CFR 50 (Appendix F) have the most immediate national impact. These regulations state specifically that all high-level nuclear waste must be disposed of in solid form on federally owned and controlled land. This clearly affects all liquid waste/melting disposal concepts, all extraterrestrial and ice sheet concepts and, most probably, the seabed concepts. However, the AEC rules and regulations appear to be more easily modified than international treaties.

The Antarctic Treaty of 1959 is an international agreement to which the United States is a party. It specifically prohibits any disposal of radioactive waste material in the Antarctic. This would clearly affect all the ice sheet disposal concepts which envision the use of the Antarctic. This treaty is in effect until 1989. At that time any of the participants may suggest amendments. If these are not accepted within 2 years, any of the parties may withdraw.

If the Greenland ice sheet were considered as a waste repository, negotiations must be effected with Denmark.

The Nuclear Test Ban Treaty might affect the concepts using nuclear explosives. Any release of radioactive materials across international boundaries is prohibited. Although the treaty is of unlimited duration, any of the parties have the right to withdraw if their "supreme interests" have been jeopardized.

The Nonproliferation Treaty could conceivably impinge on any of the concepts since it provides for the safeguarding of all source and special fissionable materials. The treaty specifies that International Atomic Energy Agency safeguard standards must be observed in all peaceful nuclear activities whether within a state or under its control anywhere.

The Treaty on Outer Space of 1967 and the Convention on International Liability for Damage Caused by Space objects of 1972 (not yet ratified by the U.S.) would affect all the extraterrestrial concepts. These treaties define the responsibilities of parties to the treaty in any space launch operations. They also define methods for fixing liabilities for damage caused by any space launch.

The seabed and ice sheet disposal concepts would most probably be impacted by the Convention on the High Seas and the Convention on the Continental Shelf of 1958. These treaties protect the high seas and the continental shelf respectively from pollution by radioactive waste. Additionally, the United States' Marine Protection, Research, and Sanctuaries Act of 1972 prohibits transportation and disposal at sea of radiological warfare agents and high-level radioactive waste. 


\subsection{PUBLIC RESPONSE}

A method for the measurement of the major elements of public perception of risk associated with nuclear waste was developed as part of this study. From the recommendations of a specifically assembled task force of advisors on risk and public acceptance, seven major elements of perceived risk were identified: distance, population density, emplacement operations, stability, detectability of leaks, retrievability, and protective reaction in event of a release of waste.

A before-after research design was used in a preliminary pilot study based upon these seven elements of perceived risk. Two identical questionnaires were administered to 21 respondents from Battelle's Human Affairs Research Center in Seattle. In the pre-test only the barest of descriptive material included in the questionnaire was used as an information basis. In the post-test, respondents were asked the same questions after a videotape presentation of a 5-minute description of each disposal method. Five generic methods of nuclear waste disposal (geologic, ice sheet, seabed, high earth orbit, and surface retrievable storage) were used to illustrate a wide range of characteristics.

In both the pre-test and post-test sessions, respondents were asked to evaluate each of the five disposal methods with their perception of the seven elements of risk. They were asked to make a comprehensive judgment of the overall risk involved in each of the concepts. They were also asked to rank the relative importance of the elements of risk for each concept.

Although this experiment was administered to a small group and the results have 1 imited significance, some of the results are interesting. Some of the judgments changed between the pre-test and post-test. After exposure to the information on the videotape, the respondents perceived geologic disposal as being safer with respect to the elements of distance and stability but as more dangerous with respect to retrievability and protective reaction. Similarly, the ice sheet disposal method was perceived as being more dangerous for all elements of risk after information was presented. The standard deviation of the responses, was almost universally less in the post-test than in the pre-test. All of these results suggest that the respondents have objective risk attitudes which are subject to change with more detailed information.

High correlation factors were found in the correlation of importance of each risk element and perceived danger for each risk element.

Multiple regression analys is of the pilot survey results was inconclusive. However, it was concluded that this analytical technique can indirectly measure the respondents' attitudes. The technique could prove to be a useful approach towards measurement of public response to waste disposal concepts and perceived risk elements if the survey were administered 
to larger and more representative groups. With such information based on in depth analysis, public attitudes could be factored into concept design. Favorable attitudes by the public on technically sound waste management practices is a most desirable objective. 


\subsection{SELECTED BIBLIOGRAPHY}

Advisory Committee on the Biological Effects of Ionizing Radiations, The Effects on Populations of Exposure to Low Levels of Ionizing Radiations, National Academy of Sciences, National Research Council, Washington, D.C., 1972 .

Bader, H., The Greenland Ice Sheet, U.S. Army Cold Regions Research and Engineering Laboratory, I-B2, September 1961.

Barnes, H., "Geologic and Hydrologic Background for Selecting Site of Pilot-plant Repository for Radioactive Waste," Bulletin of the Association of Engineering Geologists,

vol. XI, no.1, 1974 .

Bartlett, J. W., L. A. Bray, L. L. Burger, R. E. Burns, and J. L. Ryan, Feasibility Evaluation and R\&D Program Plan for Transuranic Partitioning of High-Level Fuel Reprocessing Waste, USAEC Report BNWL-1776, Battelle Pacific Northwest Laboratory, Richland, Washington, November 1973 .

Battelle, Pacific Northwest Laboratory Staff, Program for the Management of Hazardous Wastes, Report to the Environmental Protection Agency, Office of Solid Waste Management Programs, Contract No. 68-01-0762, Richland, WA, July 1973.

Blomeke, J. 0., C. W. McKee, and J.P. Nichols, Projections of Radioactive Wastes To Be Generated by the U.S. Nuclear Power Industry, USAEC Report ORNL-TM-3965, February 1974.

Boch, A. L., J. 0. Blomeke, W. C. McClain and B. F. Bottenfield, Radioactive Waste Repository Project Annual Progress Report for Period Ending september 30, 1972, ORNL-4824, Oak Ridge National Laboratory, Oak Ridge, TN, December 1973.

Bostrum, R. C., and M. A. Sheriff, "Disposal of Waste Material in Tectonic Sinks, "Nature, vol. 228, October 10,1970 .

Brandt, C. T., Letter proposal to E. G. Struxness at Oak Ridge National Laboratory, Fenix \& Scisson, Inc., November 1968.
Budd, W. F., "The Dynamics of Ice Masses," Australian National Antarctic Research Expeditions, ANARE Scientific Reports, Series A (IV) GTaciology, Pub. No. 108, Antarctic Div., Dept. of Supply, Melbourne, Australia, 1969 .

Budd, W. F., D. Jenssen, and U. Radok, "Derived Physical Characteristics of the Antarctic Ice Sheet," Univ. of Melbourne, Australia, Meteorology Dept., Mark I, Pub. No. 18, 1971.

Claiborne, H. C., Neutron-Induced Transmutation of $\mathrm{High-Level} \mathrm{Radio-}$ active Waste, ORNL-TM-3964, Oak Ridge Nationa 1 Laboratory, Oak Ridge, TN, December 1972.

Clark, G. A., of Marathon 0il Company, Findlay, Ohio, Letter proposal with enclosures sent to Dr. Frank K. Pittman, Division of Waste Management, AEC, Washington, D.C., November 27 , 1972 .

Code of Federal Regulations, Appendix F to 10 CFR 50, "Policy Related to the Siting of Commercial Fuel Reprocessing Plants and Related Waste Management Facilities," U.S. Government Printing Office, Washington, D.C., January 1, 1972 .

Cohen, J. J., A. E. Lewis and R. L. Braun, Use of a Deep Nuclear Chimney for the In-Situ Incorporation of $\mathrm{Nu}-$ clear Waste in Molten silicate Rock, USAEC Report, UCRL 51044, May 1971.

Dahlman, R. C. and Y. Tanaka, Ecological-Environmental Assessments Related to Federal Repository, ORNL-TIM3619, Oak Ridge National Laboratory, Oak Ridge, TN, July 1973.

Denham, D. H., D. A. Baker, J. K. Soldat, and J.P. Corley, Radiological Evaluations for Advanced Waste Management Studies, USAEC Report BNWL-1764, Battel1e, Pacific Northwest Laboratory, Richland, WA, September 1973.

Frye, J. E. et a 1., Disposal of Solid Radioactive Wastes in Bedded Salt Deposits, Report by the Committee on Radioactive Waste Management, National Academy of Sciences-National Research Council, November 1970. 
Galley, J. E. et al., Committee on Geologic Aspects of Radioactive Waste Disposal, Report to the USAEC Division of Reactor Development and Technology, National Academy of SciencesNational Research Council Division of Earth Sciences, May 1966.

General Assembly, United Nations, Report of the United Nations Scientific Committee on the Effects of Atomic Radiation, Official Records: 27th Session, Suppl. No. 25 (A/8725), United Nations, New York, NY, 1972.

Gross, M. G., Oceanography, 2nd ed. Charles E. Merritl Publishing Company, Columbus, Ohio, 1971.

Heezen, B. C., "Turbidity Currents," The Sea, vol. 3, chapter 27, Interscience Publishers, John Wiley \& Sons, New York, 1963.

Hess, H. H. et al., The Disposal of Radioactive Waste on Land, Report of the Committee on Waste Disposal of the Division of Earth Sciences, NASNRC Publication 519, September 1957.

Hughes, T., "Convection in the Antarctic Ice sheet Leading to a Surge of the Ice Sheet and Possibly to a New Ice Age," Science, vol. 170, November $6,19 \overline{70}$.

Hyland, R. E. et al., Feasibility Study of Space Disposa 7 of Nuclear Waste, NASA-AEC study group, NASA TM-X-2912, vol. 2 .

Hyland, R. E. et al., Study of Extraterrestrial Disposal of Radioactive Wastes, Part II, "Preliminary Feasibility Screening Study of Extraterrestrial Disposal of Radioactive Wastes in Concentrations, Matrix Materials and Containers Designed for Storage on Earth," NASA-TM-X-68147, Lewis Research Center, Cleveland, Ohio, October 1972 .

Koch, G. et al. Recovery of Transplutonium Elements from Fuel Reprocessing High-Level Waste Solutions, Report No. KFK-1651, November 1972.

Kubo, A. S., Technology Assessment of High-Level Nuclear Waste Management, ScD Thesis, Department of Nuclear Engineering, Massachusetts Institute of Technology, April 1973.

Kubo, A. S. and D. J. Rose, "On Disposal of Nuclear Waste," Science, December 21, 1973
Lakey, L. T. et a 1., ICPP Waste Ca Icining Facility Safety Analysis Report, USAEC Report IDO-74620, December 1963.

Larson, D. E., High-Level Liquid Radioactive Waste Management Program, USAEC Report ARH-2400, April 1972.

R. E. Leuze, R. D. Baybarz, and B. Weaver, "Application of Amine and Phosphonate Extractants to Transplutonium Element Production," Nucl. Sci. Eng., vol. 17, p. 252, $196 \overline{3 .}$

McCarthy, J.F. Jr. et a 1 , Concepts for Space Disposal of Nuclear Waste, M.I.T., Graduate Student Summary, October 1972 .

McElroy, J. L., K. J. Schneider, J. N. Hartley, J. E. Mendel, G. L. Richardson, R. W. Mckee and A. G. Blasewitz, Waste Solidification Program Summary Report, Volume 11, Evaluation of WSEP High-Level Waste Solidification Processes, USAEC Report BNWL-1667, Battelie Pacific Northwest Laboratory, Richland, WA, July 1972 .

Mellor, M., The Antarctic Ice Sheet, U.S. Army Cold Regions Research and Engineering Laboratory Report No. 1-B1, February 1961.

Mellor, M., Snow and Ice on the Earth's Surface, U.S. Army Cold Regions Research and Engineering Laboratory, II-C1, July 1964.

Menard, H. W., "The Deep Ocean Floor," Scientific American, vol. 221 , no. $3, p$ p. 127-142, 1969.

Nye, J. F., "The Response of Glaciers and Ice Sheets to Seasonal and Climatic Changes," Proc. of the Royal Society, Series A, vol. 256, 1960.

Oak Ridge National Laboratory Staff, Pilot Plant Repository Group, site Selection Factors for Bedded Salt Pilot Plant, USAEC Report ORNL-TM4219 , May 1973.

0'Keefe, D. R., Feasibility of Using an Orbiting Accelerator to Eject Radioactive Waste Products into space, GuTf-RT-C12457, Interim Summary Report, July 1973.

Peppard, D. F., "Liquid-Liquid Extraction of Metal Ions," Advances in Inorganic Chemistry and Radiochemistry, vol. 7, H. J. Emeleus and A. G. Sharp, Editors, Academic Press, 1965. 
Perona, J. J. et a 7 , Design and Safety Considerations of Shipping Solidified High-Level Radioactive Wastes, USAEC Report, ORNL-TM-2971, December 1970.

Pettijohn, F. J., Sedimentary Rocks, Harper and Brothers, New York, 1957.

Reactor Handbook, Vol. II, Fuel Reprocessing - Section B, Aqueous Separation Processes, S. M. Stoller, R. B. Richards, Editors, Interscience, New York, 1961 .

Ross, D. A., Introduction to 0ceanography, Appleton-Century-Crofts, New York, 1970.

Routson, R. C., A Review of Studies on Soil-Waste ReTationships on the Hanford Reservation from 1944 to 1967, BNWL-1464, March 1973.

Sagan, L. A. Editor, Human and Ecologic Effects of Nuclear Power, Charles C. Thomas, Springfield, Il, (in Publication).

Schneider, K. J., "Solidification and Disposal of High-Level Radioactive Wastes in the United States," A Critical Review, Reactor Technology, vol. 13, no. 4, winter 1970-71.

Schneider, K. J., and A. M. Platt, editors and compilers, Advanced Waste Management Studies: High-Level Waste Disposal Alternatives, USAEC Report BNWL-1900, vol. 1-4, Battelle, Pacific Northwest Laboratory, Richland, WA, May 1974 .
Soldat, J. K., N. M. Robinson and D. A. Baker, Models and Computer Codes for Evaluating Environmental Radiation Doses, BNWL-1754, BatteTle, Pacific Northwest Laboratory, Richland, Washington, June 1973.

United States Atomic Energy Commission, Office of Planning and Analysis, Nuclear Power 1973-2000, Report

WASH-1139 (72), Washington, D.C., December 1, 1972 .

Weertman, J., "Stability of Ice-Age Ice Sheets," Journal Geoph. Research, vol. 66, no. 11, November 1961.

Wheelwright, E. J., Ion Exchange: A Generic Nuclear Industry Process for the Recovery and Final Purification of $\mathrm{Am}, \mathrm{Cm}, \mathrm{Pm}, \mathrm{Sr}, \mathrm{Pu}, \mathrm{Np}, \mathrm{Cs}, \mathrm{Tc}$, Rh, and Pd, BNWL-SA-1945, October 1968 .

Wolkenhauer, W. C., et al., Transmutation of High-Level Radioactive Waste with a Controlled Thermonuclear Reactor, USAEC Report, BNWL-1772,

Battelle, Pacific Northwest Laboratory, Richland, WA, September 1973.

Zeller, E. J., D. F. Sanders and E. E. Angino, "Putting Radioactive Wastes on Ice," Bulletin of the Atomic Scientists, January 1973. 


\subsection{STUDY CONTRIBUTORS}

Following is a listing of the primary study contributors. Unless otherwise noted, they are affiliated with the Pacific Northwest Laboratory of Battelle Memorial Institute.

\section{Overall Study Coordination}

K. J. Schneider

A. M. Platt

Background on High-Level Waste and Its Managment

W. K. Winegardner, Study Leader G. Jansen

Study Methodology and Safety Considerations

D. E. Deonigi, Study Leader

J. P. Corley, Study Leader

J. B. Burnham

T. I. McSweeney

D. H. Denham

D. A. Baker

J. K. Soldat

G. Jansen

R. C. Routson

Geologic Disposal Concepts

K. J. Schneider, Study Leader

M. R. Kreiter, Study Leader

R. W. Wallace

D. D. Til1son

W. K. Winegardner

J. R. Sheff

J. D. Kaser

J. N. Hartley

L. L. Ames

G. Jansen

D. H. Stewart

E. B. Ekren, USGS-Denver

G. A. Dinwiddie, USGS-Denver

J. W. Mytton, USGS-Denver

W. Thordarson, USGS-Denver

J. E. Weir, Jr., USGS-Denver

E. N. Hinrichs, USGS-Denver

L. J. Schroder, USGS-Denver

S. H. Woodcock

Fenix and Scisson Drilling Co.

Seabed Disposal Concepts

R. W. Wallace, Study Leader

D. D. Tillson, Study Leader

W. H. Swift

J. R. Divine

P. J. Valent Civil Engineering

H. J. Lee Laboratory, U.S.

D. G. True Naval Construction

R. J. Malloy Battallion Center
Ice Sheet Disposal Concepts

R. W. Wallace, Study Leader

D. S. Tillson, Study Leader

W. H. Swift

J. R. Divine

\section{Extraterrestrial Disposal Concepts}

K. Drumheller, Study Leader

C. L. Brown

B. Griggs

R. E. Hyland et al., NASA-Lewis

J. S. Mackay, NASA-Ames

D. R. O'Keefe, Gulf Energy \&

Environmental

Systems Company

Transmutation Elimination Concepts

R. C. Liikala, Study Leader

B. R. Leonard, Jr.

W. C. Wolkenhauer

D. L. Lessor

E. T. Merril1

T. I. McSweeney

J. B. Burnham

C. M. Heeb

C. W. Lindenmeir

Waste Partitioning

R. E. Burns, Study Leader

J. W. Bartlett, Study Leader

L. A. Bray

L. L. Burger

J. L. Ryan

Waste Management Costs

R. W. McKee, Study Leader

J. B. Burnham

S. A. Rao

R. D. Spil1man Automation Indus-

N. F. Stark $\} \begin{aligned} & \text { tries, Inc., Vitro } \\ & \text { Engineering }\end{aligned}$ Division

\section{Policy Conflicts}

J. B. Burnham

\section{Public Response}

J. B. Burnham, Study Leader

S. M. Nealey Human Affairs

W. S. Maynard Research Center, 


\subsection{ACKNOWLEDGMENTS}

This study, performed over a period of about 1.5 years, received significant support from many people who are not listed as key contributors. The contributions of these persons are gratefully acknowledged. Although the total of such participants is too numerous to mention, the following list shows many of the major contributors.

Program Guidance, Funding and Review

F. K. Pittman

U.S. A.E.C., Division of Waste Management and Transportation

A. F. Perge

U.S. A.E.C., Division of Waste Management and Transportation

R. W. Ramsey

U.S. A.E.C., Division of Waste Management and Transportation

H. F. Soule U.S. A.E.C., Division of Waste Management and Transportation

0. J. Elgert U.S. A.E.C., Richland office

R. B. Goranson

U.S. A.E.C., Richland Office

N. T. Karagianes

U.S. A.E.C., Richland office

R. D. Fogerson

U.S.A.E.C., Richland office

\section{Overa 11 Review}

G. H. Daly

U.S. A.E.C., Division of Waste

Management and Transportation

M. Skalka

U.S. A.E.C., Division of Waste Management and Transportation

R. D. Walton

U.S. A.E.C., Division of Waste Management and Transportation

W. K. Eister

U.S. A.E.C., Division of Waste Management and Transportation

A. F. Kluk

U.S. A.E.C., Division of Waste Management and Transportation

V. G. Trice

U.S. A.E.C., Division of Waste Management and Transportation

T. L. Dunckel

U.S. A.E.C., Division of Waste

Management and Transportation

C. L. Osterberg

U.S. A.E.C., Division of Biomedical and Environmental

Research

H. M. Parker

Battelle, Pacific Northwest

Laboratory
C. M. Unruh

Battelle, Pacific Northwest

Laboratory

R. F. Foster

Battelle, Pacific Northwest

Laboratory

Study Methodology and Safety Considerations

\section{Fault Tree Consultant}

P. A. Crosetti

United Nuclear Industries

Risk and Public Response Task Force

S. S. Epstein, M.D. Case Western University

J. McCarro11, M.D.

Los Angeles Medical Services

Division

S. M. Nealey

Battelle, Human Affairs

Research Center

L. H. Rappoport

Kansas State University

L. A. Sagan, M.D.

Palo Alto Clinic

C. Starr

Electric Power Research

Institute

P. Slovic

Oregon Research Institute

N. E. Rasmussen

Massachusetts Institute of

Technology

\section{Geologic Disposal Concepts}

\section{Reviewers}

W. S. Twenhofel

U.S. Geological Survey, Denver

R. K. Blankennagel

U.S. Geological Survey, Denver

G. D. deBuchannane U.S. Geological Survey, Washington, DC

A. L. Boch

Oak Ridge National Laboratory

T. F, Lomenick

Oak Ridge National Laboratory 


\section{W. C. McClain \\ Oak Ridge National Laboratory \\ J. 0 . Blomeke \\ Oak Ridge National Laboratory \\ Consultants}

R. F. Walters, Walters Drillina Co.

P. F. Kerr

H. A. Coombs University of Washington

J. Gilluly

R. L. Loofbourow

G. C. Kennedy University of California Los Angeles

Ice Sheet Disposal Concepts

\section{Consultant and Reviewer}

C. B. B. Bu11 Ohio State University

\section{Reviewers}

\section{J. H. Zumberge} University of Nebraska

M. F. Meier U.S. Geological Survey

E. J. Zeller University of Kansas

Seabed Disposal Concepts

Consultant and Reviewer

M. N. A. Peterson Scripps Institution of Oceanography

Reviewers and Technical Editorial Assistance

W. P. Bishop

Sandia Laboratories

C. D. Hollister Woods Hole Oceanographic Institute

\section{Reviewer}

D. A. McManus University of Washington

J. S. Creager

University of Washington

A. J. Coyle Battelle columbus

\section{Transmutation Concepts}

\section{Reviewer}
A. S. Kubo
U.S. Military Academy
West Point
B. I. Spinrad
Oregon State University
H. W. Lefevre
University of Oregon
C. J. Poncelet Carnegie-Mellon Institute
J. L. Crandall
E. I. duPont de Nemours and Co.
R. E. Hellens
Combustion Engineering, Inc.
D. G. Foster, Jr. University of California

Waste Partitioning

Amicon Corp., Cambridge, MA

C. E. Armantrout

U.S. Bureau of Mines

L. E. Bruns

Atlantic Richfield Hanford Co.

W. W. Schulz Atlantic Richfield Hanford Co.

C. R. Cooley Hanford Engineering Development Laboratory

R. E. Lerch Hanford Engineering Development Laboratory

G. L. Richardson Hanford Engineering Development Laboratory

R. E. Leuze Oak Ridge National Laboratory

D. F. Peppard Argonne National Laboratory

H. C. Rathvon Exxon Nuclear

T. H. Siddall Louisiana State University

R. E. Sparks Washington University

G. W. Watt University of Texas

\section{Report Editor}

J. A. Powe 11 
APPENDIX A

HIGH-LEVEL WASTE PROJECTIONS 


\section{APPENDIX A}

\section{HIGH-LEVEL WASTE PROJECTIONS}

This appendix summarizes projections of the quantity and radiation properties of the high-level solid waste resulting from the growth of the U.S. nuclear power industry. Information is also presented concerning forecasts of installed electrical generating capacity, the types of reactor plants that will provide this capacity, and projected fuel reprocessing schemes since such information forms the basis for the waste projections. It should be recognized that the projections are estimates for future activities and they will not be exact in fact. Furthermore, projections made by a number of sources will differ. However, the quantities presented here are useful for overall future considerations.

In general, numerical values are given in the metric system. A listing of the conversion factors used is given in Table A-1.

\section{- Power Projections}

Selected forecasts for installed electrical generating capacity for the United States are summarized in Figure A-1. (a) It is projected that the installed nuclear generating capacity will be 130,000 MW by 1980, $500,000 \mathrm{MW}$ by 1990, and 1,200,000 MW by 2000 . Additional details of the nuclear electric power generating forecast are presented in Table A-2.

\section{- Reactor Plants}

Pertinent nuclear reactor plant characteristics assumed for waste projections are shown in Table A-3. Characteristics for Light Water cooled Reactors (LWR), which can be either pressurized water (PWR) or boiling water (BWR) units, are based on the 1000 MWe Diablo Canyon PWR plant. The fuels for the LWR plants are fissionable isotopes of uranium and plutonium (U-235 and Pu-239); plutonium recycle was assumed to begin in fiscal year 1979 in LWR plants.

The High Temperature Gas Cooled Reactor (HTGR) is a thermal converter plant based on the U-235 (highly enriched) /Th/U-233 fue1 cycle that can produce more new fissile material (U-233 from fertile thorium) than conventional PWR plants but not as much as true breeder plants. The reference reactor is graphite-moderated and gas-cooled and is based upon design studies of a 1160 MWe HTGR that uses annual refueling of approximately one-fourth of the core.

The Liquid Metal Cooled Fast Breeder Reactor (LMFBR) plants use fast (unmoderated) neutrons and 1 iquid metal coolant and are designed to produce more fissile material than they consume. Fissionable plutonium will be the key fuel material for the LMFBR plants.

a. Sources of information are referenced in the Tables and Figures. References are given at the end of Appendix $A$. 
- $\quad$ Fuel Reprocessing

Irradiated enriched uranium LWR fuels typically contain the fissile plutonium that is produced by reactor irradiation and about 30 percent of the original fissile uranium. Chemical reprocessing is used to separate and recover these useful products from the fission products. In general, the fission products and actinides other than uranium, plutonium and thorium are viewed as waste constituents. There is also a small amount of unrecovered uranium, plutonium or thorium (product loss) in this high-level waste stream. Existing or planned reprocessing flowsheets are based on a solvent extraction process. Aqueous acidic "feed" solutions, arising from the dissolution of irradiated fuels in nitric acid, are fed to the initial (firstcycle) solvent extraction contact. Here, most of the nuclear fuel prodducts are retained in an organic phase while the fission products, along with a small quantity of uranium, plutonium or thorium and generally all other actinide elements are discarded as aqueous acidic highlevel waste.

- High-Level Waste Characteristics Estimates of total quantities, radioactivity, thermal power and toxicity indices of the waste that will be accumulated through the year 2000 are shown in Table A-4. (Radiation properties are also shown for selected decay times beyond the year 2000.) The waste volume accumulated through the year 2000 is based on a reprocessing load of almost 200,000 metric tons of irradiated fuel about 80 percent of which is associated with LWR plants. This reprocessing load includes some fuel with relatively low exposure as well as scrap that is recycled from fabrication plants, and radiation properties are based on 185,000 "equivalent" metric tons where it is assumed that all of the fuel has attained rated steady-state exposure. Reprocessing (product) losses are assumed to be $0.5 \%$.

The toxicity indices (a) are the base 10 logarithms for the quantity in cubic meters of air, for the inhalation hazard index, or of water, for the ingestion hazard index, required to dilute radioactive material to the 1 imits stipulated in 10 CFR 20, Appendix B. These simplified indices provide an overview of the toxicity of wastes based solely on dilution with no allowance for reconcentration or retardation in the environment. Using these bases, fission products (primarily strontium) and transplutonium elements (primarily americium) are the controlling potential hazards

a. Toxicity index is defined as the amount of air or water required to dilute the present amount of a given isotope to levels defined in the Code of Federal Regulations

(10 CFR - Part 20) as the maximum permissible concentration. The toxicity index provides only an approximate comparison of radiological risk, since it does not allow for accumulation or reconcentration of a nuclide in environmental media, nor for the total impact of a number of nuclides. For limited comparisons, it is an acceptable alternative to dose calculations if used with caution. 
in drinking water up to about

350 years and $2 \times 10^{4}$ years, respec-

tively, when times beyond the year

2000 are considered. Radioactivity

from plutonium losses during repro- cessing then becomes controlling

until about $10^{6}$ years. Finally, radioactivity remaining as the result of uranium losses during reprocessing becomes the overruling consideration.

\section{TABLE A-1. Conversion Factors}

To Convert

calories, gram centigrade centimeters cubic meters cubic meters cubic meters grams grams/liter hectares hectares kilograms kilometers kilometers kilowatts kilowatts kilowatt-hrs liters

liters

liters/min meters meters/min

millimeters mills/kilowatts-hrs* newtons square centimeters square kilometers square kilometers square meters tons (metric) tons (metric) watts

watts hours watts hours watts hours watts hours watts $/ \mathrm{cm}^{2}-{ }^{\circ} \mathrm{C}$ (watts $\left./ \mathrm{cm}^{2}\right)\left({ }^{\circ} \mathrm{C} / \mathrm{cm}\right)$
Into

Btu

Farenheit

inches

cubic feet

liter

gallons (U.S.)

pounds

pounds/cubic feet

acres

square kilometers

pounds

miles

feet

Btu/min

horsepower

Btu

cubic feet

gallons (U.S.)

cu.ft/sec

feet

feet/min

inches

dollars/kilogram U*

pounds

sq. inches

acres

square miles

square feet

kilograms

pounds

Btu/hr

Btu

ergs

foot-pounds

kilogram-calories

Btu/ (hr-sq ft- $\left.{ }^{\circ} \mathrm{F}\right)$

(Btu/hr-sq ft) ( $\left.{ }^{\circ} \mathrm{F} / \mathrm{ft}\right)$
Multiply By

$3.9685 \times 10^{-3}$

$\left(C^{\circ} \times 9 / 5\right)+32$

0.3937

35.31

1000.0

264.2

$2.205 \times 10^{-3}$

0.062427

2.47

0.01

2. 205

0.6214

3,281

56.92

1.341

3413

0.03537

0.2642

$5.886 \times 10^{-4}$

3.281

3.2.81

0.03937

277.2

0.2248

0.1550

247.1

0.3861

10.76

1000

2205

3.413

3.413
$3.60 \times 10^{10}$

2,656

0.8598

1760.6

* at 33,000 megawatt days (thermal)/ton(metric) $U$ and $35 \%$ conversion efficiency, thermal to electrical 


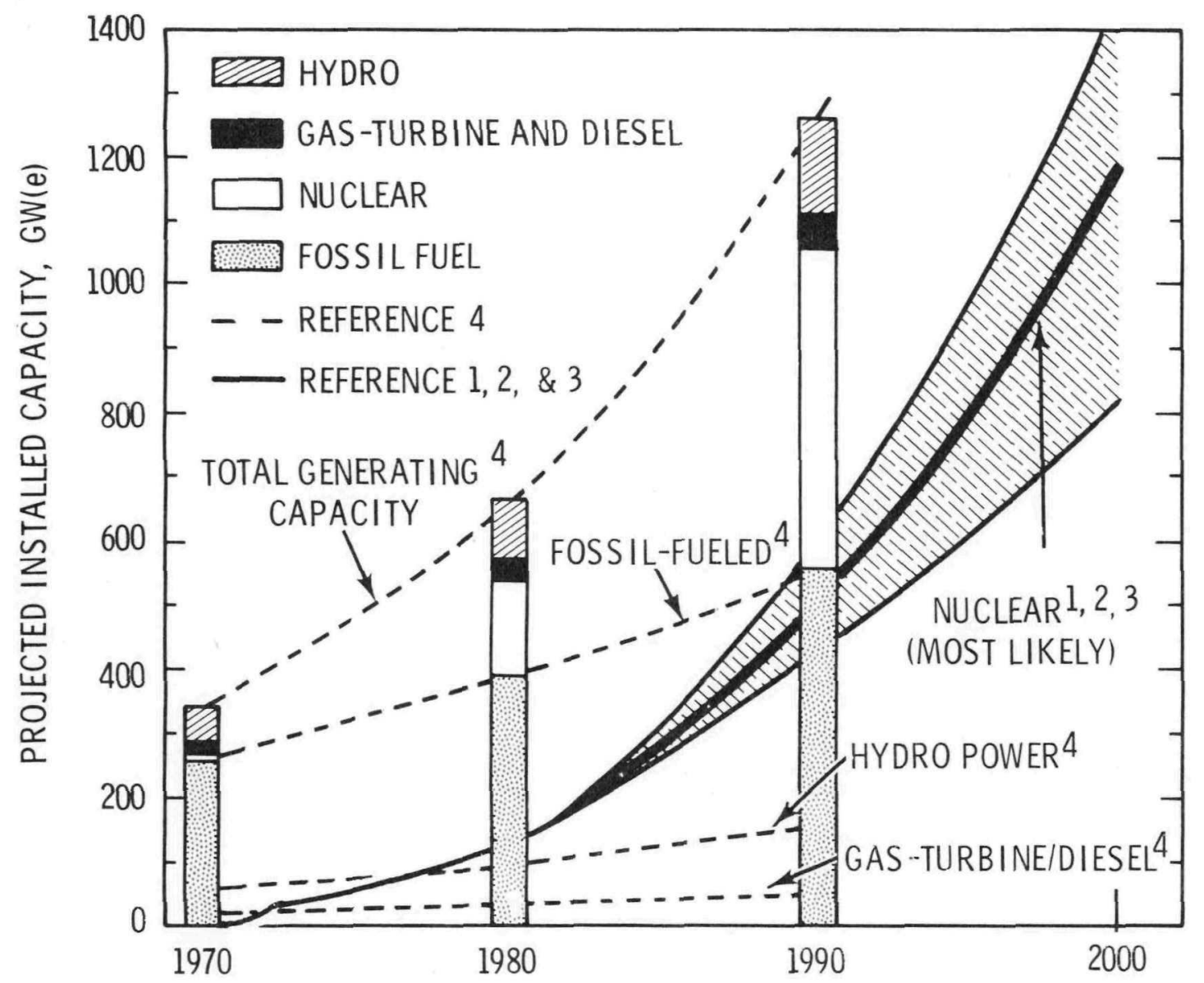

FIGURE A-1. Projected Growth of Electrical Generating Capacity in the United States 
TABLE A-2. Forecast of U.S. Nuclear Electric Power
Generating Capacity, GW(e) (net)(1)

End of

$\underline{\text { Year }}$

1970

71

72
73

73
74

75

76

77

78
79

1980

81

82

83

84

85

86

87

88

89

1990

91

92
93

93
94

95

96

97

98

99

2000

\section{Calendar Year}

$$
5.0
$$$$
8.1
$$

17

31

45

55

63

76

94

114

134

159

185

213

245

281

318

362

408

453

504

559

617

676

740

807

879

955

1033

1117

1201

LWR

5.2
8.2
17.5
31.2
45.3
55.1
62.9
76.0
94.4

111.7

129.1

149.9

168.1

187.7

209.8

235.0

260.9

289.6

318.3

344.9

374.0

404.1

432.1

456.3

476.2

490.7

505.0

519.7

533.1

546.3
Average in Fiscal Year

LMFBR

HTGR

5.2

8.2

17.5

31.2

45.3

55.1

62.9

76.0

94.4

113.9

134.4

158.7

184.7

212.7

244.7

280.7

317.7

362.2

408.2

81.4

3.5

8.5

15.5

25.0

37.0

55.0

79.0

113.0

156.0

203.0

254.0

309.0

370.0

453.2

504.2

559.2

617.2

676.2

740.3

807.4

878.6

954.8

1033.1

1117.5 
TABLE A-3. Nuclear Reactor Plant Characteristics (1)

\begin{tabular}{|c|c|c|c|c|c|c|c|c|c|c|c|c|c|c|c|c|}
\hline & \multirow[t]{2}{*}{$\underline{\mathrm{LWR}-U}$} & \multicolumn{3}{|c|}{$L W R-U, P U^{a}$} & \multicolumn{4}{|c|}{$H T G R^{b}$} & \multicolumn{4}{|c|}{ A.I. Follow-on $L_{M F B R}^{f}$} & \multicolumn{4}{|c|}{ G.E. Follow-on LMFBR $^{g}$} \\
\hline & & $\begin{array}{c}U \\
\text { Fraction }\end{array}$ & $\begin{array}{c}\mathrm{Pu} \\
\text { Fraction } \\
\end{array}$ & Total & $\begin{array}{l}\text { Th- } \\
\text { U-233 } \\
\end{array}$ & $\begin{array}{l}\text { U-235 } \\
\text { Fresh } \\
\text { Makeup } \\
\end{array}$ & $\begin{array}{c}\text { U-235 } \\
\text { Recycled } \\
\text { Makeup } \\
\end{array}$ & Total & Core & $\begin{array}{c}\text { Axial } \\
\text { Blanket }\end{array}$ & $\begin{array}{l}\text { Radial } \\
\text { Blanket } \\
\end{array}$ & Total & Core & $\begin{array}{c}\text { Axial } \\
\text { Blanket }\end{array}$ & $\begin{array}{l}\text { Radial } \\
\text { Blanket }\end{array}$ & Total \\
\hline Electric Power, MWe(net) & 1000 & 676 & 324 & 1000 & - & - & - & 1160 & - & - & - & 1002 & - & - & - & 1011 \\
\hline Thermal Power, MW & 3077 & 2081 & 996 & 3077 & - & - & - & 3000 & 2219 & 107 & 74 & 2400 & 2081 & 195 & 141 & 2417 \\
\hline $\begin{array}{l}\text { Ave. Specific Power, b } \\
\text { MW/metric ton }\end{array}$ & 37.5 & 37.5 & 37.5 & 37.5 & - & - & - & 80.65 & 116.1 & 8.1 & 4.7 & 50.18 & 155.6 & 13.0 & 8.5 & 53.76 \\
\hline Avg. Burnup, MWd/metric ton & 32,873 & 32,873 & 32,873 & 32,873 & - & - & - & 94,264 & 67,594 & 4739 & 7970 & 37,098 & 104,542 & 8725 & 9051 & 41,792 \\
\hline Refueling Interval, days ${ }^{C}$ & 365.25 & 365.25 & 365.25 & 365.25 & 365.25 & 365.25 & 365.25 & 365.25 & 364 & 364 & 364 & 364 & 385 & 385 & 385 & 385 \\
\hline \multicolumn{17}{|l|}{ Steady State Charge } \\
\hline Th, kg & - & - & - & - & 8434 & - & - & 8434 & - & - & - & - & - & - & - & - \\
\hline $\mathrm{U}-233, \mathrm{~kg}$ & - & - & - & - & 217 & - & - & 217 & - & - & - & - & - & - & - & - \\
\hline $\mathrm{U}-235, \mathrm{~kg}$ & 875.2 & 592.0 & 59.8 & 651.8 & 29.6 & 373.0 & 30.4 & 433 & 16 & 13 & 5 & 34 & - & 20 & 14 & 34 \\
\hline Total U, kg & 27,350 & 18,500 & 8409 & 26,909 & 357.9 & 403.0 & 104.5 & 865.4 & 7890 & 6571 & 2702 & 17,163 & 5038 & 6884 & 4798 & 16,720 \\
\hline Fissile $\mathrm{Pu}, \mathrm{kg}^{\mathrm{d}}$ & - & - & 270.3 & 270.3 & - & - & - & - & 1196 & - & - & 1196 & 786 & - & - & 786 \\
\hline Total Pu, kge & - & - & 441.0 & 441.0 & - & - & - & - & 1663 & - & - & 1663 & 1093 & - & - & 1093 \\
\hline$(u+P u+T h), k g$ & 27,350 & 18,500 & 8850 & 27,350 & 8792 & 403.0 & 104.5 & 9299.4 & 9553 & 6571 & 2702 & 18,826 & 6131 & 6884 & 4798 & 17,813 \\
\hline \multicolumn{17}{|l|}{ Steady State Discharge } \\
\hline $\mathrm{Th}, \mathrm{kg}$ & - & - & - & - & 7819 & - & - & 7819 & - & - & - & - & - & - & - & - \\
\hline $\mathrm{U}-233, \mathrm{~kg}$ & - & - & - & - & 219.3 & - & - & 219.3 & - & - & - & - & - & - & - & - \\
\hline $\mathrm{U}-235, \mathrm{~kg}$ & 243.4 & 164.6 & 26.4 & 191.0 & 30.7 & 30.8 & 2.6 & 64.1 & 8 & 11 & 3 & 22 & - & 14 & 10 & 24 \\
\hline Total U, kg & 26,137 & 17,679 & 8190 & 25,869 & 366.1 & 105.3 & 70.0 & 541.4 & 7255 & 6415 & 2543 & 16,213 & 4439 & 6580 & 4583 & 15,602 \\
\hline Fissile $\mathrm{Pu}, \mathrm{kg}^{\mathrm{d}}$ & 180.1 & 121.8 & 151.2 & 273.1 & - & - & - & 2.7 & 1143 & 133 & 119 & 1395 & 714 & 234 & 163 & 1111 \\
\hline Total Pu, kge & 254.9 & 172.4 & 273.1 & 445.5 & - & - & - & 10.0 & 1655 & 137 & 126 & 1918 & 1051 & 245 & 171 & 1467 \\
\hline$(U+P u+T h), k g$ & 26,572 & 17,851 & 8463 & 26,315 & 8185 & 105.3 & 70.0 & 8370 & 8910 & 6552 & 2669 & 18,131 & 5490 & 6825 & 4754 & 17,069 \\
\hline
\end{tabular}

a. PWR with self-sustaining Pu recycle.

b. Based upon full power and fuel charged.

c. At $80 \%$ load factor.

d. $\mathrm{Pu}-239+\mathrm{Pu}-241$

e. $\mathrm{Pu}-238+\mathrm{Pu}-239+\mathrm{Pu}-240+\mathrm{Pu}-241+\mathrm{Pu}-242$

f. A.I. plant representative of early units, F.Y. -87 through F.Y.-90.

g. G.E. plant typical of advanced units, i.e., beyond F.Y.-90. 
TABLE A-4. Projected Accumulation of Solidified High-Level Waste Through End of Year 1974-2000(1)

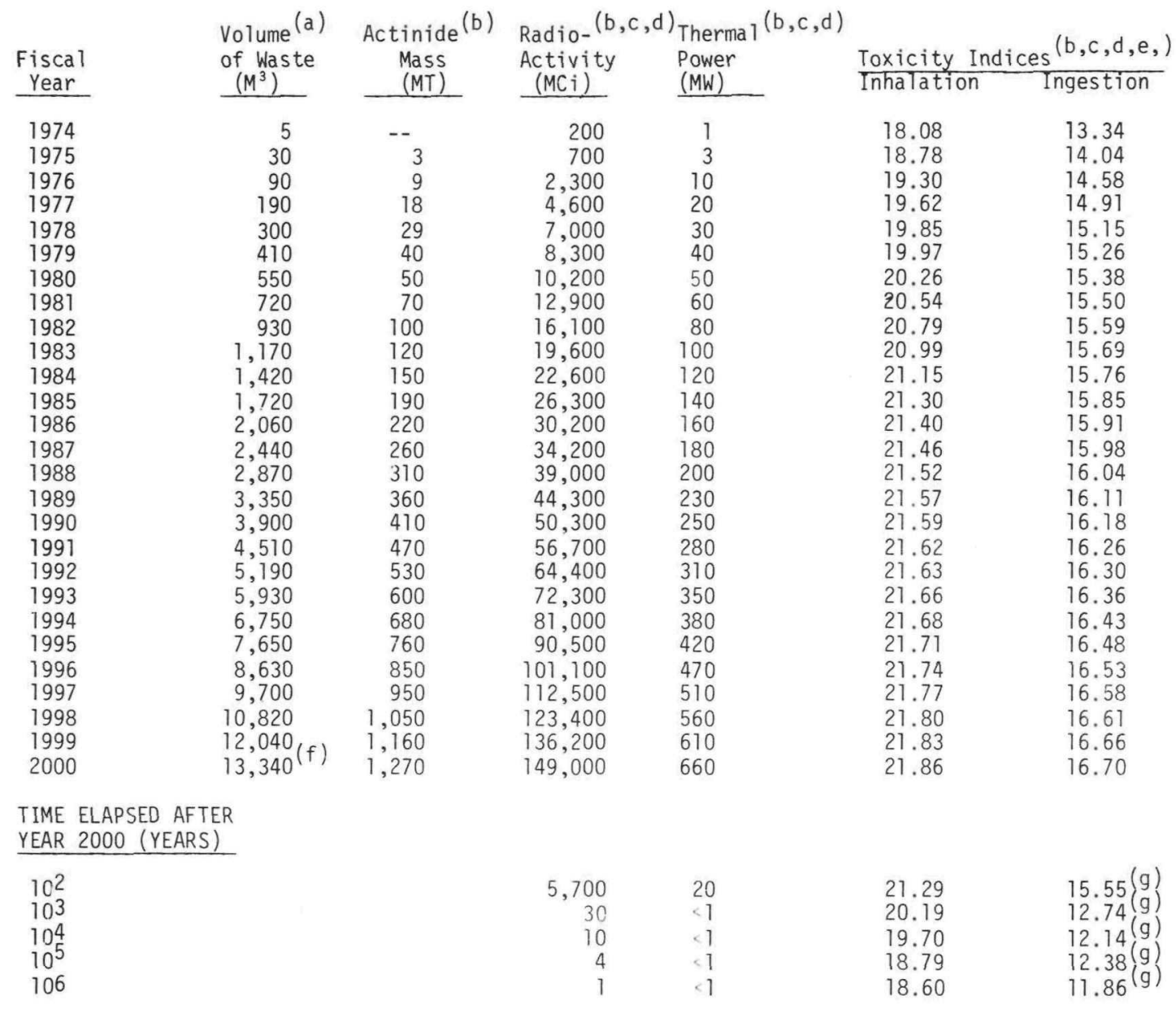

a. Volume based on $0.057,0.170$, and $0.085 \mathrm{~m}^{3}$ of solidified waste per MT of heavy metal for LWR, HTGR, and LMFBR fuels, respectively.

b. Assumes $0.5 \%$ product ( $U$ and Pu in the LWR and LMFBR and Th and $U$ in the HTGR) loss; all other actinides in waste.

c. Waste initially generated 150,365 , and 90 days after spent fuel discharged from LWR, HTGR, and LMFBR units, respectively.

d. All tritium and noble-gas fission products and $99.9 \%$ of iodine and bromine fission products excluded.

e. Base 10 logarithms for the quantity in cubic meters of air, for the inhalation index, or of water, for the ingestion hazard index, required to dilute radioactive material to 1 imits stipulated in 10 CFR 20, Appendix B. (5)

f. Volume of waste generated through the year 2000 result of the reprocessing of almost 200,000 metric tons of irradiated fuel, about 80 percent of which is associated with LWR plants.

g. Beyond the year 2000 fission products (primarily strontium) and transplutonium elements (primarily americium) are the controlling potential hazards in drinking water up to about 350 and $2 \times 10^{4}$ years, respectively. Radioactivity from plutonium losses during reprocessing then becomes controlling until about $10^{6}$ years. Finally radioactivity remaining as the result of uranium losses during reprocessing becomes the predominant contribution to the ingestion toxicity index. 


\section{REFERENCES}

1. J. 0. B lomeke et a 1, Projections of Radioactive Wastes To Be Generated by the U.S. Nuclear Power Industry, ORNL-TM-3965, February, 1974 .

2. Office of Planning and Analysis, USAEC, Nuclear Power 1973-2000, Report WASH-1139 (72), Washington D.C., December 1, 1972.

3. Nucleonics Week, January 1970 through JuTy 1972.
4. Federal Power Commission, The 1970 National Power Survey, Part I, U.S. Government Printing Office, Washington, D.C. pp. I-1-17, December 1971 .

5. Code of Federal Regulations, Appendix B to 10 CRF 20, U.S. Government Printing office, Washington, D.C., January 1, 1972. 
APPENDIX B

GENERALIZED MAPS OF THE UNITED STATES

B-1 Seismic Risk Map of the United States

B-2 Principal Faults Located in the United States

B-3 Areas of the United States that would Be Inundated by 60and 150-Meter Sea Level Rise

B-4 Productive Aquifers and Withdrawal from Wells 
○

○ 


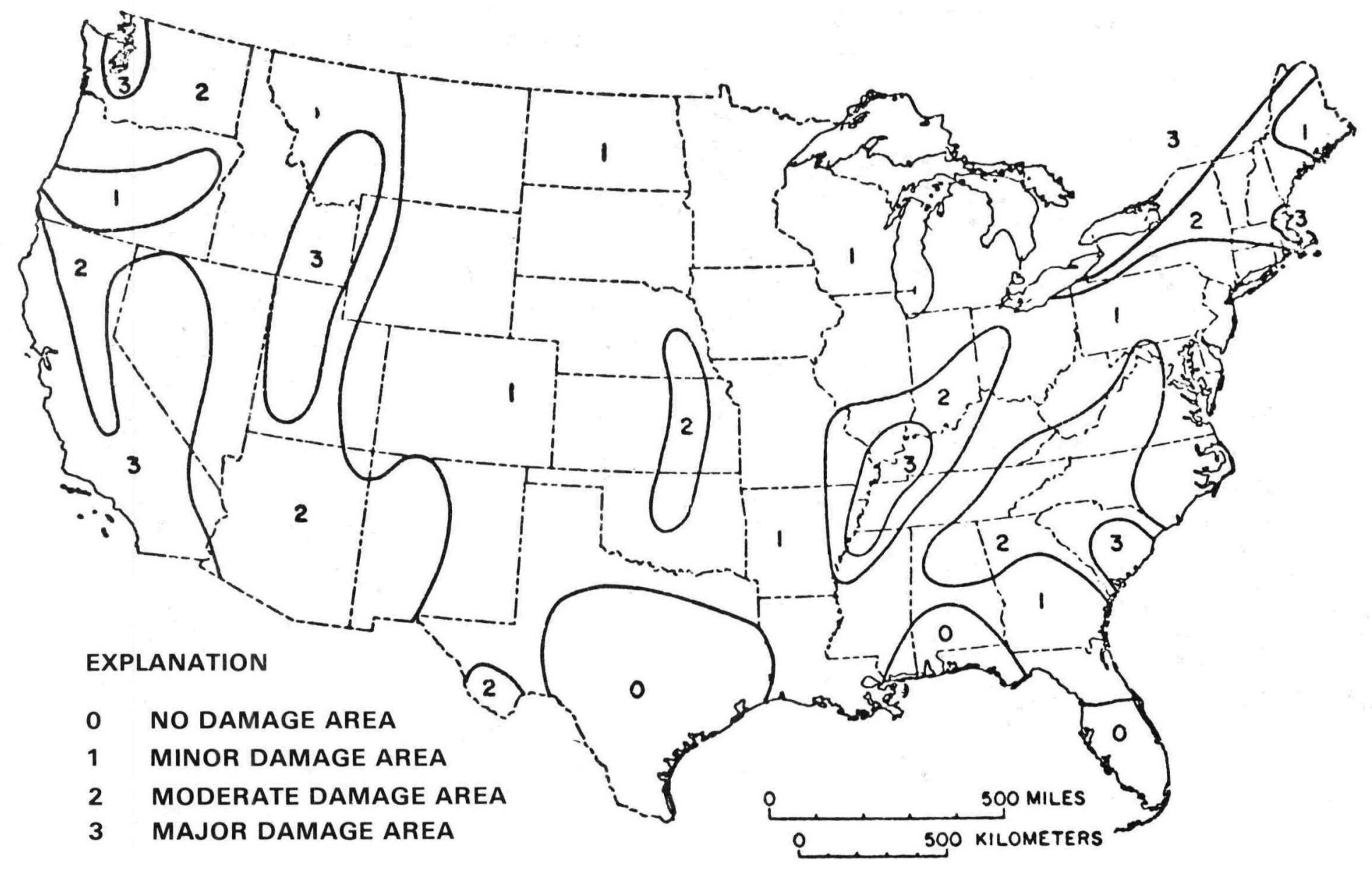




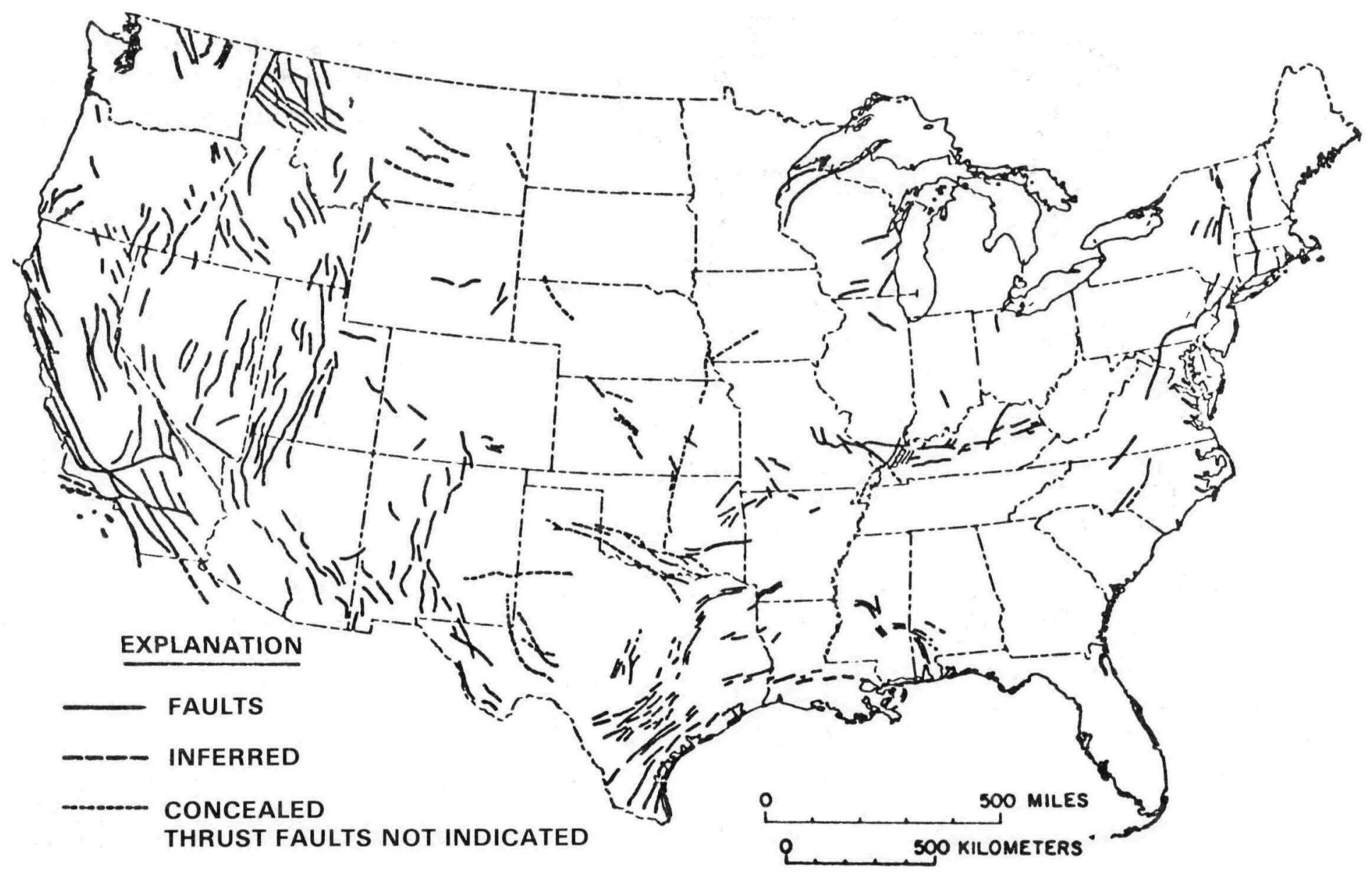

FIGURE B-2. Principal Faults Located in the United States (Modified from P. B. King, 1967) 


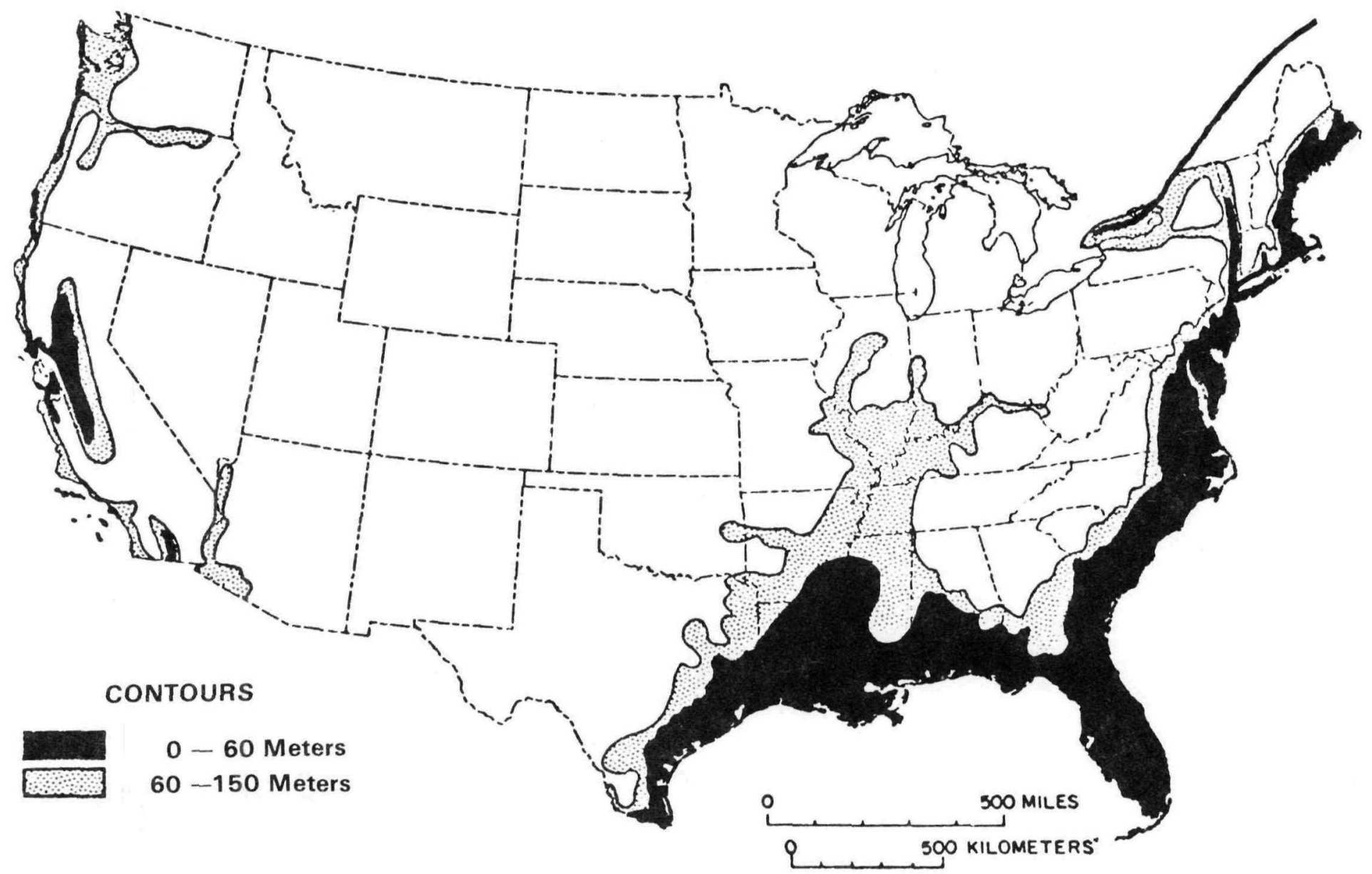

FIGURE B-3. Areas of the United States that Would

Be Inundated by 60 and $150-$ Meter Sea

Level Rise (Modified from U.S. Geolog-

ical Survey Maps) 


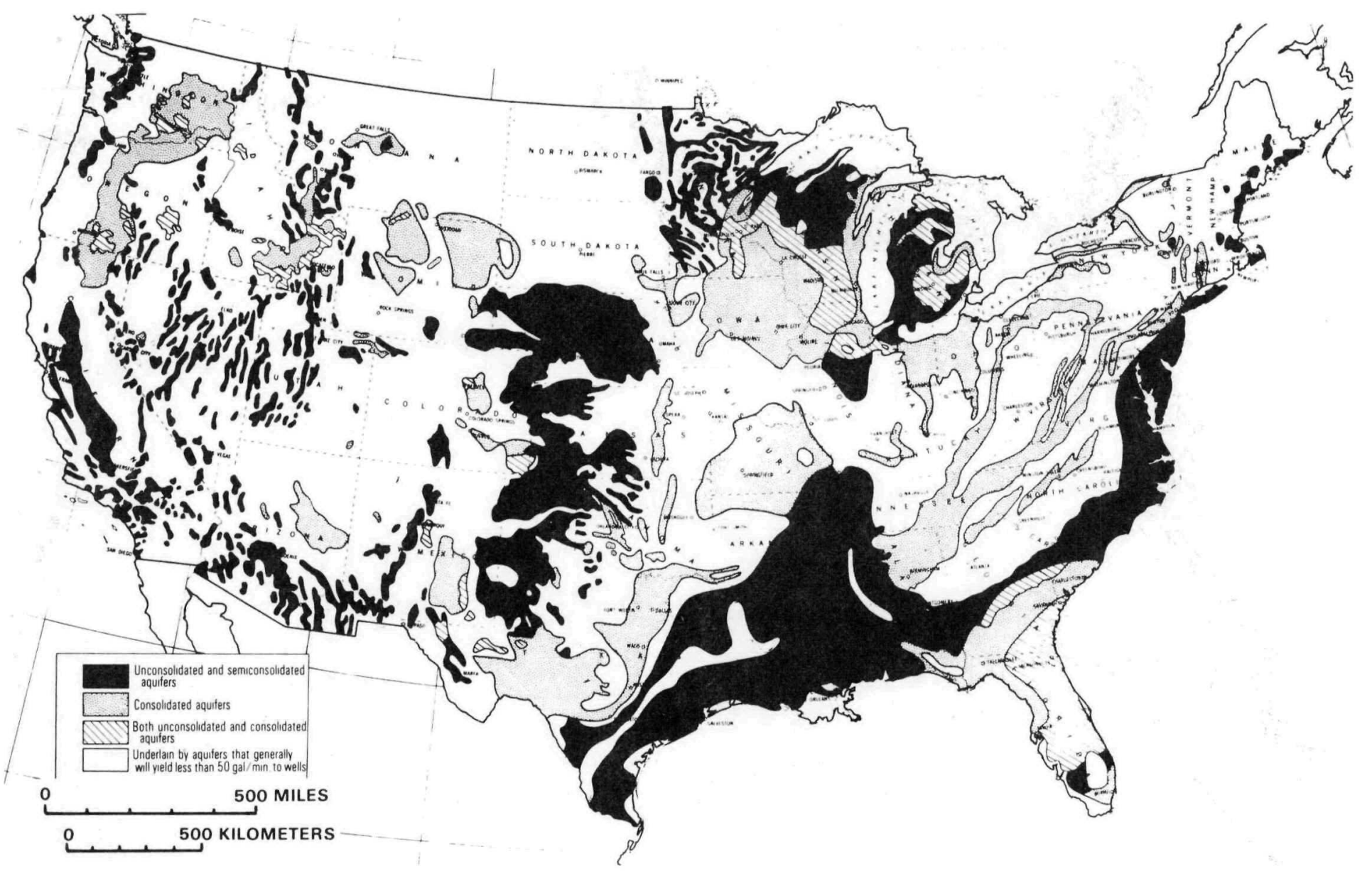

FIGURE B-4. Productive Aquifers and Withdrawals from Wells ( $\mathrm{J}$. J. Geraghty et al, 